\title{
Recent trends in the chemistry of Sandmeyer reaction: a review
}

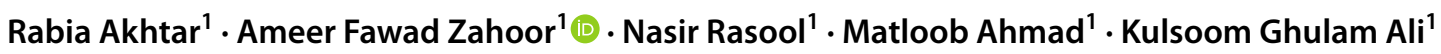

Received: 23 June 2021 / Accepted: 10 August 2021 / Published online: 20 August 2021

(c) The Author(s), under exclusive licence to Springer Nature Switzerland AG 2021

\begin{abstract}
Metal-catalyzed reactions play a vital part to construct a variety of pharmaceutically important scaffolds from past few decades. To carry out these reactions under mild conditions with low-cost easily available precursors, various new methodologies have been reported day by day. Sandmeyer reaction is one of these, first discovered by Sandmeyer in 1884. It is a well-known reaction mainly used for the conversion of an aryl amine to an aryl halide in the presence of $\mathrm{Cu}(\mathrm{I}) \mathrm{halide}$ via formation of diazonium salt intermediate. This reaction can be processed with or without copper catalysts for the formation of $\mathrm{C}-\mathrm{X}\left(\mathrm{X}=\mathrm{Cl}, \mathrm{Br}\right.$, I, etc.), $\mathrm{C}-\mathrm{CF}_{3} / \mathrm{CF}_{2}, \mathrm{C}-\mathrm{CN}, \mathrm{C}-\mathrm{S}$, etc., linkages. As a result, corresponding aryl halides, trifluoromethylated compounds, aryl nitriles and aryl thioethers can be obtained which are effectively used for the construction of biologically active compounds. This review article discloses various literature reports about Sandmeyer-related transformations developed during 2000-2021 which give different ideas to synthetic chemists about further development of new and efficient protocols for Sandmeyer reaction.
\end{abstract}

\section{Graphical abstract}

An updated compilation of new approaches for Sandmeyer reaction is described in this review to construct a variety of carbon-halogen, carbon-phosphorous, carbon-sulfur, carbon-boron etc. linkages.

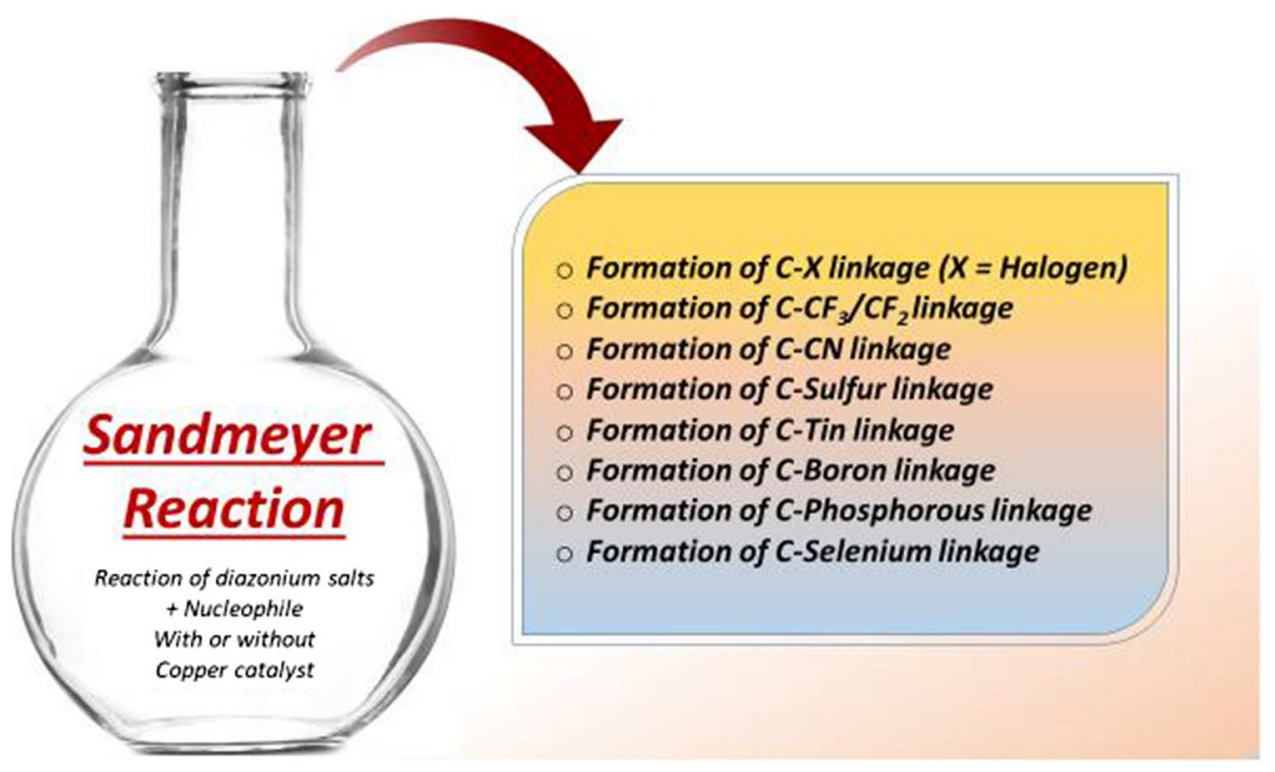

Keywords Diazonium salts $\cdot$ Sandmeyer reaction · Dediazoniation · Trifluoromethylation · Benzonitriles · Aryl halides

Ameer Fawad Zahoor

fawad.zahoor@gcuf.edu.pk; fawad.zahoor@gmail.com

1 Department of Chemistry, Government College University

Faisalabad, Faisalabad 38000, Pakistan 


\section{Introduction}

Aromatic diazonium salts, discovered by Griefs in 1858 [1], have wide spread applications in organic synthesis as well as at industrial level. They are frequently used for the preparation of organic nanocompounds and grafted a variety of organic molecules on metallic surfaces [2]. Furthermore, Meerwein arylation [3, 4], Balz-Schiemann $[5,6]$ and various metal-catalyzed reactions $[7,8]$ involve diazonium salts as starting precursors for the production of various halides, phenols, cyanides, azides and alkenes [9] which serve as effective intermediates for the synthesis of important molecules [10-13]. Sandmeyer reaction is one of them, in which diazonium salts are used for the construction of carbon-halogen, carbon-phosphorous, carbon-sulfur, carbon-selenium, carbon-boron bond formation. Moreover, various trifluoromethylated compounds as well as a number of pharmaceutically important drugs can be synthesized via Sandmeyer approach [14].

Literature study reveals the importance of metal-catalyzed cross-coupling reactions which are extensively used in organic synthesis and in pharmaceutical industry. These reactions are carried out by the treatment of various organic halides with a suitable coupling partner using a variety of catalysts and ligands [15-19]. Sandmeyer approach, first discovered in 1884 by Sandmeyer $[20,21]$, is one of these metal-catalyzed reactions which effectively converts benzenediazonium salts into bromo-, chlorobenzene, benzonitriles, etc., in the presence of different copper catalysts. Since 1884, different methods have been discovered to improve the efficacy of Sandmeyer reaction as an innovation of organic phase diazotization process reported by Doyle et al. in 1977 [22, 23] and the effective utilization of these diazonium salts in a variety of metal-catalyzed reactions (Kikukawa and Matsuda, 1977) $[24,25]$, etc. Although the mechanism of this reaction is not yet clear however, a general mechanism reported by Waters [26] and later on by Kochi [27] is highlighted in Scheme 1 according to which diazonium salt readily undergoes homolytic dediazoniation in the presence of copper salt, resultantly affording aryl radical. This radical upon treatment with reactive species gives desired product with regeneration of copper(I) species.

Owing to the extensive applications of Sandmeyer reaction, herein we describe an updated compilation of new approaches reported during 2000-2021 for Sandmeyer reaction.

\section{Review of literature: applications of Sandmeyer reaction}

\section{Formation of carbon-halogen linkage}

\section{Chlorination via Sandmeyer reaction}

Marco-Contelles and colleagues reported copper-catalyzed Sandmeyer reaction of $N$-(prop-2-yn-1-ylamino) pyridines in the presence of organic nitrites afforded various bicyclic chlorinated pyridones [28]. For example, reaction of pyridine $\mathbf{3}$ in combination with isopentyl nitrite and cupric chloride gave pyridone 4 in $62 \%$ yield. Temperature was maintained at $65{ }^{\circ} \mathrm{C}$ to achieve maximum conversion in acetonitrile solvent. Mechanism of this reaction first involved the coordination of nitrosyl complex of cupric chloride with alkyne group followed by the breakage of RO-NO bond releasing alkoxy radical that captured hydrogen from $\mathrm{NH}_{2}$ group to give $\mathrm{ROH}$ molecule. On the other side, breakage of $\mathrm{NH}_{2}$ bond started the free radical chain reaction resultantly affording E-exo-chloromethylene intermediate which after hydrolysis gave targeted pyridone 4 (Scheme 2).

A single report considering the importance and synthesis of monofluorinated polychlorinated biphenyls has been disclosed by Sott et al. [29] in which Suzuki and Sandmeyer reactions are the key steps. Table 1 presents some of these reactions performed under optimized conditions. Suzuki coupling between arylboronic acid $\mathbf{5}$ and

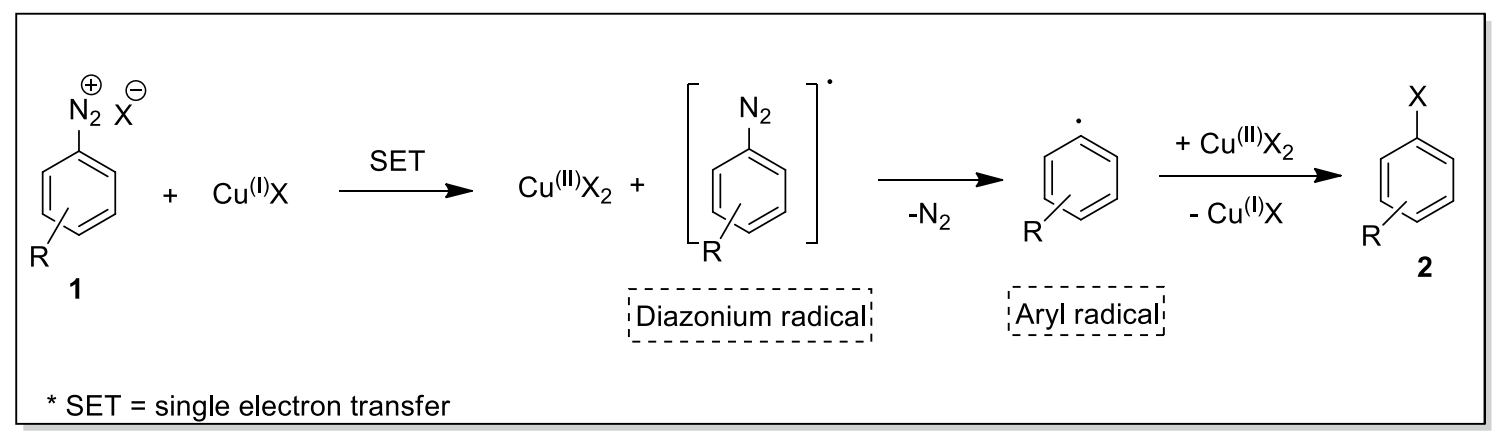

Scheme 1 General mechanism of Sandmeyer reaction 


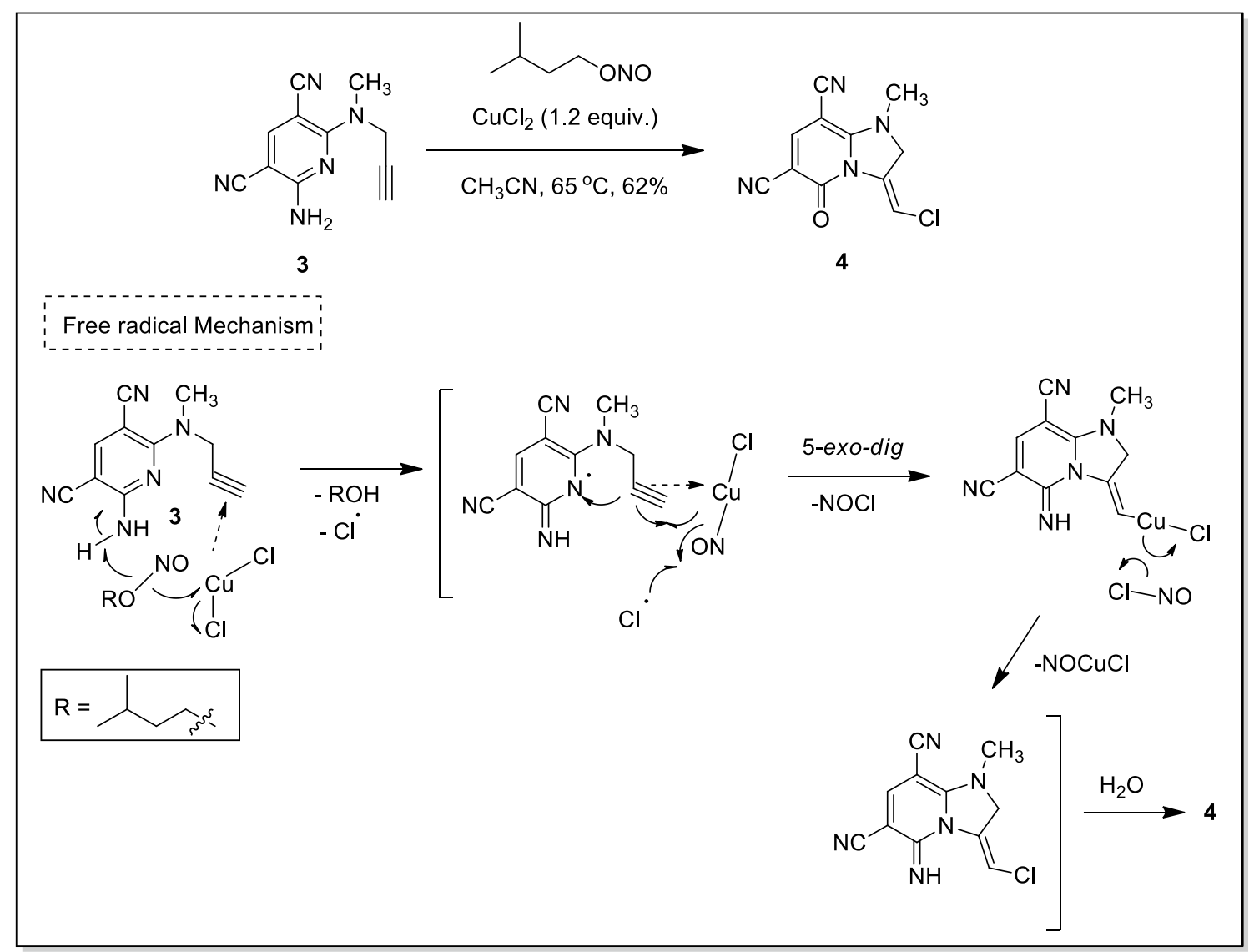

Scheme 2 Copper-catalyzed Sandmeyer reaction for the conversion of $N$-(prop-2-yn-1-ylamino) pyridine 3 to pyridone 4

2,3,5,6-tetrachloro-bromoaniline (6) was processed using 3\% $\mathrm{Pd}\left(\mathrm{PPh}_{3}\right)_{4}$ as catalyst, sodium carbonate as base and toluene as solvent. As a result, biphenyl product 7 was obtained which subsequently subjected to Sandmeyer reaction in the presence of $t$-BuONO and $\mathrm{CuCl}_{2}$ to obtain required $\mathrm{PCB}$ (polychlorinated biphenyls) 8 in $4 \%$ overall yield. Likewise, other two reactions were also performed; however, deamination in the absence of $\mathrm{CuCl}_{2}$ gave desired PCB $\mathbf{1 1}$ and $\mathbf{1 2}$ in $26 \%$ and $7 \%$ overall yields, respectively, which could be used as analytical standards for PCB analysis.

An approach for the synthesis of tetrasubstituted pyrazole derivatives and their fungicidal properties against Uncinula necator was investigated by Dumeunier et al. [30]. Their methodology started from the reaction of acetonitrile $\mathbf{1 3}$ with 4-chloro benzaldehyde (14) to afford 2,3-diarylacrylonitrile $\mathbf{1 5}$ which was subjected to ring closure reaction with hydrazine. Resultantly, pyrazoline derivative $\mathbf{1 6}$ was obtained which readily converted into desired pyrazole $\mathbf{1 7}$ by applying standard protocol of Sandmeyer reaction $(\mathrm{HCl}$, $\mathrm{NaNO}_{2}, \mathrm{CuCl}$ ) (Scheme 3).

Hughes et al. [31] proposed a strategy for the synthesis of a variety of 4-aryl-5-cyano-2-aminopyrimidines which are effectively used as VEGF (vascular endothelial growth
factor)-R2 kinase inhibitors. These inhibitors stop angiogenesis process successfully, resultantly inhibiting the growth of tumor cells. The synthetic protocol of these inhibitors started from the reaction of aryl methyl ester $\mathbf{1 8}$ with lithium salt of the acetonitrile to obtain corresponding $\alpha$-cyanoketone which on treatment with $N, N$-dimethylformamide diethyl acetal afforded vinylogous amide. In the next step, pyrimidine ring 19 was obtained by the reaction of vinylogous amide with guanidinium salt. Sandmeyer reaction of pyrimidine 19 in the presence of antimony trichloride and tert-butyl nitrite gave 2-chloropyrimidine derivative $\mathbf{2 0}$ which was efficiently converted into targeted 4-aryl-5-cyano-2-aminopyrimidine derivative $\mathbf{2 1}$ by the displacement of chloro group with a variety of aliphatic amines in $73-95 \%$ yield range (Scheme 4).

A quite efficient and simple way to synthesize different arylpiperazines involving Sandmeyer reaction as key step was demonstrated by Rancati et al. [32]. A reference pathway is described in Scheme 5 which started from the nitration of 1,4-benzodioxin-5-carboxylic acid 22 followed by catalytic hydrogenation provided hydrochloride form of amino derivative $\mathbf{2 3}$ in quantitative yield. This benzodioxine was subjected to Sandmeyer reaction in the 
Table 1 Synthesis of monofluorinated polychlorinated biphenyls via Suzuki coupling followed by Sandmeyer reactions

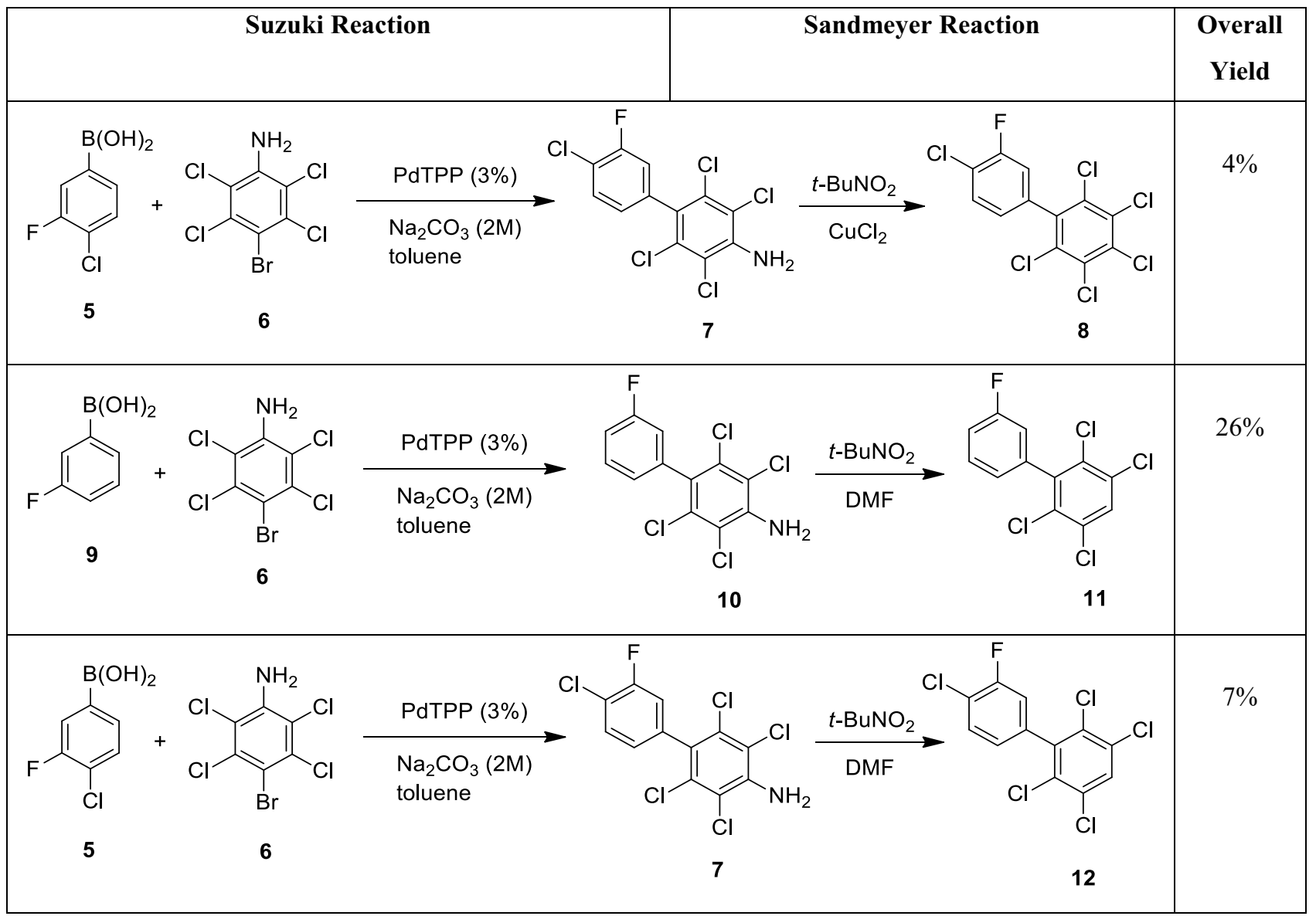

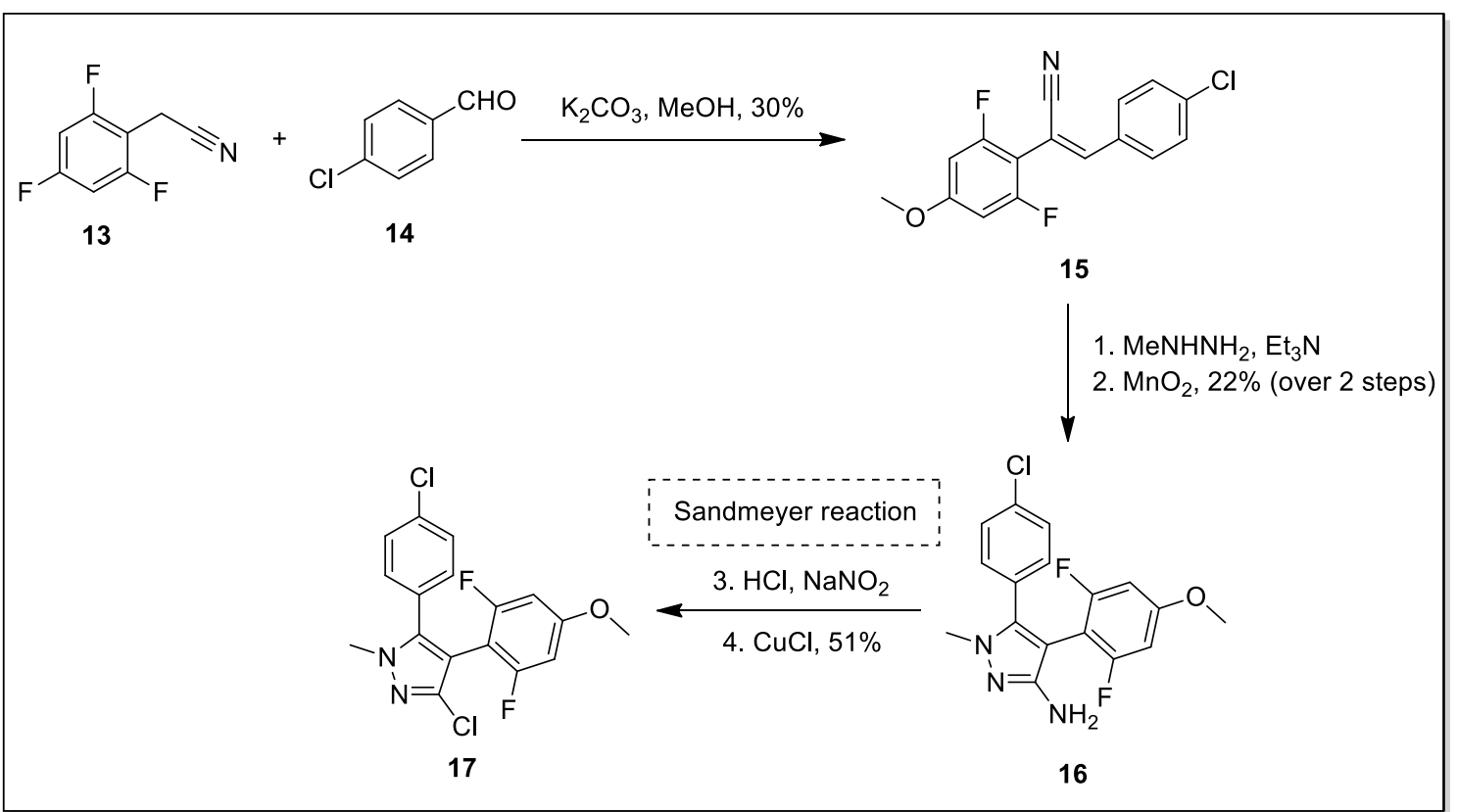

Scheme 3 Synthesis of pyrazole $\mathbf{1 7}$ by applying standard protocol of Sandmeyer reaction 


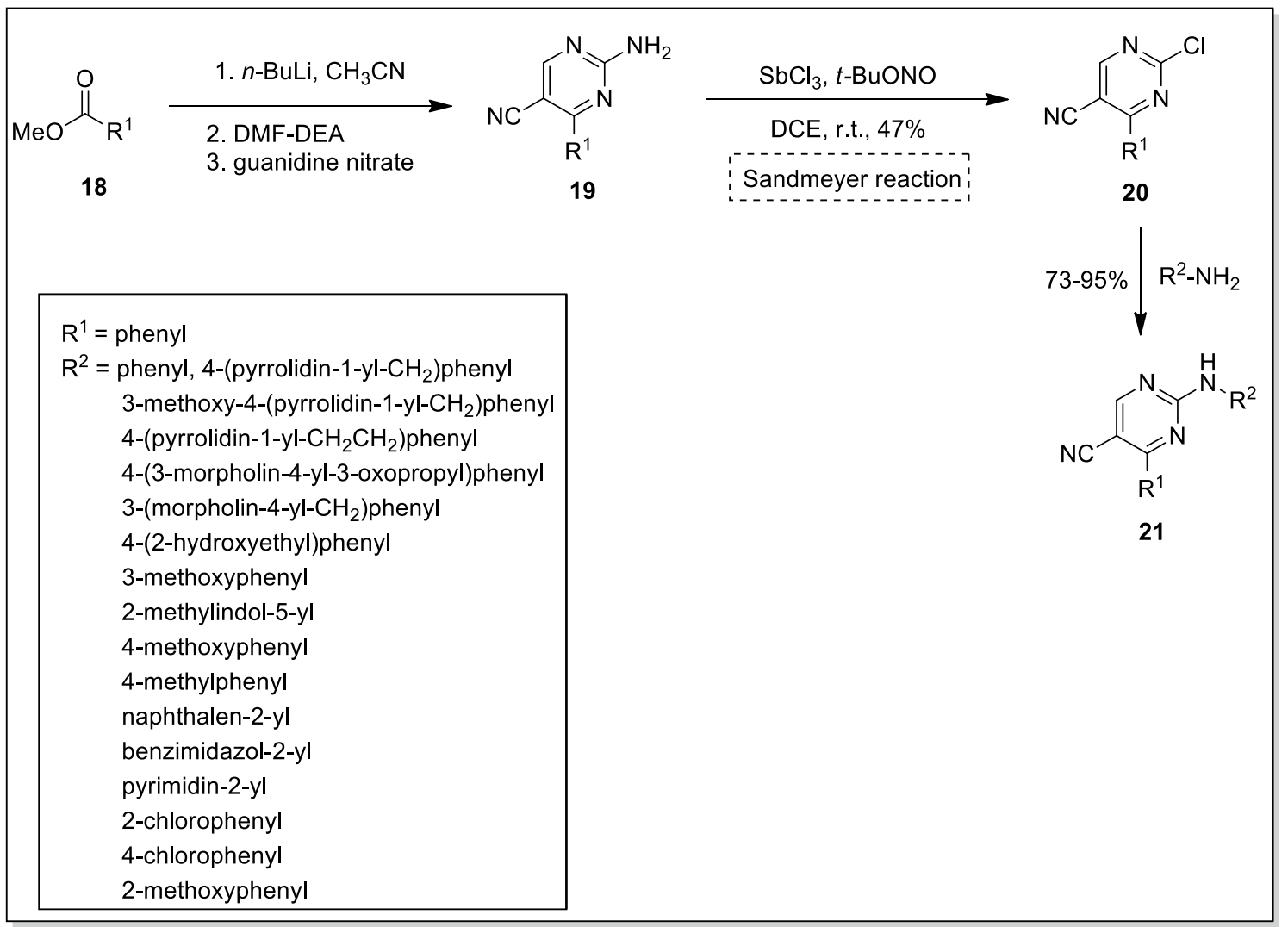

Scheme 4 Sandmeyer reaction for the preparation of aminopyrimidines derivatives

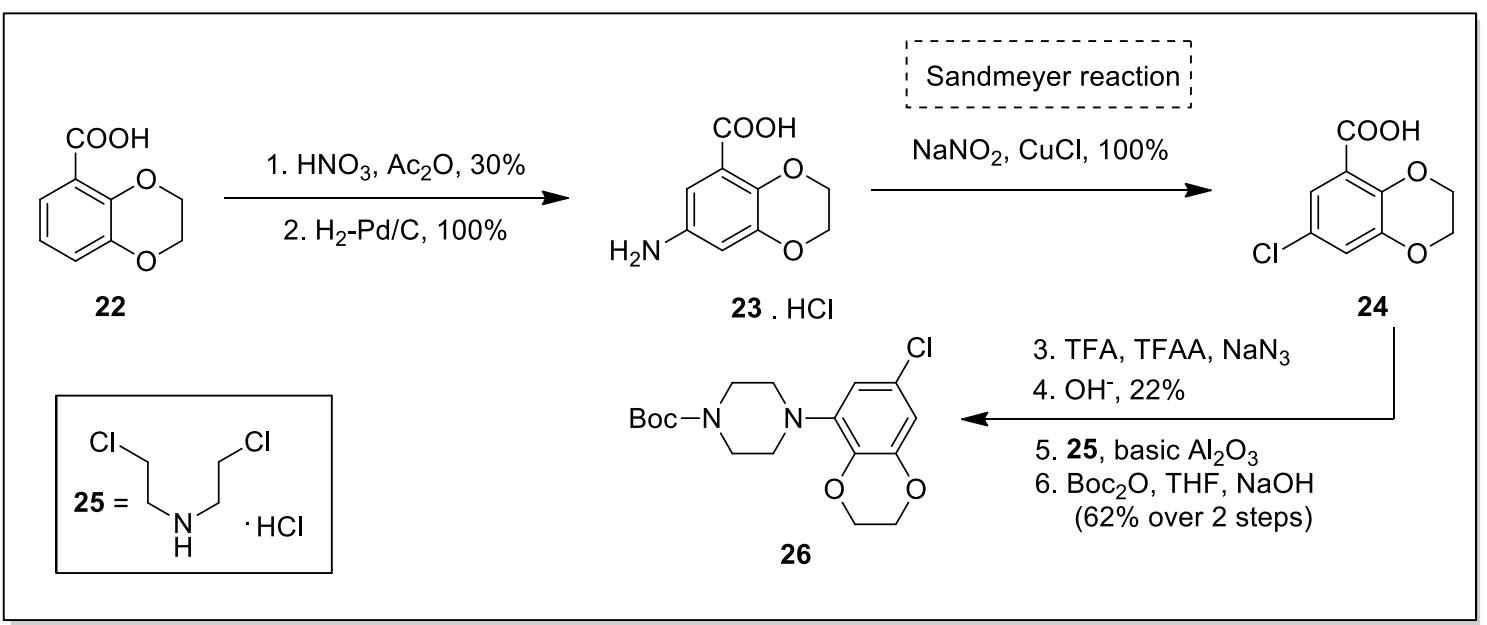

Scheme 5 Preparation of arylpiperazines using Sandmeyer reaction as key step

presence of sodium nitrite and $\mathrm{CuCl}$ to obtain halogenated benzodioxine $\mathbf{2 4}$ quantitatively. Later, conversion of carboxylic acid group of this chloro residue (24) to acyl azide followed by decomposition process afforded 5-amino derivative (22\% yield) which upon treatment with basic alumina supported amine $\mathbf{2 5}$ and subsequent reaction with
Boc anhydride gave desired piperazine derivative $\mathbf{2 6}$ in $62 \%$ yield (over 2 steps).

Research group of Han disclosed the synthetic route of thienopyrimidine analogs which were found to be effective FLT3 inhibitors [33]. Standard conditions to carry out this protocol started from the Knoevenagel condensation 
of 2-acetylthiophene $\mathbf{2 7}$ with malononitrile $\mathbf{2 8}$ followed by the treatment with elemental sulfur to obtain corresponding thiophene, ready to produce thienopyrimidine $\mathbf{2 9}$ after treatment with formamide. Next, Sandmeyer reaction of thienopyrimidine 29 proceeded well at $70{ }^{\circ} \mathrm{C}$ in the presence of $t$ - $\mathrm{BuONO}$ and $\mathrm{CuCl}_{2}$. THF/ $\mathrm{CH}_{3} \mathrm{CN}$ was used as solvents to carry out maximum conversion. Later on, reaction of chloride $\mathbf{3 0}$ with hydrazine monohydrate and furan $\mathbf{3 1}$ afforded required thienopyrimidine $\mathbf{3 2}$ efficiently. By using same reaction pathway, a variety of thienopyrimidine derivatives were obtained in good yield range (Scheme 6).

Ding et al. [34] presented a valuable approach to obtain biologically active isatin derivatives which play an important role in pharmaceutical industry due to their excellent antitumor properties against a variety of cell lines (K562, HepG2, HT-29, HL60, etc.). Focusing the synthesis of isatin derivatives, a quite simple and easy pathway is outlined in Scheme 7 involving the condensation of aniline 33 with hydroxylamine hydrochloride at $90{ }^{\circ} \mathrm{C}$ and chloral hydrate in $2 \mathrm{~mol} / \mathrm{L}$ of $\mathrm{HCl}$ and water solution to afford oxime 34. Cyclization of this oxime (34) in the presence of sulfuric acid with subsequent bromination reaction afforded required isatin 36 in $86 \%$ yield.

Player et al. [35] reported the synthesis of 2-(2-chloro6-fluorophenyl)acetamides and proved their potential applicability as thrombin inhibitors. A reference synthetic protocol is highlighted in Scheme 8 which started from the reaction of nitrobenzene $\mathbf{3 7}$ with diethyl malonate followed by decarboxylation (in the presence of $\mathrm{LiCl}$ ) and aromatic nucleophilic substitution reaction (with amine 38) provided aryl fluoride 39. Protection of - $\mathrm{NH}$ group of compound 39 with subsequent reduction $(\mathrm{Zn}, \mathrm{AcOH})$ and Sandmeyer reaction (tert-butyl nitrite, $\mathrm{CuCl}_{2}, \mathrm{CH}_{3} \mathrm{CN}$ ) provided derivative 40. Later on, deprotection of the $-\mathrm{NH}$ and ester groups followed by the reaction with $O$-guanidine segment afforded desired 2-(2-chloro-6-fluorophenyl) acetamide 41.

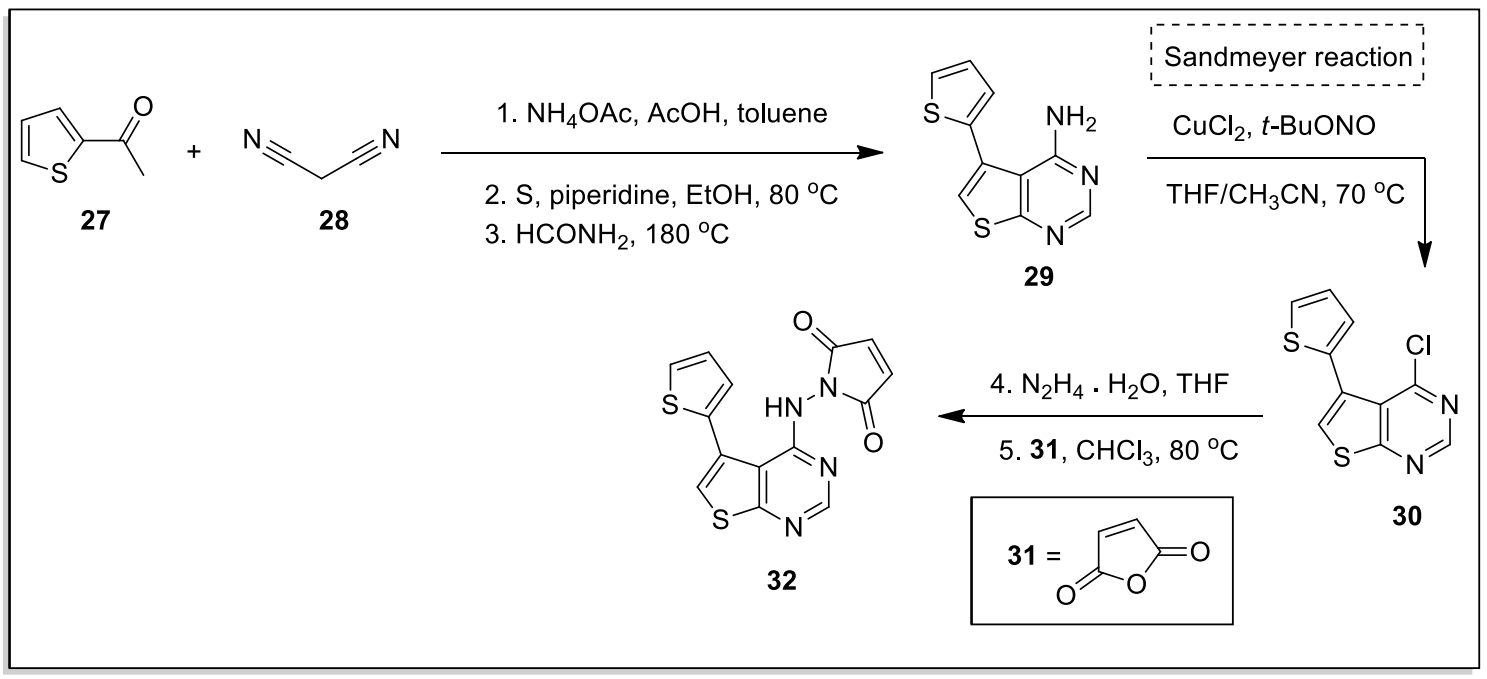

Scheme 6 Synthetic route for thienopyrimidine analogs

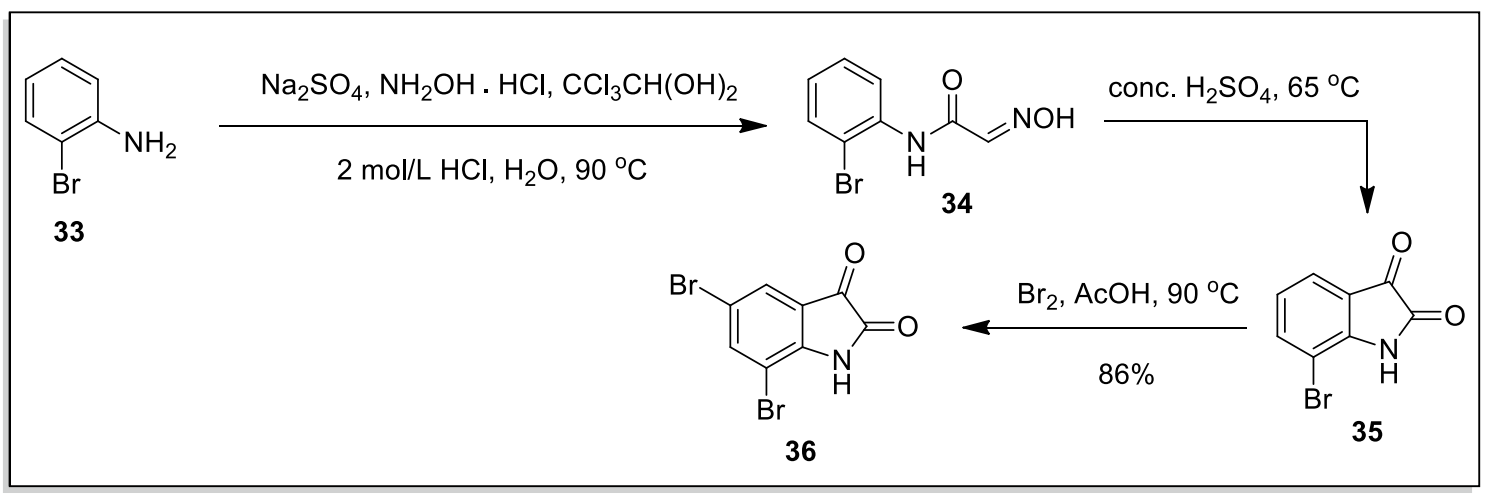

Scheme 7 Synthesis of isatin $\mathbf{3 6}$ from oxime $\mathbf{3 4}$ 


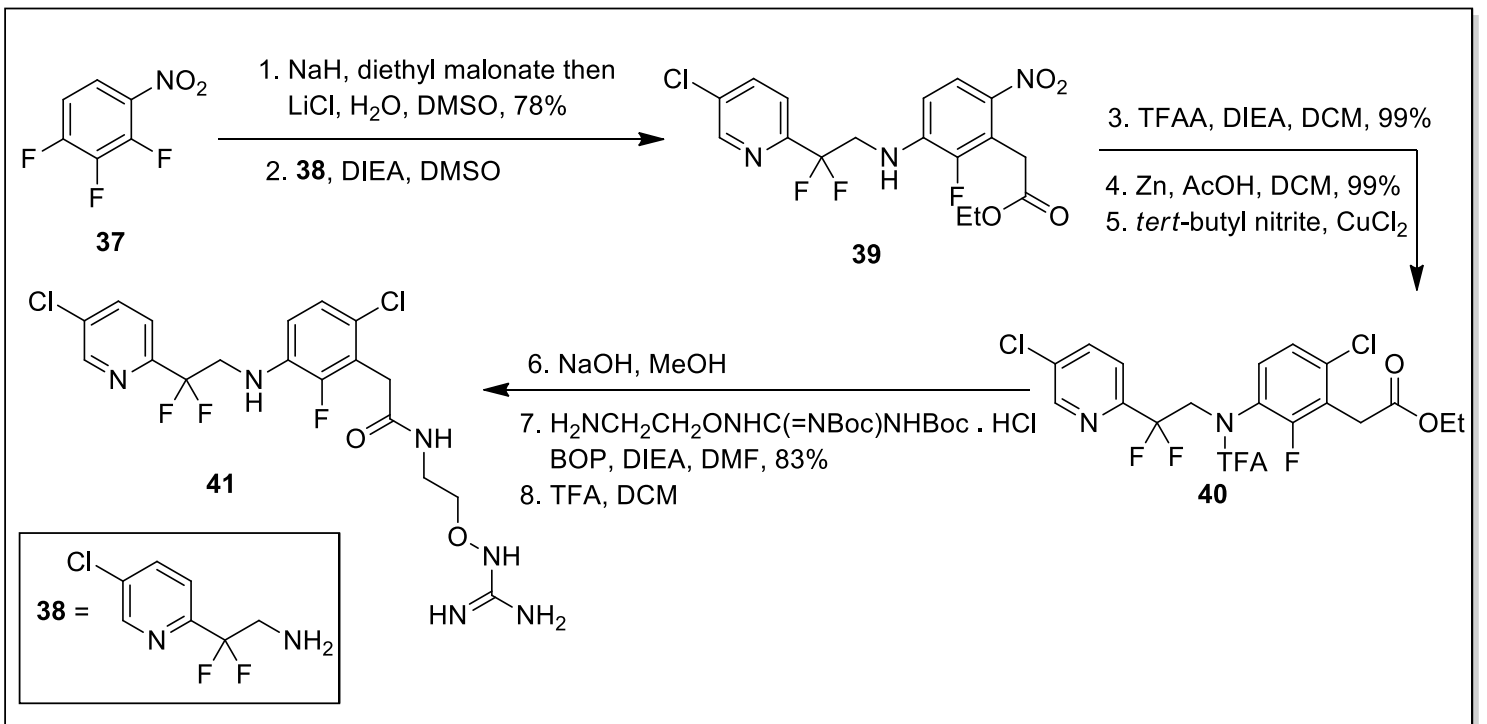

Scheme 8 Preparation of 2-(2-chloro-6-fluorophenyl)acetamide $\mathbf{4 1}$ as thrombin inhibitor

\section{Bromination via Sandmeyer reaction}

Lobana and colleagues reported a first example of Sandmeyer reaction for the conversion of 2-mercapto-1-methylimidazoline to 2-bromo-1-methyl-imidazole at ambient temperature [36]. Copper(I) bromide was selected as suitable catalyst for this purpose, and the reaction was carried out in $\mathrm{CH}_{3} \mathrm{CN}-\mathrm{CHCl}_{3}$ mixture. Plausible mechanism for this conversion is presented in Scheme 9 which started from the oxidation of $\mathrm{Cu}(\mathrm{I})$ to $\mathrm{Cu}(\mathrm{II})$ ion. This copper ion further used to oxidize thio moiety $\mathbf{4 2}$, resultantly produced disulfide imidazoline $\mathbf{4 4}$ which in the last step was converted into required 2-bromo-1-methyl-imidazole $\mathbf{4 5}$. This brominated imidazole (45) coordinated with bromide ions in the presence of $\mathrm{Cu}^{2+}$ to obtain tetranuclear complex $\left[\mathrm{Cu}_{4}\left(\eta^{1}-N-\left(\mathrm{N}_{2} \mathrm{C}_{4} \mathrm{H}_{5} \mathrm{Br}\right)_{4}\left(\mu_{4}-\mathrm{O}\right)(\mu-\mathrm{Br})_{6}\right]\right.$.

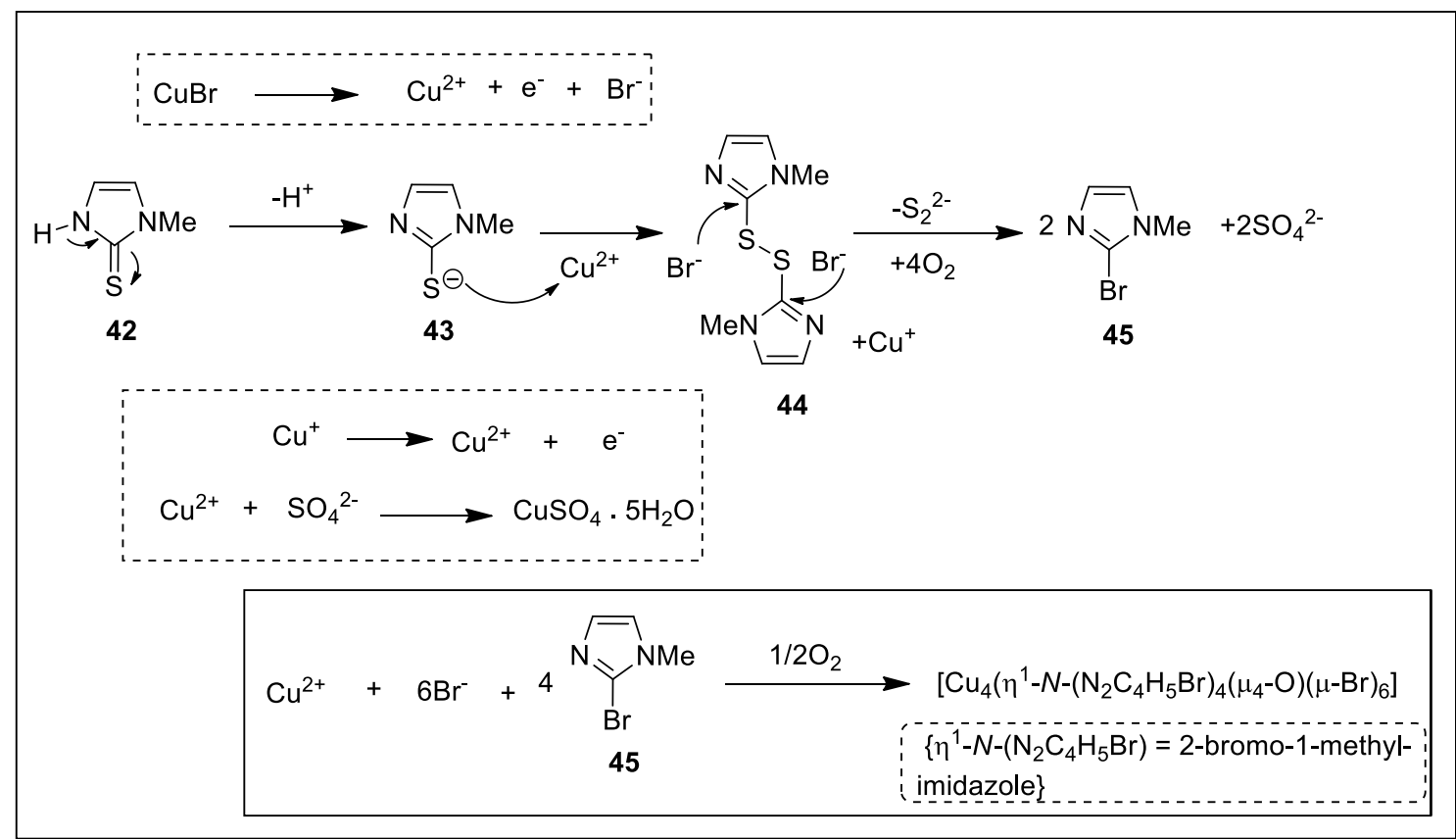

Scheme 9 Mechanism for the conversion of 2-mercapto-1-methyl-imidazoline 42 to 2-bromo-1-methyl-imidazole 45 
The research group of Laali performed Sandmeyer reaction for the bromodediazotization of the diazonium salt $\mathbf{4 6}$ [37]. Reaction performed under nitrogen atmosphere using $[\mathrm{BMIM}]\left[\mathrm{PF}_{6}\right]$ ionic liquid, as solvent. Copper(I) bromide was used as bromine source, and temperature was maintained at $65-75^{\circ} \mathrm{C}$. Resultantly, halogenated products were obtained and their formation ratio strictly depended upon the nature of the substituents of the diazonium salts. As depicted in Scheme 10, diazonium salts having electron-donating substituents gave mainly Schiemann product; however, electronwithdrawing substituents afforded Sandmeyer product predominantly along with the formation of hydrodediazoniation product.

Evans and coworkers described an impressive reaction pathway to synthesize 5-amino-3-aryl-1-(tert-butyl)1 Hpyrazole-4-carboxamides in good yield range [38]. Reaction of potassium tricyanomethanide (50) with tertbutylhydrazine (51) in a mixture of $\mathrm{HCl}$ and water gave $41 \%$ yield of pyrazole $\mathbf{5 2}$ which was successfully subjected to Sandmeyer reaction. This reaction worked very well by using $t$-BuONO and $\mathrm{CuBr}_{2}$ in acetonitrile solvent. As a result, corresponding 3-bromo regioisomer $\mathbf{5 3}$ was afforded in $59 \%$ yield. Later on, hydrolysis of cyano group of compound $\mathbf{5 3}$ followed by Suzuki-Miyaura reaction gave desired pyrazole-4-carboxamide 56 in $87 \%$ yield. By using similar reaction approach, a variety of targeted compounds were obtained in 25-87\% yield range (Scheme 11).

Özkan et al. [39] published a report on the facile synthesis of bromobenzenes by using Sandmeyer approach. In their methodology, a quick reaction of aniline with concentrated $\mathrm{HCl}$ produced corresponding anilinium salt which was diazotized in the presence of ethyl nitrite. In the next step, this diazonium salt was treated with bromine radical, obtained by the reaction of molecular bromine with ammonium persulfate. As a result, desired substituted bromobenzene was afforded in moderate to good yield range (55-80\%). A reference example is highlighted in Scheme 12.

Research group of Schäfer reported a simple, efficient and cost-effective synthetic pathway for ethyl 5-(2,4-difluorophenyl)-1,3,4-thiadiazole-2-carboxylate (64) including Sandmeyer bromination and Suzuki-Miyaura couplings as key steps [40]. Reactions performed at gram scale and kilogram scale level under mild conditions. An outline of these reactions is presented in Scheme 13 which started first from the conversion of ethyl 5-amino-1,3,4-thiadiazole-2-carboxylate (61) into bromo thiadiazole $\mathbf{6 2}$ in $71 \%$ yield. Reaction processed at room temperature in the presence of tert-butyl nitrite

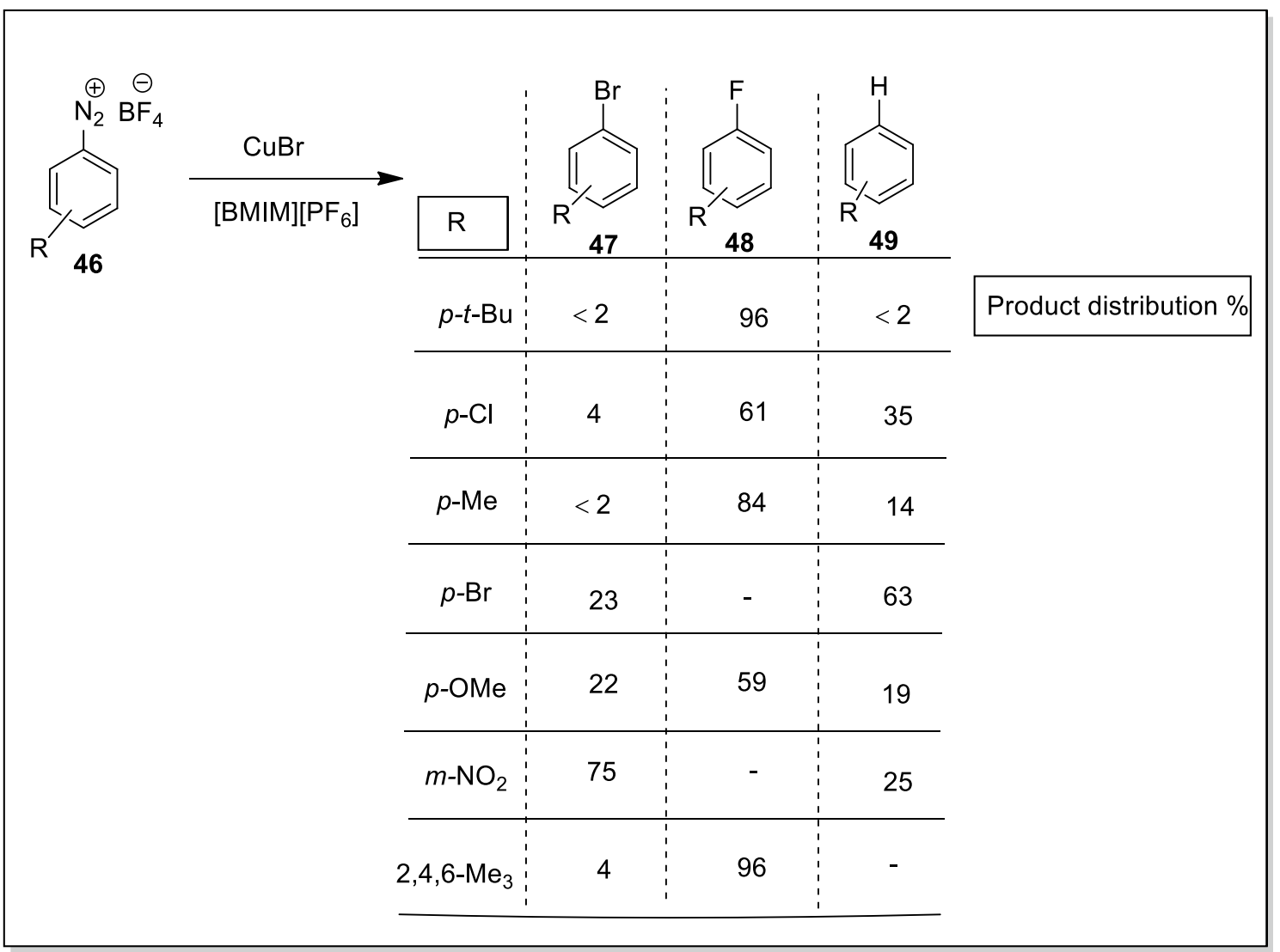

Scheme 10 Sandmeyer reaction for the bromodediazotization of the diazonium salt 46 


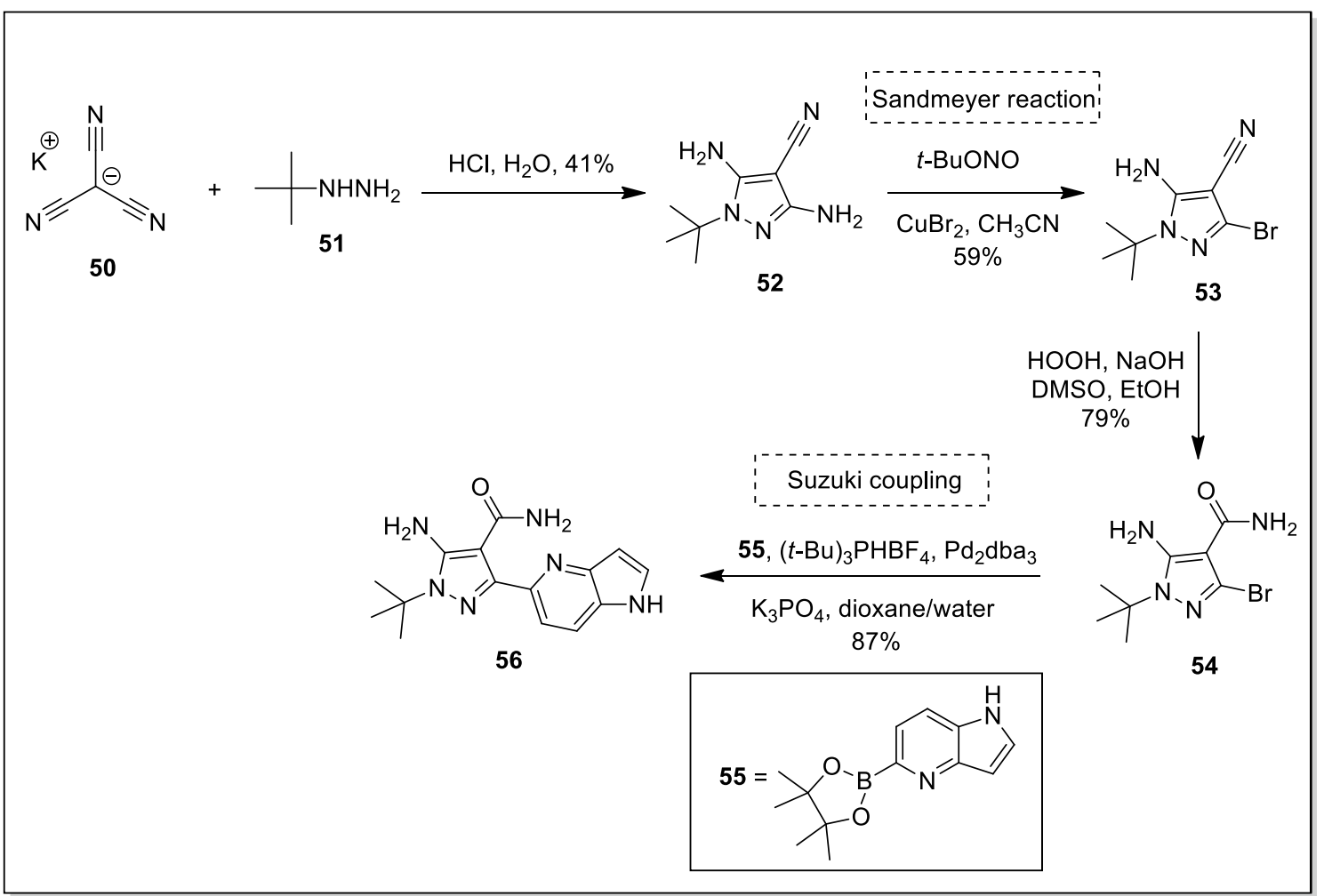

Scheme 11 Synthesis of pyrazoles by adopting Sandmeyer and Suzuki-Miyaura approaches

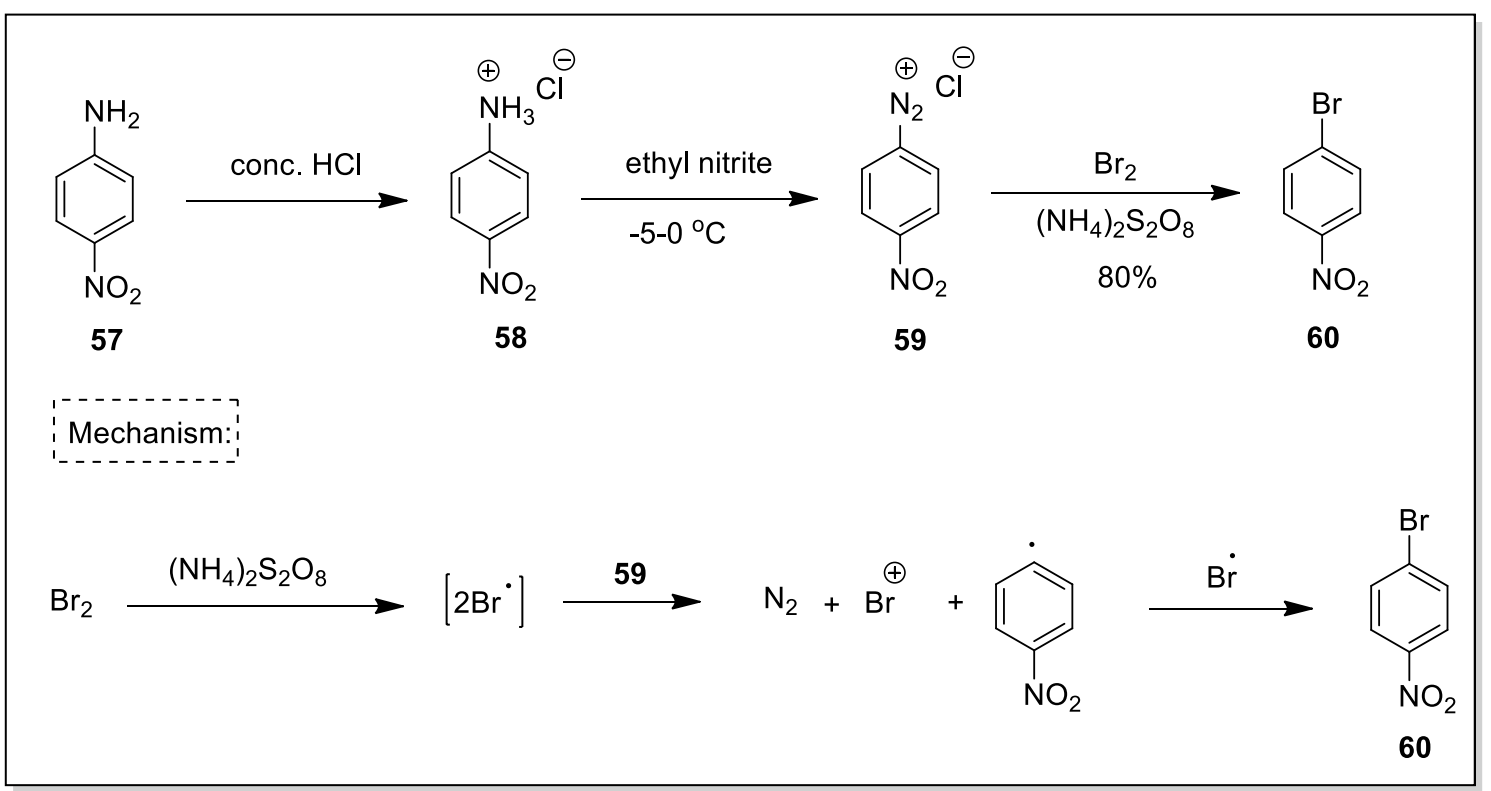

Scheme 12 Facile synthesis of bromobenzene $\mathbf{6 0}$ by using Sandmeyer protocol

and 1.5 equivalents of copper bromide using acetonitrile as an effective reaction media. Later, compound $\mathbf{6 2}$ was subjected to Suzuki-Miyaura reaction using boronic acid $\mathbf{6 3}$ as another coupling partner. This palladium-catalyzed reaction along with xanthphos ligand afforded desired cross-coupled product 64 in $85 \%$ yield.

A variety of pharmaceutical agents having cyclopropylpyridine scaffold are good inhibitors of interleukin 


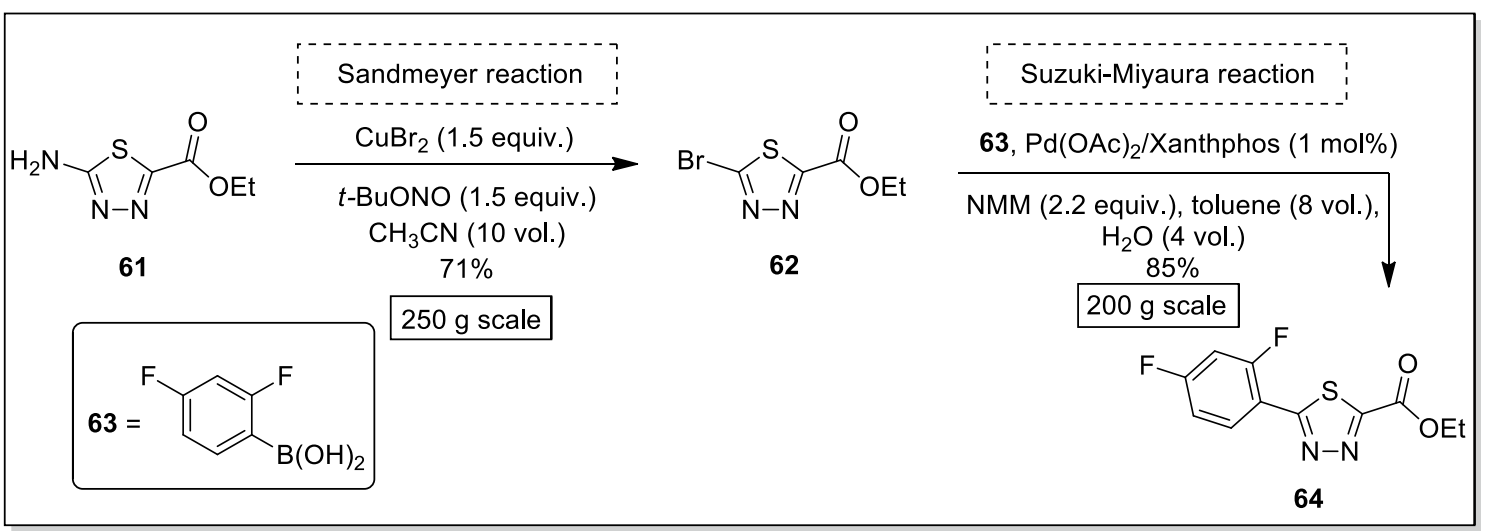

Scheme 13 Synthesis of ethyl 5-(2,4-difluorophenyl)-1,3,4-thiadiazole-2-carboxylate (64) via Sandmeyer bromination and Suzuki-Miyaura couplings

receptor-associated kinases, PDE4 enzyme inhibitors and have been widely used to synthesize canabinoid receptor 2 agonists. Considering their importance, Striela et al. [41] prepared bromocyclopropylpyridines by the reaction of aminocyclopropylpyridines (obtained via Suzuki reaction of aminobromopyridines) with amyl nitrite through Sandmeyer approach. Reaction proceeded at room temperature in dibromomethane solvent using 0.5 equivalent $\mathrm{CuBr}_{2}$ to obtain good yield range.

A competent method for the synthesis of aryl bromides involved the reaction of arenediazonium salts with $\mathrm{KBr}$, resultantly affording a variety of aryl bromides in an excellent yield range. This Sandmeyer reaction was carried out at $20-25^{\circ} \mathrm{C}$ in acetonitrile solvent. Maximum conversion was achieved by using equimolar (10 mol\%) catalytic mixture of $\mathrm{CuBr}$ and $\mathrm{CuBr}_{2}$ along with dibenzo-18-crown-6 as a phase transfer catalyst and 1,10-phenanthroline (phen) as ligand. This protocol covers a wide substrate scope by allowing the preparation of different electron-donating and withdrawing groups containing aryl bromides and dibromides in 56-99\% yield range [42].

Siméon et al. [43] reported halogenation reactions of 2-amino-1,3-thiazoles in the presence of $\mathrm{CuBr} / \mathrm{CuBr}_{2}$ for the preparation of monohalo and dihalo 1,3-thiazole derivatives. Temperature played a vital part to achieve required products in reasonable yield. For instance, reaction of 2-aminothiazole 65 in the presence of $\mathrm{CuBr}, n$-butyl nitrite and acetonitrile gave desired monohalogenated product 66 in $46 \%$ yield. This reaction was completed at $60^{\circ} \mathrm{C}$ within $15 \mathrm{~min}$. However, when the same reaction was performed first at $40{ }^{\circ} \mathrm{C}$ then at $25^{\circ} \mathrm{C}$ (for $15-120 \mathrm{~min}$ ) and $65^{\circ} \mathrm{C}$ (for $15 \mathrm{~min}$ ) using $\mathrm{CuBr}_{2}$ as catalyst, dihalo product 67 was obtained in $79 \%$ yield. On the other hand, in the absence of $n$-butyl nitrite 2 -aminothiazole $\mathbf{6 5}$ gave halogenated product $\mathbf{6 8}$ at room temperature within $10 \mathrm{~h}$ in $94 \%$ yield. In this methodology, all reactions were performed in a regioselective fashion under mild conditions which led to the formation of a variety of novel iodo, bromo and chloro derivatives (Scheme 14).

\section{lodination via Sandmeyer reaction}

Synthesis of a variety of hydroxycoumarin and pyranocoumarin derivatives and evaluation of their anti-proliferative activity was reported by Mao et al. [44]. 3,5-Dimethoxyaniline (69), starting precursor of this methodology first underwent Sandmeyer reaction in the presence of $\mathrm{NaNO}_{2}$, $\mathrm{H}_{2} \mathrm{SO}_{4}$ and $\mathrm{KI}$. Resultantly, iodine-substituted methoxy ether $\mathbf{7 0}$ was obtained in 75\% yield which demethylated followed by the reaction with $\beta$-ketoester afforded iodo-substituted 5 -hydroxycoumarin 71. Conversion of this coumarin (71) to chromene $\mathbf{7 2}$ by annulation with 3-methylbut-2-enal was achieved in $79-82 \%$ yield range. After that, these coumarin and chromene derivatives were successfully subjected to palladium-catalyzed Suzuki cross-coupling reaction using different arylboronic acids to obtain desired hydroxycoumarin and pyranocoumarin derivatives in good to excellent yield range (Scheme 15).

Another application of Sandmeyer reaction was reported by Kim et al. [45] where they described [5,5]-sigmatropic rearrangement reactions of $N, N^{\prime}$-diaryl hydrazides, resultantly affording 4,4'-diamino-biphenyls (benzidines). Their methodology started from the copper-catalyzed coupling of bis ( $m$-bromophenyl) ethers $\mathbf{7 3}$ followed by cyclization reaction in the presence of palladium catalyst furnished corresponding diaryl hydrazides which were then subjected to benzidine rearrangement in the presence of aq. $\mathrm{HCl}$. As a result, benzidines $\mathbf{7 4}$ were obtained whose structures were confirmed by treating one of the derivatives with sodium nitrite and KI. As expected, corresponding diiodide $\mathbf{7 6}$ was obtained which confirmed the structural integrity of benzidines $\mathbf{7 4}$. Later, these benzidines $\mathbf{7 4}$ were readily converted 


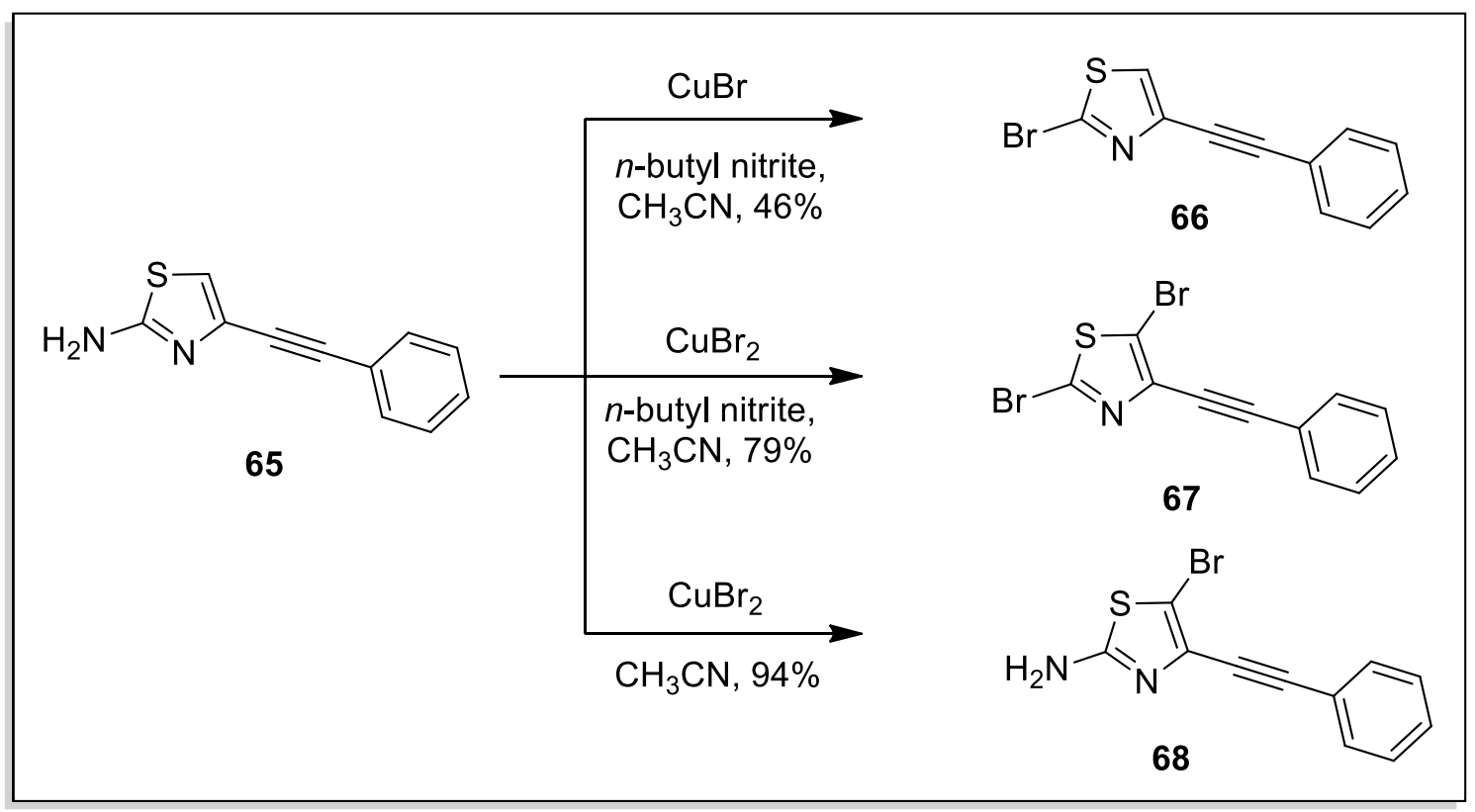

Scheme 14 Thiazole derivatives 66-68 obtained by Sandmeyer reaction

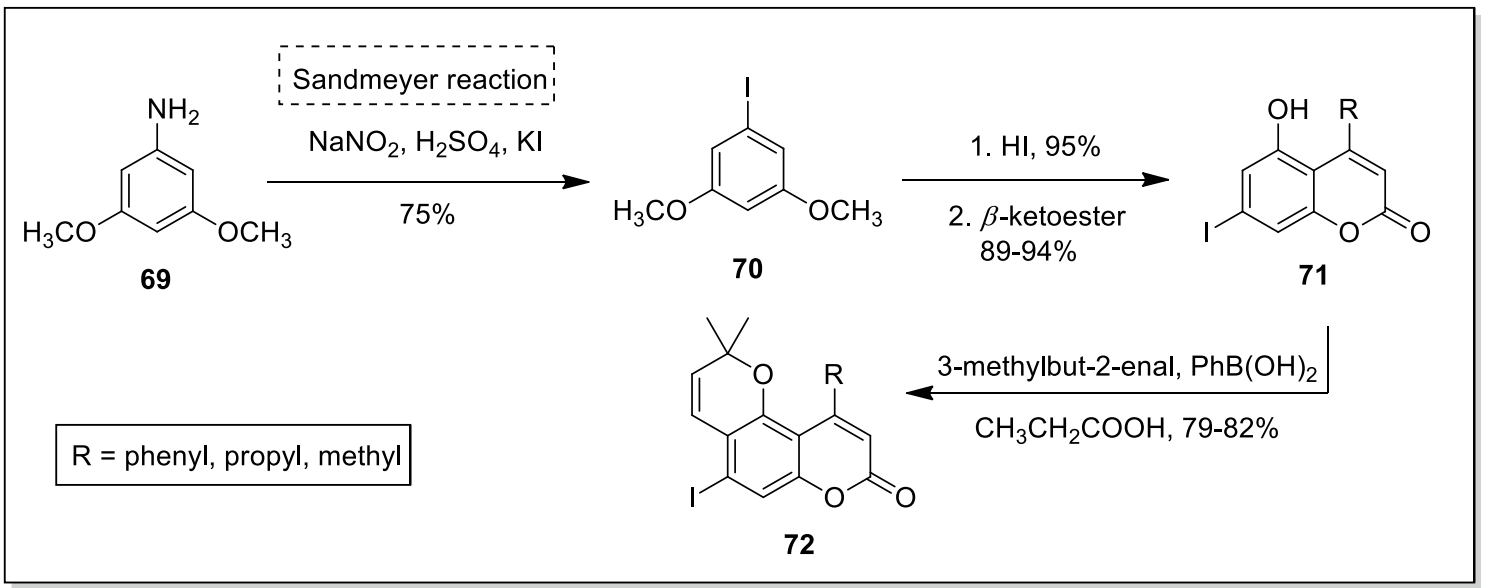

Scheme 15 Sandmeyer reaction of 3,5-dimethoxyaniline (69) for iodine-substituted methoxy ether 70

into desired acetamides 75 (45-47\%) via passing through acetylation process (Scheme 16).

Owing to the wide spread applications of conjugated compounds in optoelectronic devices due to their charge transfer and luminescent properties, synthesis of newly functionalized conjugated polymers and oligomers has fascinated a great deal of consideration. [2.2] Paracyclophane skeleton plays a main role in this regard and has been synthesized by different era of chemists due to its exclusive conjugated system. To carry out this research work, Gon et al. [46] synthesized tetrasubstituted [2.2]-paracyclophane core which involved Sonogashira-Hagihara coupling $\left(\mathrm{PdCl}_{2}\left(\mathrm{PPh}_{3}\right)_{2}\right.$, $\left.\mathrm{PPh}_{3}, \mathrm{CuI}, \mathrm{Et}_{3} \mathrm{~N}, \mathrm{THF}\right)$ and Sandmeyer reactions $\left(\mathrm{H}_{2} \mathrm{SO}_{4}\right.$,
$\left.\mathrm{NaNO}_{2}, \mathrm{KI}\right)$ as key steps. Results declared that targeted derivatives showed good optical properties due to their larger molar extinction coefficient and photoluminescence quantum efficiency.

\section{Miscellaneous}

Liu et al. [47] proposed a complementary electrochemical method for Sandmeyer halogenation in which graphite can be used as cathode material which is an inexpensive metal as compared to platinum. This electrochemical reaction generated a variety of aryl halides by treating diazonium salts with different halogen sources such as $\mathrm{CBrCl}_{3}, \mathrm{CH}_{2} \mathrm{I}_{2}$, 


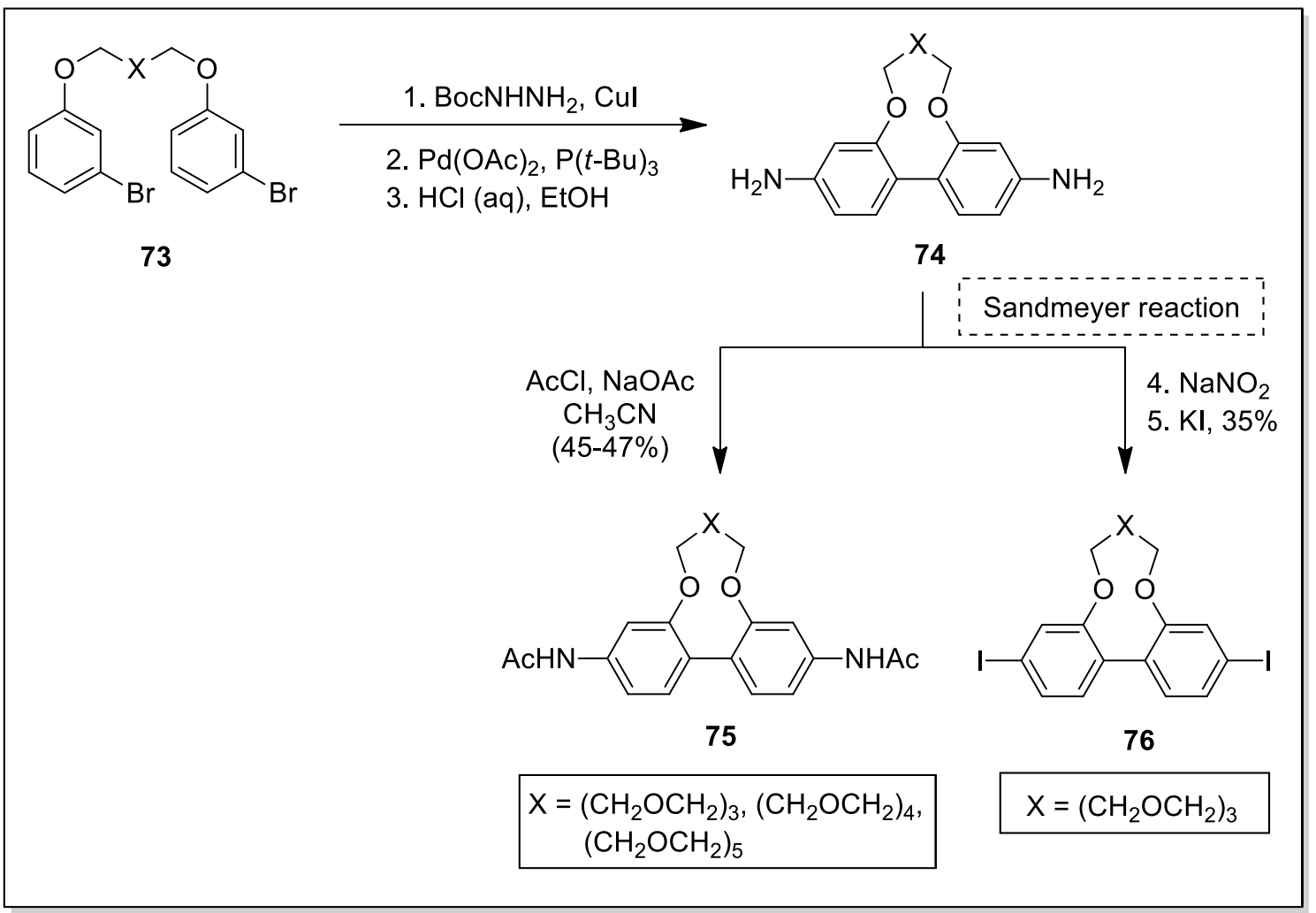

Scheme 16 Sandmeyer approach for the confirmation of benzidine $\mathbf{7 4}$ structure

$\mathrm{LiCl}, \mathrm{CCl}_{4}, \mathrm{NaBr}$, NBS. Reaction processed at $20^{\circ} \mathrm{C}$ in $5: 1$ mixture of $\mathrm{MeOH} / \mathrm{DMF}$ using $\mathrm{Bu}_{4} \mathrm{NClO}_{4}$ as an electrolyte. Moreover, this reaction can also be performed in a one-pot fashion by obtaining diazonium salt from different anilines in the presence of tert-butyl nitrite followed by halogenation under optimized conditions provided required aryl halides.

The efficient synthesis of novel benzo-substituted phthalazines was reported by Tsoungas and Searcey [48]. Their synthetic pathway started from the catalytic hydrogenation of aldehyde $\mathbf{7 7}$ to obtain alcohol $\mathbf{7 8}$ in $\mathbf{7 4 \%}$ yield which was then subjected to Sandmeyer reaction in the presence of sodium nitrite and trimethysilyl bromide. As a result, diazonium salt $\mathbf{7 9}$ was formed which readily converted into compound $\mathbf{8 0}$. After deprotection 58\% yield of free alcohol 81 (from compound 78) was obtained that further underwent halogen lithium exchange process followed by oxidation (PCC, DCM) and cyclization $\left(\mathrm{N}_{2} \mathrm{H}_{4}, \mathrm{EtOH}\right)$ reactions to provide targeted phthalazine $\mathbf{8 2}$ in $82 \%$ yield (Scheme 17 ).

An alternate route to obtain phthalazine 82, started from the reduction of aldehyde $\mathbf{7 7}$ followed by diazotization and Sandmeyer reaction ( $t$-BuONO, $\mathrm{CuBr}, \mathrm{HBr}$ ), provided aldehyde $\mathbf{8 5}$ in $45 \%$ yield. This aldehyde after protection $\left(\left(\mathrm{CH}_{2} \mathrm{OH}\right)_{2}\right.$, TSA) followed by lithium halogen exchange process gave resulting intermediate in $76 \%$ yield (over 2 steps). Deprotection in the presence of $3 \mathrm{~N} \mathrm{HCl}$ and cyclization of 4-methoxyphthalaldehyde with $\mathrm{N}_{2} \mathrm{H}_{4}$ provided required phthalazine $\mathbf{8 2}$ in $82 \%$ yield (Scheme 18 ).

Buchtík et al. [49] reported a simple experimental procedure for the synthesis of polynuclear heterocyclic molecules based on 5-phenyl-6-azauracil scaffold. For this purpose, 3-[3-(6-azauracil-5-yl)-2-aminophenyl]-1,2-dihydro-quinoxaline-2-one (86) was used as starting precursor which first converted into diazonium salt that further produced a variety of heterocyclic $\mathrm{N}-\mathrm{H}$ acids in good yield range. Two reference compounds, prepared via Sandmeyer reaction, are highlighted in Scheme 19. Reaction proceeded well when 6-azauracil $\mathbf{8 6}$ was reacted with sodium nitrite followed by the treatment with $\mathrm{CuCl}$ or $\mathrm{CuBr}$ in the presence of $\mathrm{HCl} / \mathrm{HBr}$ provided 2-chloro (87) and 2-bromo (88) derivatives in 57 and $80 \%$ yield, respectively.

\section{Formation of carbon- $\mathrm{CF}_{2} / \mathrm{CF}_{3} / \mathrm{C}_{2} \mathrm{~F}_{5}$ linkage}

Highlighting the medicinal importance of organofluorine compounds, research group of Zheng synthesized trifluoromethylated arenes via Sandmeyer trifluoromethylation process [50]. Simple and mild reaction conditions, easy availability of the reagents and wide functional groups tolerance are the prominent features of this methodology. The reaction proceeded first from the formation of diazonium 


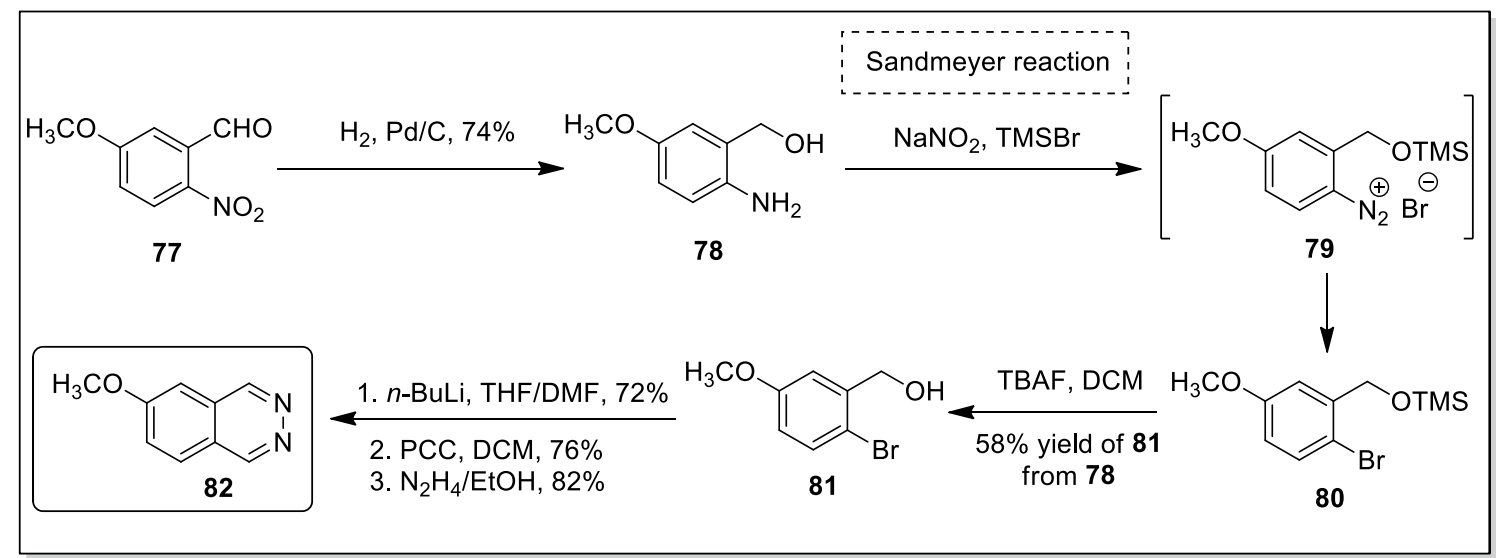

Scheme 17 Synthesis of benzo-substituted phthalazine $\mathbf{8 2}$ via Sandmeyer reaction

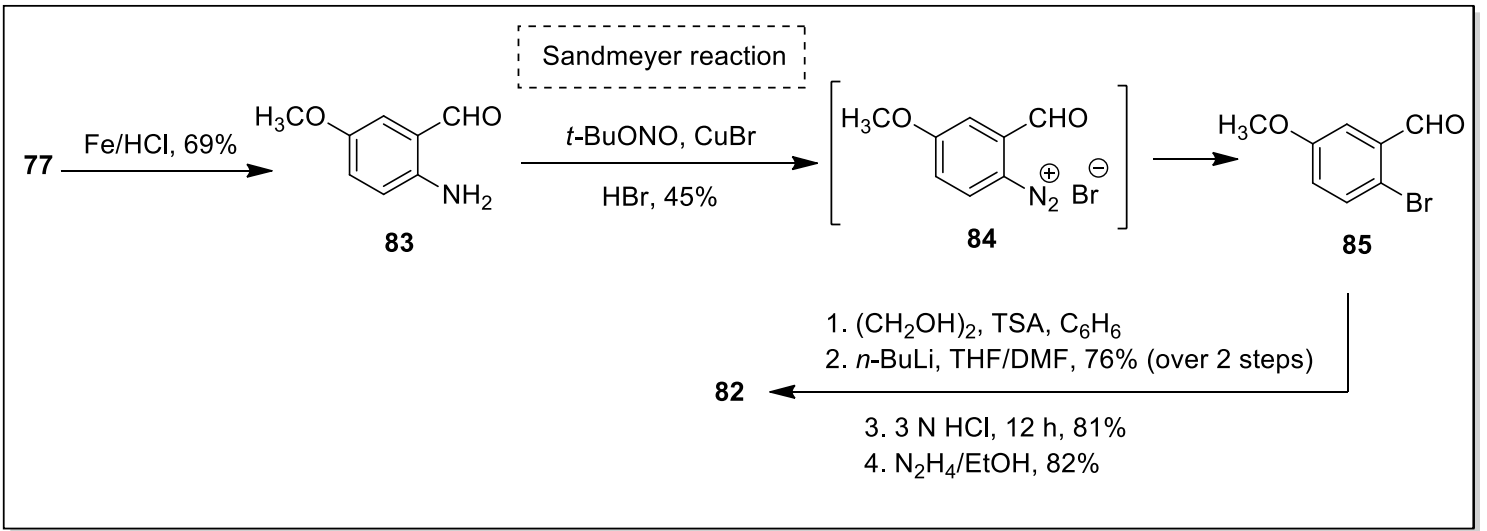

Scheme 18 An alternate route for phthalazine 82 by diazotization and Sandmeyer reaction ( $t$-BuONO, $\mathrm{CuBr}, \mathrm{HBr})$

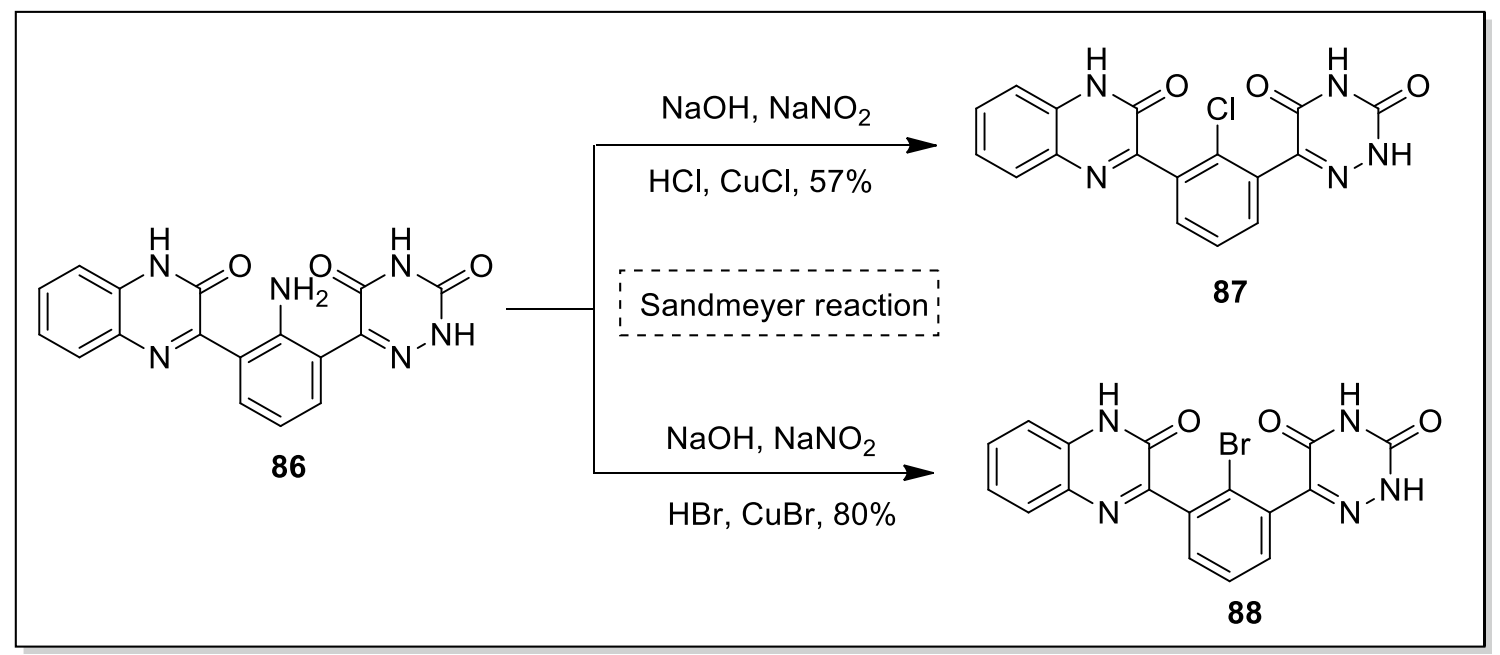

Scheme 19 Synthesis of polynuclear heterocyclic molecules based on 5-phenyl-6-azauracil scaffolds 
salt 90 which subsequently treated with Langlois' reagent and $\mathrm{CuCl}$ in the presence of sodium bicarbonate (additive). Maximum conversion was achieved within $20 \mathrm{~h}$ by carrying out reaction at room temperature in acetonitrile solvent. Proposed mechanism of this reaction is presented in Scheme 20 which started from the conversion of diazonium salt to diazo radical via $\mathrm{Cu}(\mathrm{I})$-mediated singleelectron transfer process. This azo radical was further transformed into aryl radical 92 by releasing nitrogen gas. On the other side, Langlois' reagent upon treatment with TBHP produced trifluoromethyl radical whose reaction with $\mathrm{CuCl}$ generated $\mathrm{Cu}(\mathrm{II}) \mathrm{CF}_{3}$ species that was used to insert $\mathrm{CF}_{3}$ group in aryl radical 92 in the last step.

Danoun et al. [51] designed convenient, competent and inexpensive practical procedures for the trifluoromethylthiolation of arenediazonium salts via Sandmeyer reaction. Optimized parameters of this reaction involved $\mathrm{TMSCF}_{3}$, $\mathrm{CuSCN}, \mathrm{Cs}_{2} \mathrm{CO}_{3}$ and sodium thiocyanate as sulfur source. Reaction worked very well at room temperature in acetonitrile solvent to obtain 23-98\% yield range. Mechanism of this reaction is highlighted in Scheme 21.

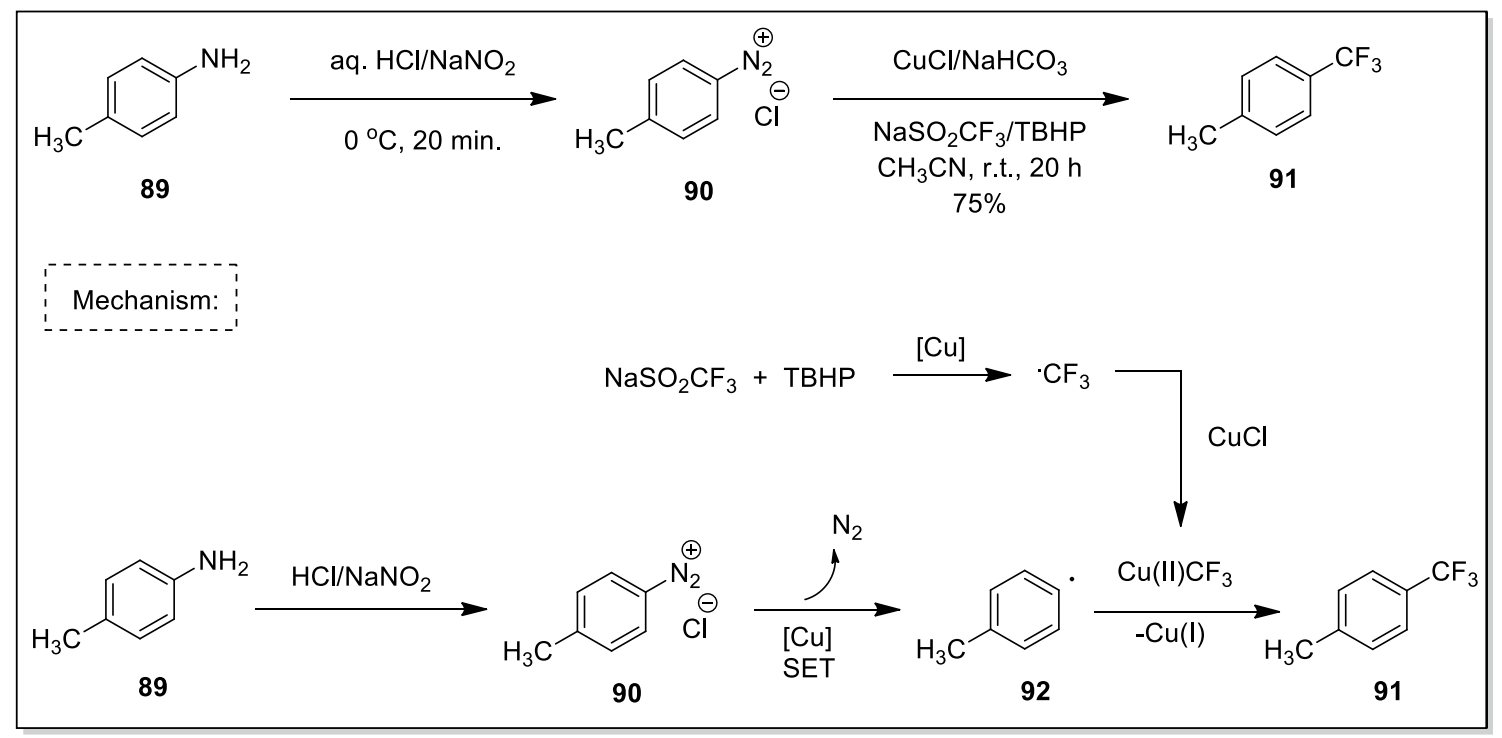

Scheme 20 Sandmeyer trifluoromethylation approach in the presence of Langlois' reagent

Scheme 21 Trifluoromethylation in the presence $\mathrm{TMSCF}_{3}$ and $\mathrm{CuSCN}$

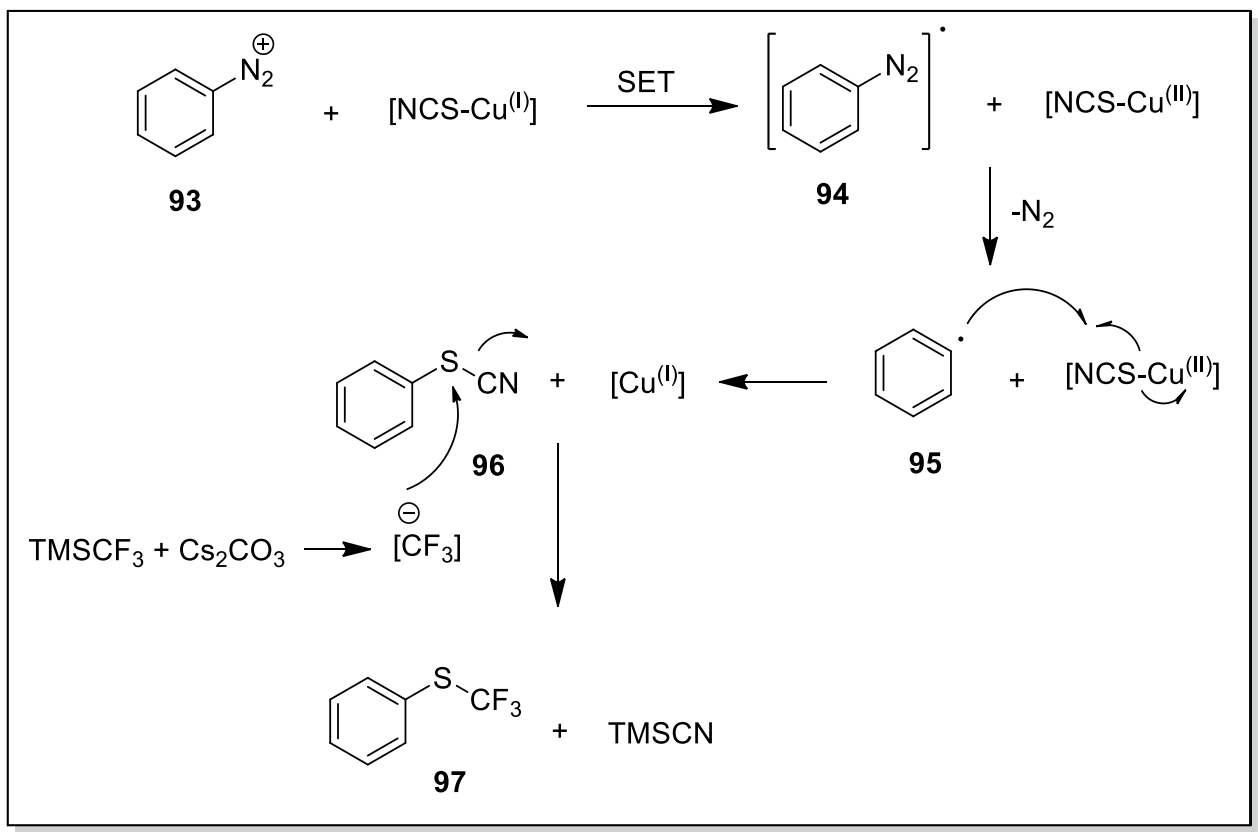


Later on, the same research group reported either one pot or sequential diazotization and trifluoromethylation as presented in Scheme 22 [52]. In method A, 4-methoxyaniline (98) was first diazotized in the presence of equimolar amount (2 equiv.) of $t$-BuONO and $\mathrm{HBF}_{4}$ to produce diazonium salt 99 which was then dissolved in acetonitrile mixture containing $\mathrm{TMSCF}_{3}$, copper(I) thiocyanate and cesium carbonate. As a result, $81 \%$ yield of the targeted product $\mathbf{1 0 0}$ was achieved at room temperature. On the other side, in a one-pot procedure a reaction mixture containing diazotized aniline was added to a suspension of $\mathrm{TMSCF}_{3}$, copper(I) thiocyanate and cesium carbonate, resultantly afforded benzotrifluoride $\mathbf{1 0 0}$ in $85 \%$ yield. Yields of targeted derivatives were almost comparable of both pathways or sometimes higher in the later one. Wide functional group tolerance such as ether, ester, ketone and cyano groups and good yield range broadened the scope of this methodology.

Another application of Sandmeyer reaction for the trifluoromethylation of arenediazonium tetrafluoroborates was disclosed by Danoun et al. [53]. Plausible mechanism of this reaction started first by the reaction of copper(I) thiocyanate with trimethylsilyl cyanide in the presence of cesium carbonate; as a result, trifluoromethyl copper(I) species was generated which reacted with diazonium salt to obtain corresponding benzotrifluoride as described in Scheme 23. The methodology covers wide substrate scope giving rise to $40-98 \%$ yield range.

Goossen et al [54] provided detailed investigation of novel copper-catalyzed Sandmeyer reaction in which Ruppert-Prakash trifluoromethylating reagent produced a variety of trifluoromethylated arenes in good yield range without formation of $\mathrm{CuCF}_{3}$ species. They began their investigation by treating 4-methoxyaniline with tert-butyl nitrite for the formation of diazonium salt. To select suitable acid for this conversion, the performance of eight acids ( $p$-toluenesulfonic acid ( $p$-TSA), $p$-TSA $\cdot \mathrm{H}_{2} \mathrm{O}$, trifluoroacetic acid (TFA), ethereal $\cdot \mathrm{HCl}$, acetic acid, methanesulfonic acid (MSA), trichloroacetic acid (TCA), benzenesulfonic acid (BSA)) was observed and concluded that $p$-TSA gave maximum yield (85\%). In addition to this, $\mathrm{TMSCF}_{3}, \mathrm{CuSCN}, \mathrm{Cs}_{2} \mathrm{CO}_{3}$ and room temperature were the other parameters to carry out trifluoromethylation and trifluoromethylthiolation in $41-98 \%$ and $32-70 \%$ yield range, respectively.

A new synthetic approach of trifluoromethylated arenes via copper-catalyzed Sandmeyer reaction in the presence of Umemoto's reagent was established by Dai et al. [55]. The potential applicability of Umemoto's reagent in combination with copper powder was proven by carrying out reaction using a variety of aryl amines; as a result, desired trifluoromethylated arenes were obtained in moderate to good yield range. Two equivalents $\mathrm{Cu}$ powder, 1.5 equivalents Umemoto's reagent 102, 3 equivalents of isoamyl nitrite and acetonitrile solvent are the optimized parameters of this methodology (Scheme 24).

Matheis et al. [56] performed direct, simple and selective Sandmeyer reaction of diazonium salt $\mathbf{1 0 6}$ by using difluoromethyl-copper complex as difluoromethylating reagent. This complex can be formed by treating 2.5 equivalents of TMS- $\mathrm{CF}_{2} \mathrm{H}$ with 1 equivalent copper thiocyanate and 3 equivalents cesium fluoride in DMF solution. This successful difluoromethylation process tolerated a wide variety of functional groups by giving $34-86 \%$ yield range. It was observed that both electron-donating and withdrawing substituents afforded almost high yields. However, by

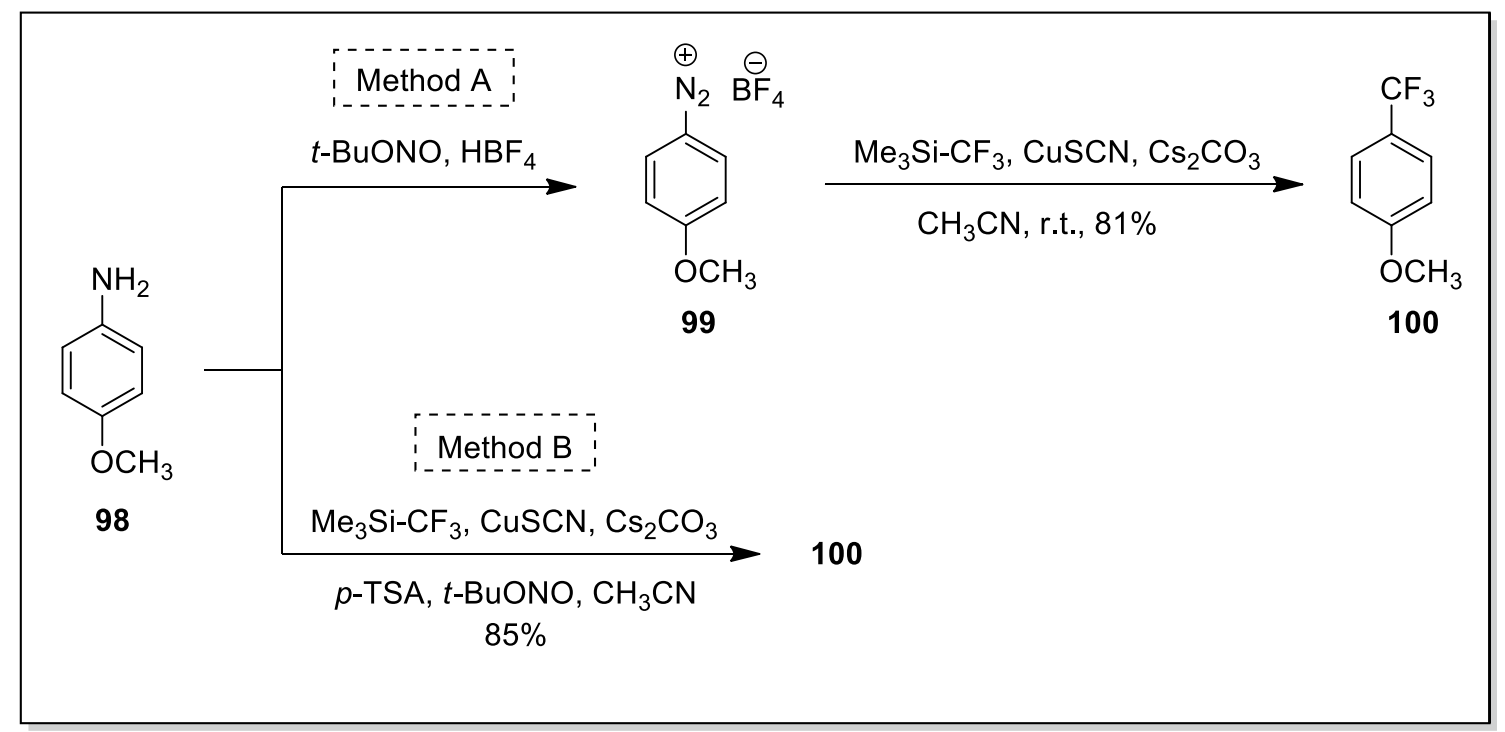

Scheme 22 Sequential (Method A) and one-pot (Method B) diazotization and trifluoromethylation to obtain benzotrifluoride $\mathbf{1 0 0}$ 


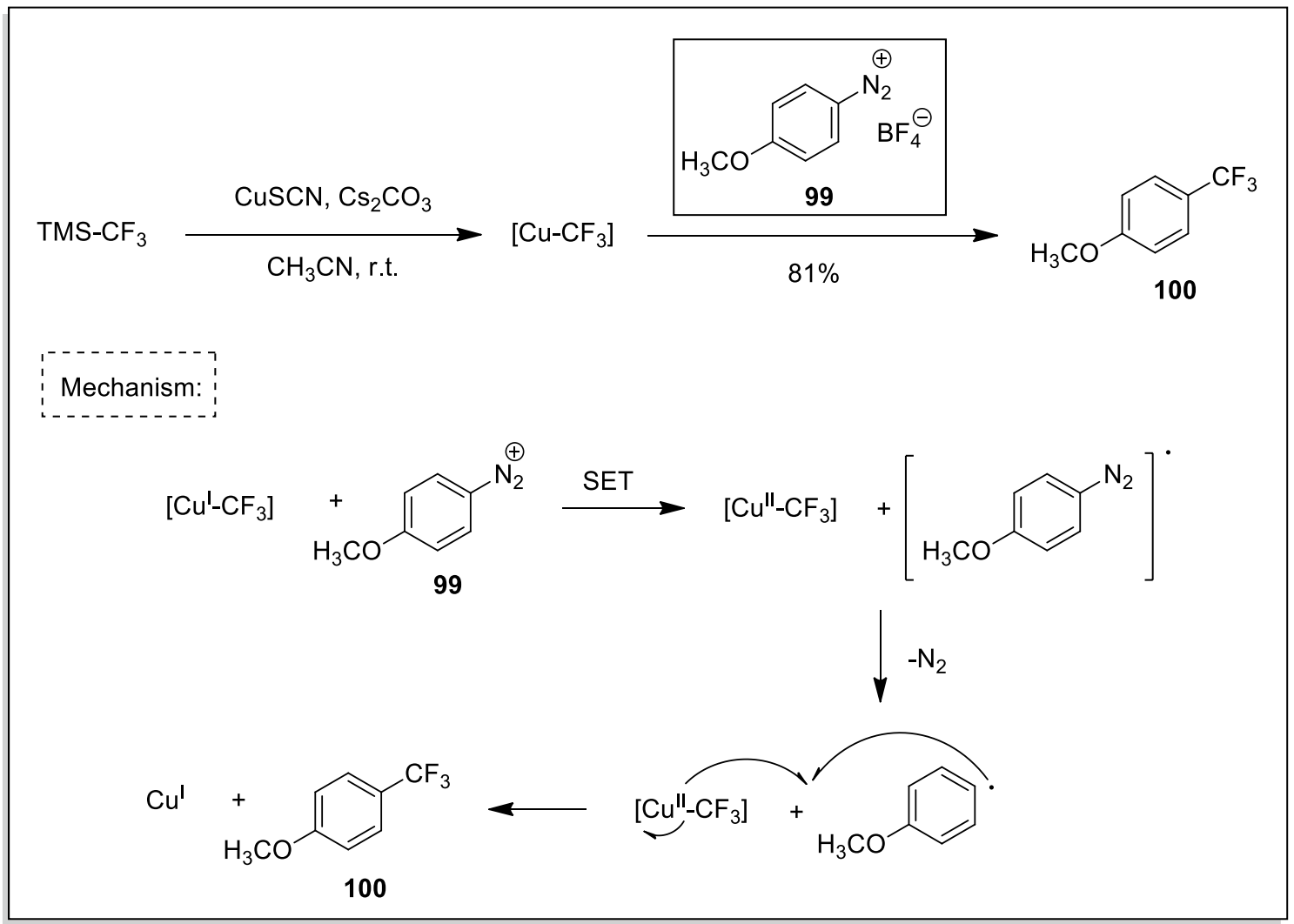

Scheme 23 Plausible mechanism for the conversion of diazonium salt 99 to benzotrifluoride $\mathbf{1 0 0}$

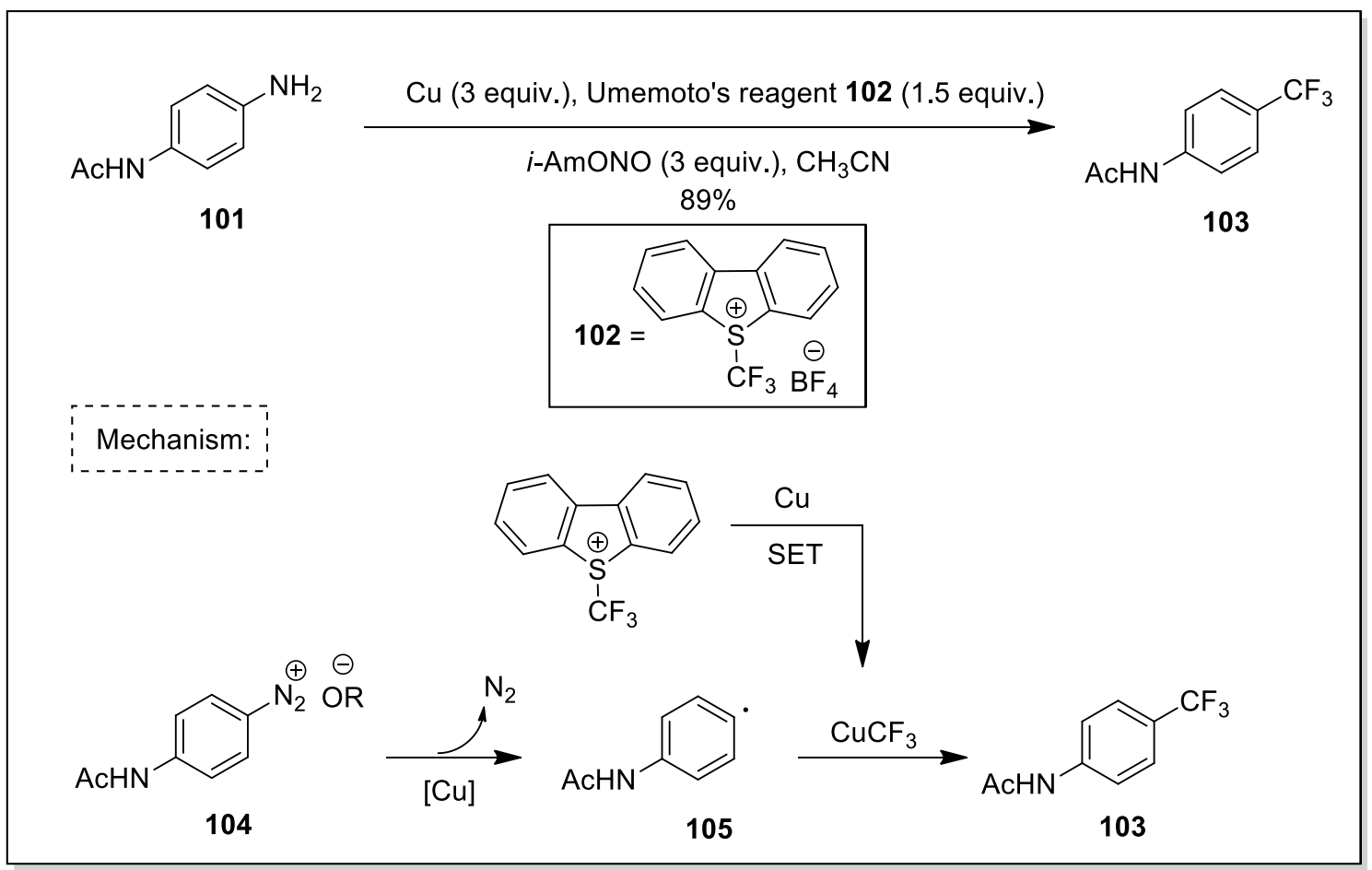

Scheme 24 Sandmeyer reaction in the presence of Umemoto's reagent 


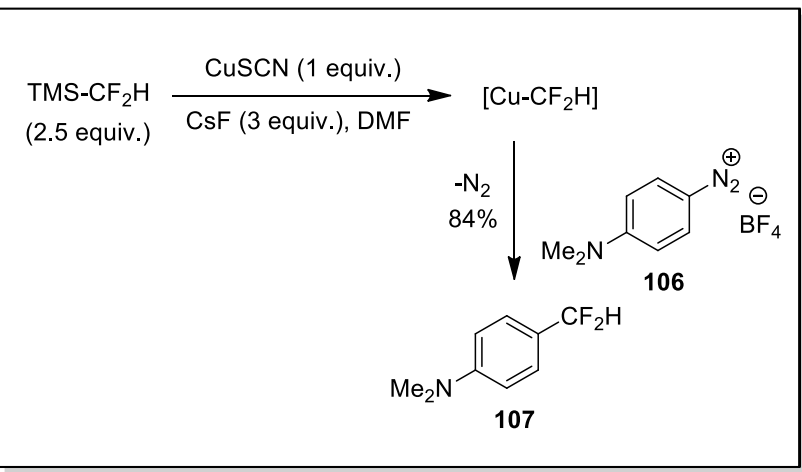

Scheme 25 Difluoromethylation in the presence of difluoromethylcopper complex $\left[\mathrm{Cu}-\mathrm{CF}_{2} \mathrm{H}\right]$

comparing ortho, meta and para positions functional groups, ortho-substituted substrates gave lower yields (38-73\%) as compared to para-substituted substrates (69-81\%). In case of heteroarene diazonium salts such as quinolone, carbazole and indole derivatives, a reasonable yield range (35-78\%) was also observed (Scheme 25).

In 2014, Wang et al. [57] have made a novel contribution toward Sandmeyer-type trifluoromethylation reaction by using trifluoromethyl-silver complex as $\mathrm{CF}_{3}$ source. This methylating reagent was prepared by treating silver fluoride with $\mathrm{TMSCF}_{3}$ in propionitrile. Temperature was first maintained at $-78{ }^{\circ} \mathrm{C}$ and then gradually raised to $25^{\circ} \mathrm{C}$. As a result, desired $\mathrm{AgCF}_{3}$ complex obtained which was subjected to Sandmeyer process. This process started from the diazotization of the different aromatic amines via standard protocol $(\mathrm{HCl}, t$-BuONO) followed by the oxidative addition of the trifluoromethyl-silver complex to diazonium salt, resultantly afforded high-valent silver intermediate which readily underwent reductive elimination reaction to obtain targeted trifluoromethylated product in 10-97\% yield range.

Later on, in $2015 \mathrm{Wu}$ et al. [58] proposed one-pot difluoromethylthiolation approach via Sandmeyer reaction under mild conditions. Optimized parameters to carry out this conversion including $\left[\mathrm{Cu}\left(\mathrm{CH}_{3} \mathrm{CN}\right)_{4}\right] \mathrm{PF}_{6}$ as copper salt, 2,2'-bipyridine as ligand, acetonitrile as solvent and [( $\mathrm{SIPr})$ $\left.\mathrm{Ag}\left(\mathrm{SCF}_{2} \mathrm{H}\right)\right]$ as difluoromethylating reagent (Fig. 1) which could be easily prepared by treating $\left[(\mathrm{SIPr}) \mathrm{Ag}\left(\mathrm{CF}_{2} \mathrm{H}\right)\right]$ with sulfur in THF solvent. This methodology gave wide substrate scope by giving 32-92\% yield range of difluoromethylthiolated heteroarenes within $24 \mathrm{~h}$ by maintaining temperature at $50{ }^{\circ} \mathrm{C}$.

In 2019, Hu and et al. [59] reported for the first time pentafluoroethylation reaction by utilizing Sandmeyer approach. In their methodology, $\mathrm{CuC}_{2} \mathrm{~F}_{5}$ was used as pentafluoroethylating reagent which obtained in a sequence manner first by treating $\mathrm{TMSCF}_{3}$ with sodium iodide in THF solvent; as a result, tetrafluoroethylene species was attained. This

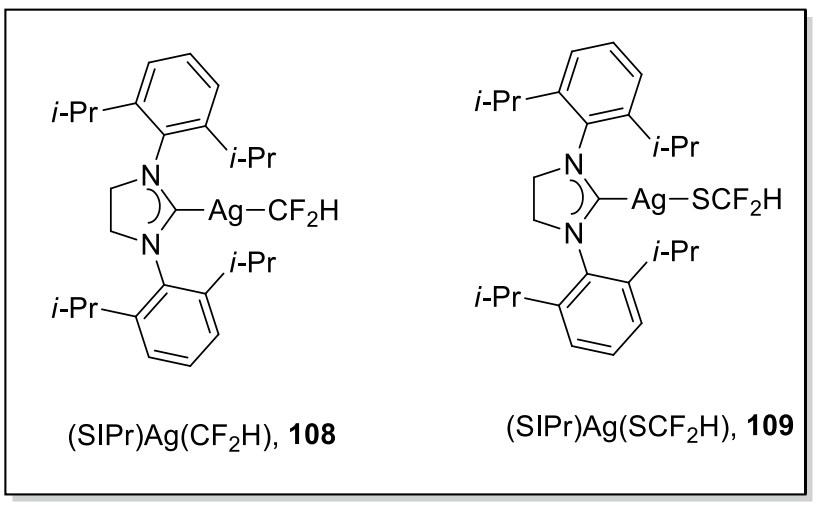

Fig. $1\left[(\mathrm{SIPr}) \mathrm{Ag}\left(\mathrm{SCF}_{2} \mathrm{H}\right)\right]$ as difluoromethylating reagent prepared from [(SIPr) $\left.\mathrm{Ag}\left(\mathrm{CF}_{2} \mathrm{H}\right)\right]$

species further reacted with cesium fluoride in the presence of copper thiocyanate at $70{ }^{\circ} \mathrm{C}$ to afford targeted $\mathrm{CuC}_{2} \mathrm{~F}_{5}$. In the last step, diazonium salt $\mathbf{1 1 0}$ was treated with $\mathrm{CuC}_{2} \mathrm{~F}_{5}$ in acetonitrile solvent; resultantly, desired product $\mathbf{1 1 1}$ was obtained in 93\% yield. This protocol covered wide substrate scope by giving targeted derivatives in 51-93\% yield range within short reaction time (Scheme 26).

Hong et al. [60] examined the use of Togni's reagent in one-pot Sandmeyer trifluoromethylation reaction. Their pathway started from the diazotization of the aromatic amines in the presence of $\mathrm{HCl}$ and $t$-BuONO. Then this salt was treated with Togni's reagent II and copper salt, $\mathrm{Cu}(\mathrm{MeCN})_{4} \mathrm{BF}_{4}$ at $45^{\circ} \mathrm{C}$. Sodium bicarbonate was used as base in dichloroethane solvent. As a result, corresponding tifluoromethylated analogs were obtained in $42-90 \%$ yield range. A plausible mechanism is highlighted in Scheme 27 according to which Togni's reagent was used to produce $\mathrm{CF}_{3}$ radical via copper(I)-mediated single-electron transfer (SET) approach.

Some other reports on Sandmeyer-type fluoromethylation are presented in Table 2.

\section{Formation of carbon-CN linkage}

In 2014, Xu et al. [63] reported $\mathrm{Cu}_{2} \mathrm{O}$-catalyzed Sandmeyer reaction of arenediazonium tetrafluoroborates with TMSCN. The reaction worked very well and gave maximum yield with 0.4 equivalent catalyst loading that was not even significantly increased by using 1 equivalent of $\mathrm{Cu}_{2} \mathrm{O}$ in acetonitrile solvent. Temperature was maintained at $55{ }^{\circ} \mathrm{C}$ to obtain targeted products in $38-92 \%$ yield range within $10 \mathrm{~h}$. This ligand and halogen-free protocol provided many benefits over classic Sandmeyer reaction as nontoxic, mild reaction conditions, low catalyst loading and wide substrate scope are the salient features of this methodology.

Later on, this research group presented another nontoxic palladium-catalyzed cyanation via Sandmeyer approach in 


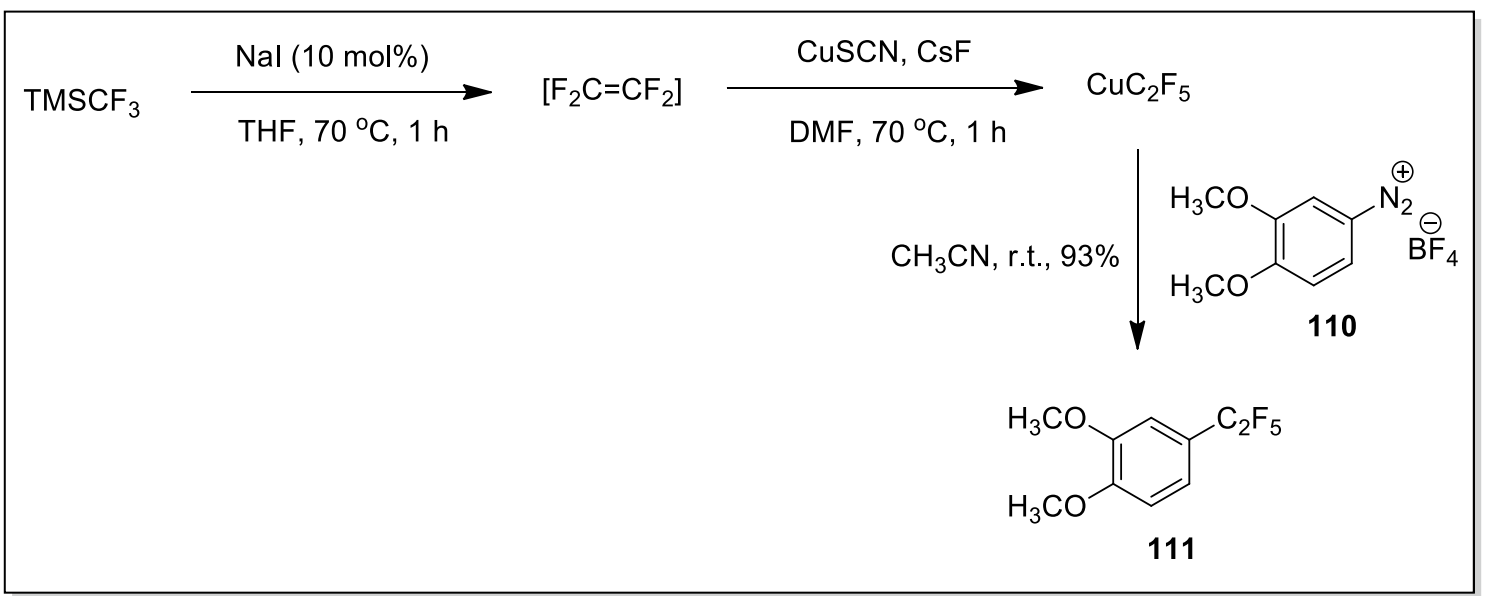

Scheme 26 Pentafluoroethylation via Sandmeyer reaction<smiles>O=C1OI(C(F)(F)F)c2ccccc21</smiles>

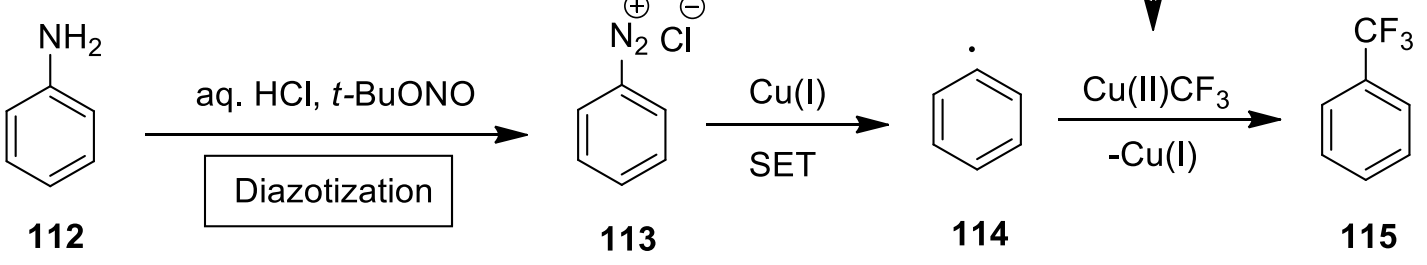

Scheme 27 Sandmeyer trifluoromethylation reaction in the presence of Togni's reagent II

which acetonitrile was used as nonmetallic $\mathrm{CN}$ source [64]. Reaction processed under ambient air in the presence of 0.1 equivalent of $\mathrm{PdCl}_{2}$ and 1 equivalent of $\mathrm{Ag}_{2} \mathrm{O}$ (additive) at $55^{\circ} \mathrm{C}$. As a result, 30-64\% yield range was obtained of the targeted derivatives. A plausible mechanism is highlighted in Scheme 28 which started from the reduction of divalent palladium to zero-valent palladium. In the next oxidative step, this zero-valent palladium added to $\mathrm{ArN}_{2}{ }^{+} \mathrm{BF}_{4}{ }^{-}$to obtain Ar-Pd species (A) followed by the cleavage of $\mathrm{CH}_{3}-\mathrm{CN}$ bond in the presence of $\mathrm{Ag}_{2} \mathrm{O}$ gave intermediate $(\mathbf{C})$. Reductive elimination was the last step which provided aromatic nitrile along with zero-valent palladium.

In order to develop new and efficient conditions for Sandmeyer cyanation, Barbero et al. [65] utilized arene and heteroarenediazonium $o$-benzenedisulfonimides as starting precursors and tetrabutyl ammonium cyanide as $\mathrm{CN}$ source.
Reaction was carried out at room temperature in acetonitrile solvent. This approach under mild reaction conditions gave targeted compounds in 34-92\% yield range. A reference example is presented in Scheme 29 which highlighted the mechanism of this copper-free protocol started by the transfer of electron from anionic part of the salt $\mathbf{1 1 9}$ toward cation. As a result, resonance-stabilized complex 119a was formed which reacted with $\mathrm{CN}^{-}$part of tetrabutyl ammonium cyanide to provide corresponding aryl nitrile $\mathbf{1 2 0}$.

Da Silva et al. [66] designed an effective approach for the synthesis of 2-chloro-3-carbonitrile analogs which are wellknown intermediates and can be transformed into a variety of useful and biologically important heterocyclic molecules, for example the highly polyfunctionalized $4 \mathrm{H}$-pyran, oxazolo, pyrazolo, 1,4-dihydropyridine or pyridines derivatives. The authors used 2-amino-3-carbonitriles as starting 
Table 2 Sandmeyer-type fluoromethylation

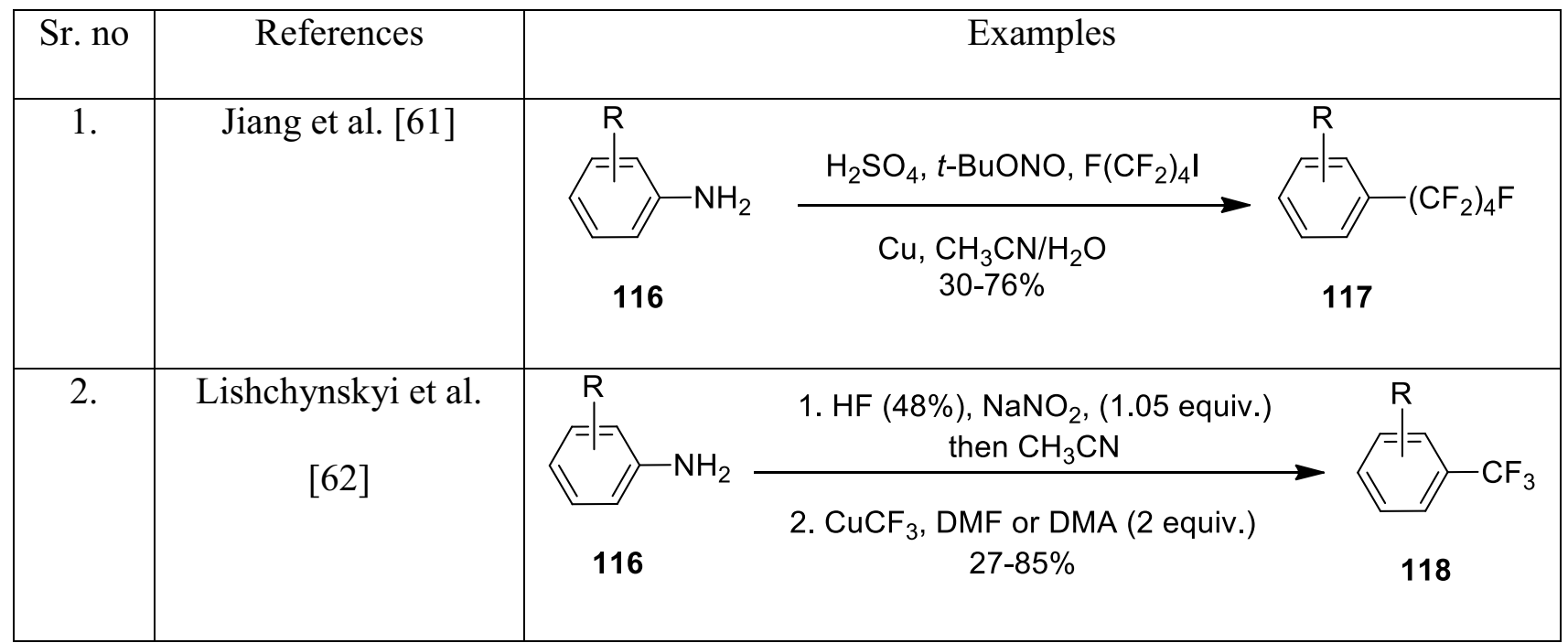

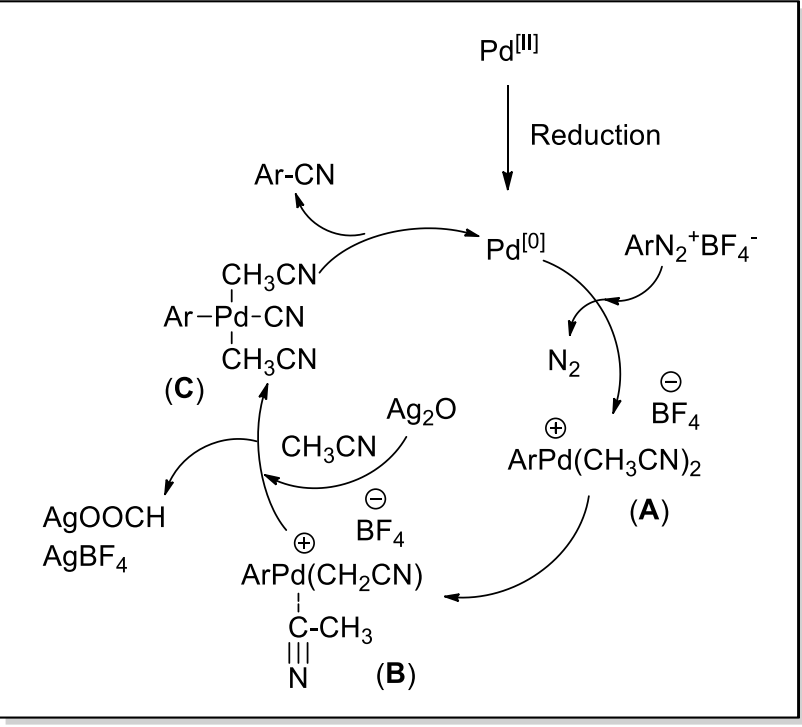

Scheme 28 Plausible mechanism for palladium-catalyzed cyanation via Sandmeyer approach

precursors to obtain corresponding 2-chloro-3-carbonitriles via Sandmeyer approach. The reaction was catalyzed by 1.5 equivalents of $\mathrm{CuCl}_{2}$ in acetonitrile solvent. After the addition of isoamyl nitrile, temperature was maintained at $65^{\circ} \mathrm{C}$ to obtain targeted derivatives in 10-69\% yield range (Fig. 2).

For the construction of medicinally important indole-1,2,4-benzotriazine derivatives, Sandmeyer reaction seems to be a suitable methodology as elaborated by $\mathrm{Xu}$ et al. [67]. Their protocol started by the $S_{N} A r$ reaction of the indole 133 with 2-nitrophenyl halide 134 in the presence of cesium carbonate to obtain respective indole derivative 135 which was subsequently reduced with stannous chloride dihydrate. As a result, indole 136 obtained (45\% yield) that was cyclized by using tert-butyl nitrite via a modified Sandmeyer reaction to afford targeted indole-1,2,4-benzotriazine 137 ( $24 \%$ yield) which proved to be a promising lead compound against a variety of phytopathogenic fungi (Scheme 30).

The research group of Beletskaya reported copper-catalyzed Sandmeyer cyanation approach with a variety of diazonium salts [68]. Reaction proceeded very well using potassium cyanide as $\mathrm{CN}$ source, equimolar amount (10 mol\%) of $\mathrm{CuCN}$ as catalyst, 1,10-phenantroline as ligand, dibenzo18-crown- 6 as phase transfer catalyst and $\mathrm{Cu}\left(\mathrm{BF}_{4}\right)_{2}$ as cocatalyst. Maximum yield range (52-93\%) was obtained by carrying out reaction at room temperature in acetonitrile solvent.

\section{Formation of carbon-sulfur linkage}

Sulfonyl fluorides have gained tremendous interest in synthetic organic chemistry due to their unique characteristics such as stability, reactivity pattern and proton-mediated reactivity. They are extensively used for the construction of a variety of pharmacologically important scaffolds. Considering their importance, Lin et al. developed an efficient, cost-effective and copper-free methodology for the synthesis of arenesulfonyl fluorides via Sandmeyer approach. In their protocol, different arenediazonium salts having electrondonating and withdrawing substituents were treated with $\mathrm{N}$-fluorobenzenesulfonimide (NFSI), a fluorine source and $\mathrm{K}_{2} \mathrm{~S}_{2} \mathrm{O}_{5}$ which plays dual role as a reductant and a sulfonyl source simultaneously. Reaction conducted very well under argon atmosphere in a mixture of acetonitrile, water and acetic acid (co-solvent). Maximum conversion was attained within $6 \mathrm{~h}$ at room temperature. 


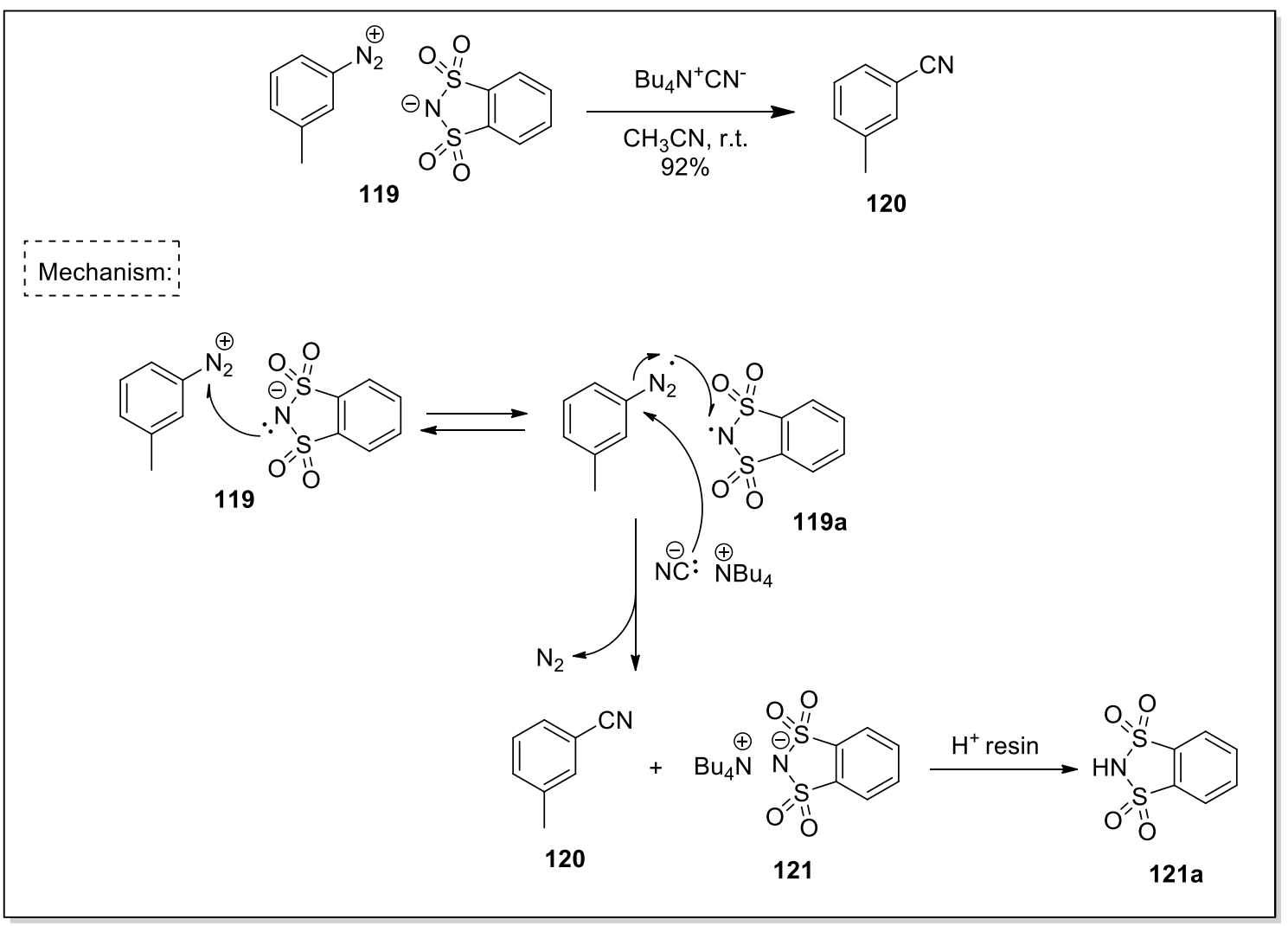

Scheme 29 Sandmeyer cyanation, using arenediazonium $o$-benzenedisulfonimide $\mathbf{1 1 9}$ as starting precursor and tetrabutyl ammonium cyanide as $\mathrm{CN}$ source

Diaryl sulfones exhibit a wide range of biological activities; for example, they act as anticancer, antifungal, antibacterial agents and are efficient thymidylate synthase and HIV-1 reverse transcriptase inhibitors. Besides this, they play a vital role as synthetic intermediates in organic chemistry. Despite the discovery of various synthetic methods for diaryl sulfones, search of new and efficient conditions is still under process. In this regard, Yang et al. [70] reported a competent copper-catalyzed Sandmeyer approach for the synthesis of diaryl sulfones. For example, reaction of aryl amine $\mathbf{8 9}$ with arylsulfinic acid $\mathbf{1 3 8}$ in the presence of equimolar amounts (3 equivalents) of copper powder and isoamyl nitrite (diazotizating agent) gave $82 \%$ yield of the corresponding product 139. Reaction processed under nitrogen atmosphere by maintaining temperature at $0-25{ }^{\circ} \mathrm{C}$ in acetonitrile solvent. This approach depicted a wide substrate scope, allowing the preparation of a variety of diaryl sulfones in $47-82 \%$ yield range (Scheme 31 ).

Research group of Goossen in 2015 reported difluoromethylthiolation of arene diazonium salts in $61-95 \%$ yield range [71]. Standard parameters to make this conversion effective included following steps: First a solution of diazonium salt 99 in acetonitrile solvent was mixed in sodium thiocyanate, cesium carbonate and copper thiocyanate mixture.
Then cesium fluoride, copper thiocyanate and $\mathrm{TMS}_{-} \mathrm{CF}_{2} \mathrm{H}$ in DMF were added in the reaction mixture; as a result, desired product $\mathbf{1 4 0}$ was obtained in $95 \%$ yield within $12 \mathrm{~h}$ by carrying out reaction at room temperature.

Later on, same research group presented trifluoromethylthiolation and pentafluoroethylthiolation by applying Sandmeyer conditions as described in Scheme 32. Reaction of 4-methoxybenzenediazonium tetrafluoroborate (99) was performed with 1.8 equivalents of $\mathrm{Me}_{4} \mathrm{NSCF}_{3}$ in the presence of copper thiocyanate. Resultantly, trifluoromethyl thioether 141 was obtained in $97 \%$ yield [72]. However, when the same reaction was performed in the presence of $10 \mathrm{~mol} \%$ elemental copper using $\mathrm{Me}_{4} \mathrm{NSC}_{2} \mathrm{~F}_{5}$ as $\mathrm{SC}_{2} \mathrm{~F}_{5}$ source, pentafluoroethyl thioether $\mathbf{1 4 2}$ was obtained in $98 \%$ yield. This methodology under mild reaction conditions tolerates a variety of functional groups by giving 61-99\% yield range [73].

Zhang et al. [74] adopted a different approach for trifluoromethylation of arenediazonium tetrafluoroborates in the presence of Langlois reagent $\left(\mathrm{NaSO}_{2} \mathrm{CF}_{3}\right)$. Reaction worked very well at $45^{\circ} \mathrm{C}$ using $t$-butyl hydroperoxide as oxidant, $\mathrm{CuBF}_{4}\left(\mathrm{CH}_{3} \mathrm{CN}\right)_{4}$ as copper salt and $2,2^{\prime} ; 6^{\prime}, 2^{\prime \prime}$-terpyridine (tpy) as ligand. As a result, 30-63\% yield range of the corresponding trifluoromethylated derivatives was obtained in a mixture of acetonitrile/water solvent. Similarly, the authors 


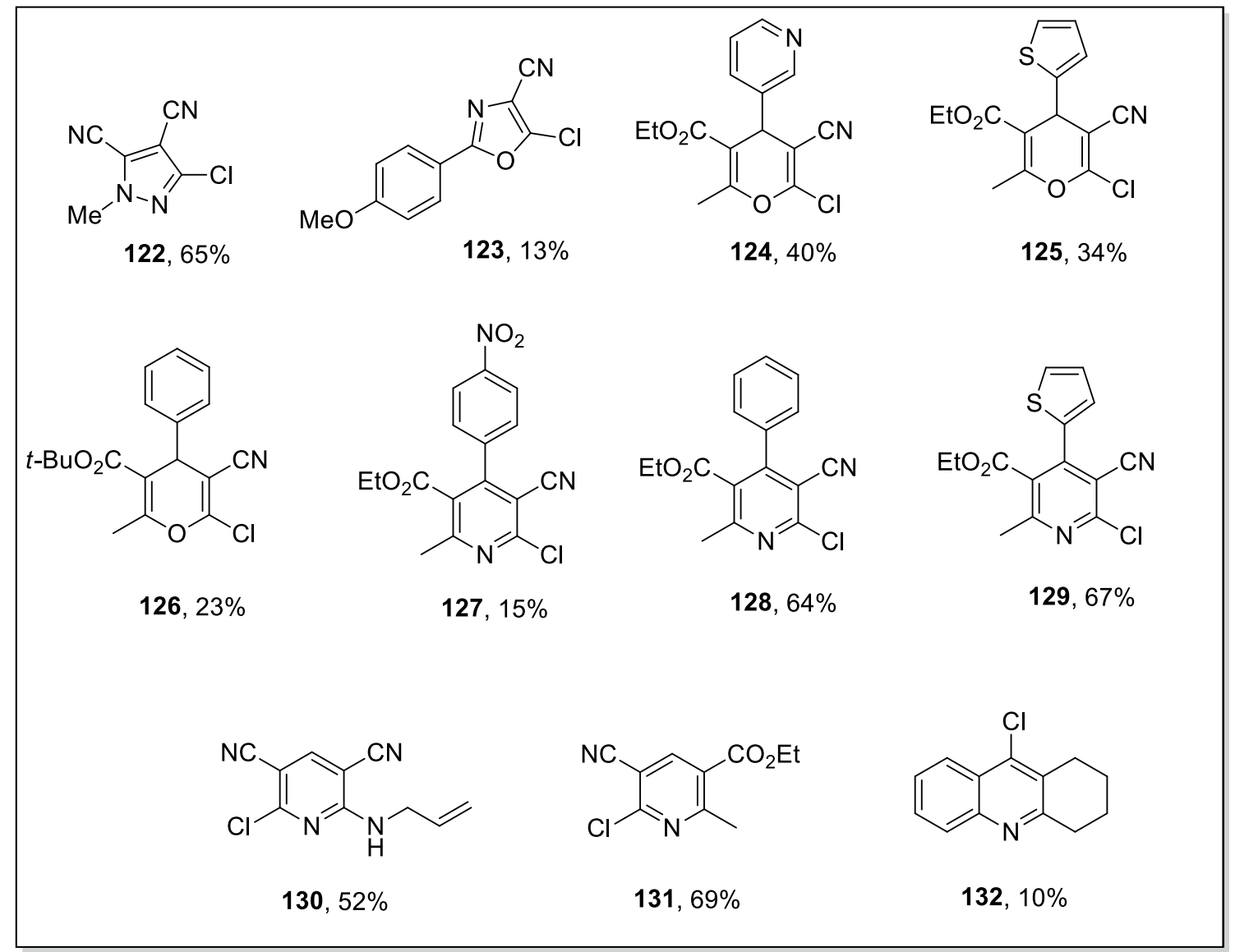

Fig. 2 2-Chloro-3-carbonitrile analogs (122-132) prepared via Sandmeyer reaction

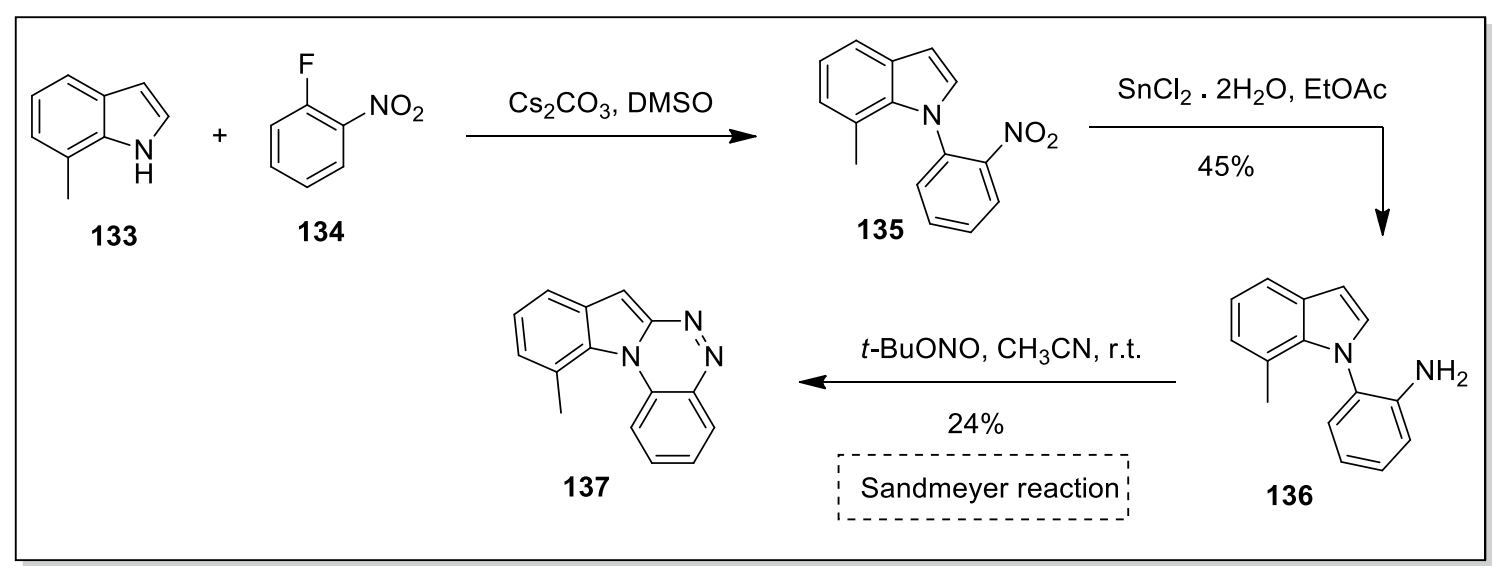

Scheme 30 Preparation of indole-1,2,4-benzotriazine derivative 137 involving Sandmeyer reaction as a key step

reported trifluoromethanesulfonylation of arenediazonium tetrafluoroborates in 45-90\% yield range in the presence of $\mathrm{NaSO}_{2} \mathrm{CF}_{3}$ and $10 \mathrm{~mol} \% \mathrm{Cu}_{2} \mathrm{O}$. To carry out maximum conversion at room temperature, DMSO was selected as suitable solvent.
Organothiophosphates are worthy of attention due to their outstanding insecticidal, antiviral and enzyme inhibition properties against acetylcholinesterase (AChE) enzyme. Their wide spread contribution in pharmaceutical chemistry encouraged Kovacs et al. [75] to disclose 
different phosphorothiolation methods mainly including phosphorothiolation of arenediazonium salts via Sandmeyer approach. In their methodology, the highlighting reagent used for phosphorothiolation was 144 which when reacted with diazonium salt 143 under standard Sandmeyer conditions (CuSCN (20 mol\%), acetonitrile, r.t.), aand phosphorothiolated arene $\mathbf{1 4 5}$ was obtained in $95 \%$ yield. The reaction covered a wide variety of substrates by giving targeted products in $47-95 \%$ yield range within $16 \mathrm{~h}$ (Scheme 33).
Ou et al. [76] in 2019 published a convenient procedure for the construction of (diethylphosphono)-difluoromethyl thioethers proceeding via two steps: Sandmeyer thiocyanation and subsequent fluoroalkylation reaction. Optimal reagents for thiocyanation included copper thiocyanate, cesium carbonate, sodium thiocyanate (sulfur source) and acetonitrile solvent. As a result, corresponding thiocyanate derivative was obtained which was subjected to fluoroalkylation reaction using $\mathrm{TMS}_{-} \mathrm{CF}_{2} \mathrm{PO}(\mathrm{OEt})_{2}$ as the difluoroalkyl source. Plausible mechanism of this reaction is presented in

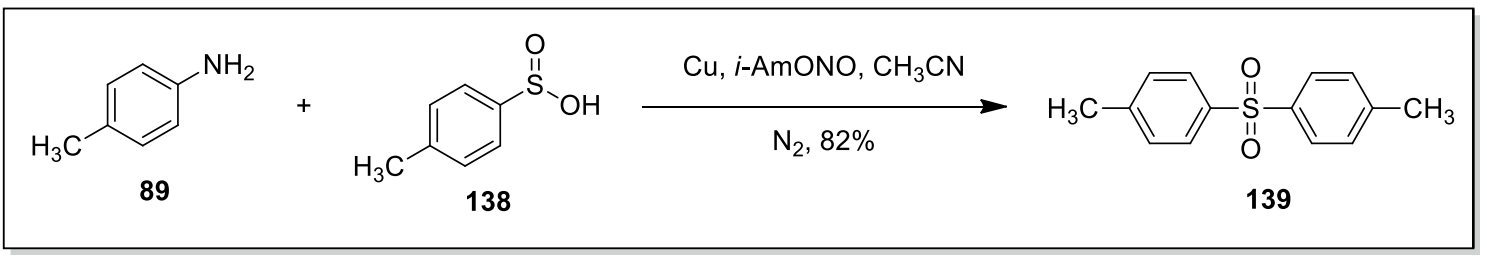

Scheme 31 Copper-catalyzed Sandmeyer approach for the synthesis of diaryl sulfones

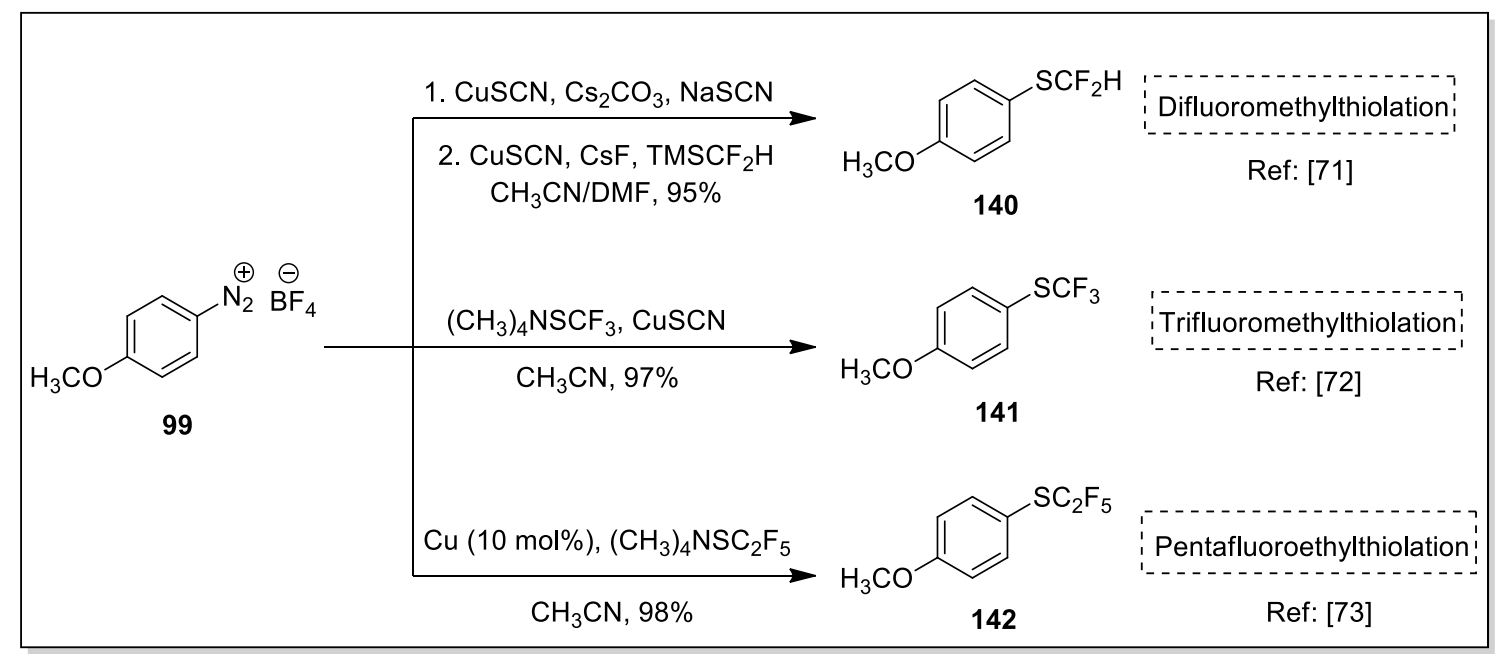

Scheme 32 Di-, trifluoromethylthiolation and pentafluoroethylthiolation via Sandmeyer approach

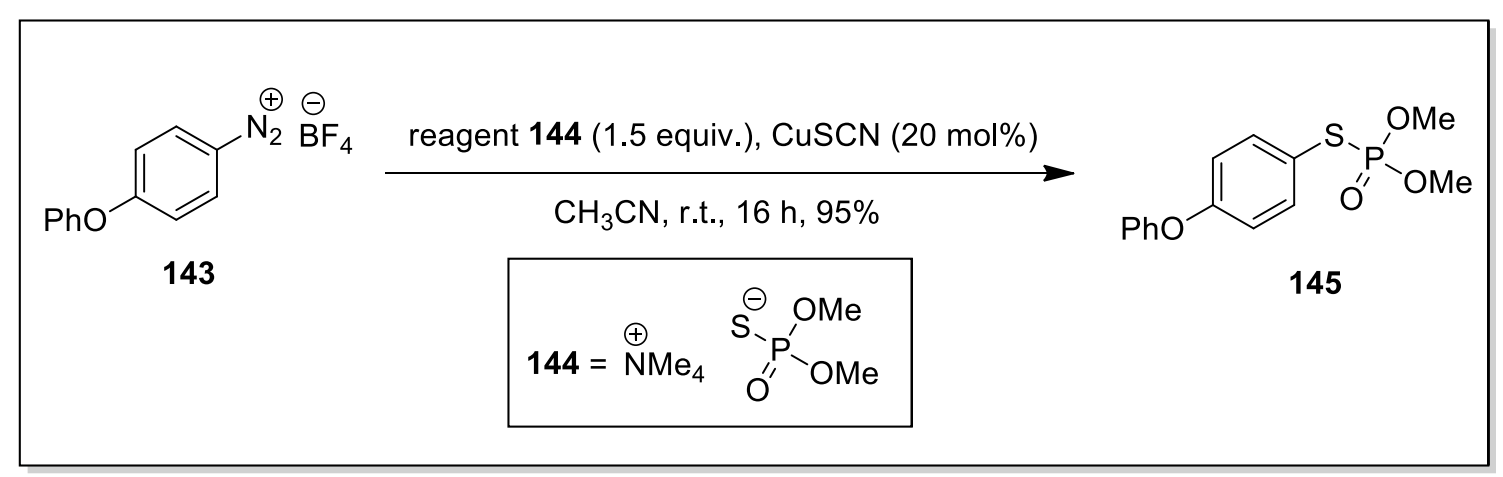

Scheme 33 Phosphorothiolation of arenediazonium salt 143 via Sandmeyer approach 
Scheme 34 which started from the generation of $\mathrm{Cu}^{\mathrm{I}}(\mathrm{SCN})_{2}$ species by the reaction of CuSCN with NaSCN. In the next step, diazonium salt 146 was treated with $\mathrm{Cu}^{\mathrm{I}}(\mathrm{SCN})_{2}$ to obtain respective thiocyanate $\mathbf{1 4 8}$ via Sandmeyer approach.

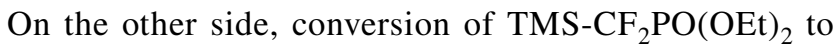

$\mathrm{Cu}-\mathrm{CF}_{2} \mathrm{PO}(\mathrm{OEt})_{2}$ in the presence of base gave species (A) which was in the final step reacted with thiocyanate 148 to afford targeted product 147.

Very recently, research group of Qing reported a similar methodology for fluorosulfonylation of arenediazonium

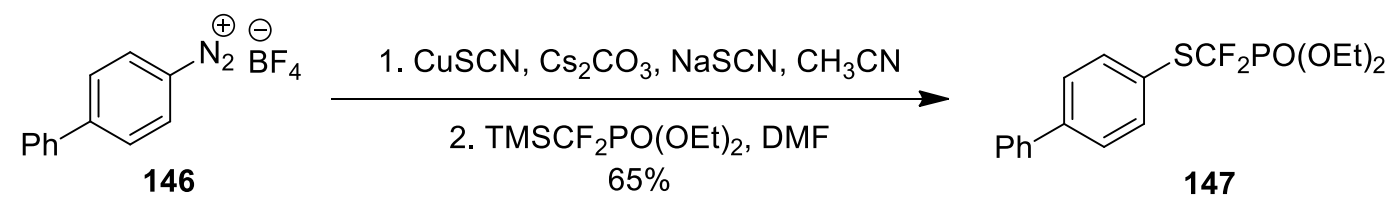<smiles>CO</smiles>

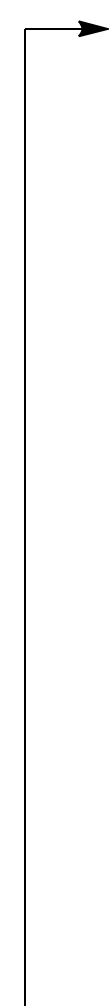

$\mathrm{Cu}^{\prime}(\mathrm{SCN})_{2}^{-}$<smiles>O=[N+]c1ccc(-c2ccccc2)cc1</smiles>

SET

$\mathrm{Cu}^{\prime \prime}(\mathrm{SCN})_{2}+$

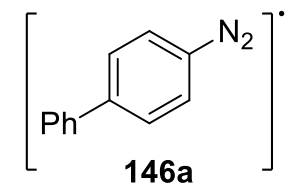

\section{$\mathrm{NaSCN}$}

NCS-Cu"-SCN<smiles>c1ccc(-c2ccccc2)cc1</smiles>

146b

$\mathrm{TMSCF}_{2} \mathrm{PO}(\mathrm{OEt})_{2}$<smiles>N#[As]c1ccc([AsH2])cc1</smiles>

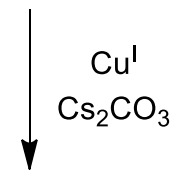

$\mathrm{Cu}-\mathrm{CF}_{2} \mathrm{PO}(\mathrm{OEt})_{2}$

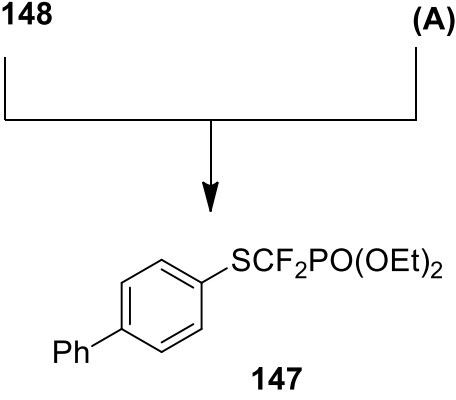

Scheme 34 Mechanism of sequential Sandmeyer thiocyanation and fluoroalkylation reactions 
tetrafluoroborates [77]. However, they used $\mathrm{Na}_{2} \mathrm{~S}_{2} \mathrm{O}_{5}$ as sulfonyl source instead of $\mathrm{K}_{2} \mathrm{~S}_{2} \mathrm{O}_{5}$. The other optimized parameters were $\mathrm{N}$-fluorobenzenesulfonimide (NFSI), 2/0.1 mixture of acetonitrile/water, $60{ }^{\circ} \mathrm{C}$ temperature under nitrogen atmosphere. As a result, $43-81 \%$ yield range was obtained within $6 \mathrm{~h}$. A plausible mechanism is highlighted in Scheme 35. Single-electron transfer reduction of aryldiazonium salt $\mathbf{1 4 9}$ provided aryl radical 114 which upon reaction with $\mathrm{SO}_{2}$ (generated from $\mathrm{Na}_{2} \mathrm{~S}_{2} \mathrm{O}_{5}$ ) gave arenesulfonyl radical 150. In the last step, transfer of fluorine atom from $\mathrm{N}$-fluorobenzenesulfonimide afforded targeted arenesulfonyl fluoride $\mathbf{1 5 1}$.

In another report, various diazonium salts were subjected to fluorosulfonylation reaction by passing through Sandmeyer approach. For this purpose, $\mathrm{Na}_{2} \mathrm{~S}_{2} \mathrm{O}_{5}$ was used as sulfur dioxide source and Selectfluor $\mathbf{1 5 2}$ as fluorine source in methanol solvent. Temperature was maintained at $70{ }^{\circ} \mathrm{C}$ to attain maximum yield $(85 \%)$ of sulfonyl fluoride 153 . This methodology was applied on a variety of substrates; resultantly moderate to good yield range was obtained (Scheme 36) [78].

Tarkhanova et al. [79] demonstrated that copper catalysts incorporating ionic liquid on Silochrom support efficiently catalyzed Sandmeyer reaction. A highlighted example for the thiocyanation of 3-methyl-4-nitrophenyldiazonium tetrafluoroborate (154) is presented in Scheme 37. For this purpose, potassium thiocyanate was used as nucleophile and reaction was catalyzed with $\mathrm{CuCl}-\mathrm{Et}_{3} \mathrm{PrNCl}$ in acetonitrile solvent. 96\% Yield of the required product 155 was obtained by carrying out reaction at room temperature. Same methodology was adopted to attain $87-97 \%$ yield range of a variety of aryl bromides.

\section{Formation of carbon-tin linkage}

Organotin reagents are highly important due to their usage in the synthesis of various $\mathrm{C}-\mathrm{N}, \mathrm{C}-\mathrm{F}$ and $\mathrm{C}-\mathrm{OCF}_{3}$ bond formation reactions. They are also used for the generation of $\mathrm{C}-\mathrm{C}$ bond by highly famous Stille cross-coupling reaction

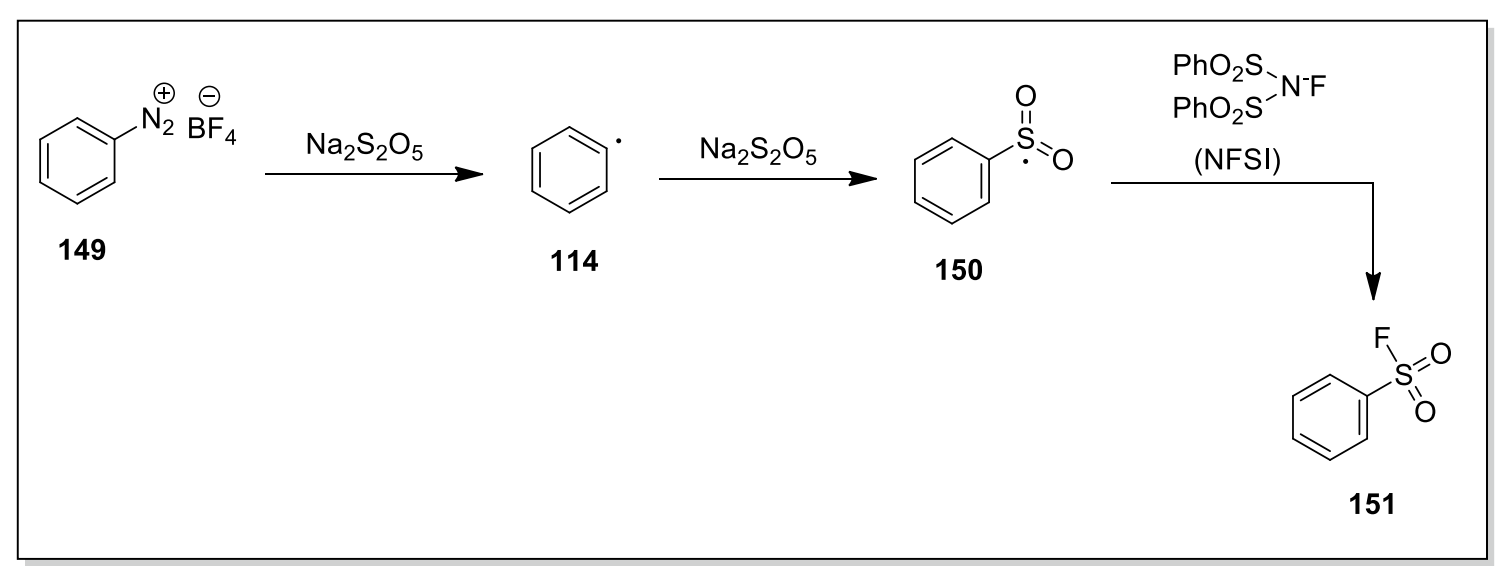

Scheme 35 Fluorosulfonylation of arenediazonium tetrafluoroborate 149 using $\mathrm{Na}_{2} \mathrm{~S}_{2} \mathrm{O}_{5}$ as sulfonyl source and $N$-fluorobenzenesulfonimide (NFSI) as fluorine source

Scheme 36 Fluorosulfonylation reaction using Selectfluor 152 as fluorine source

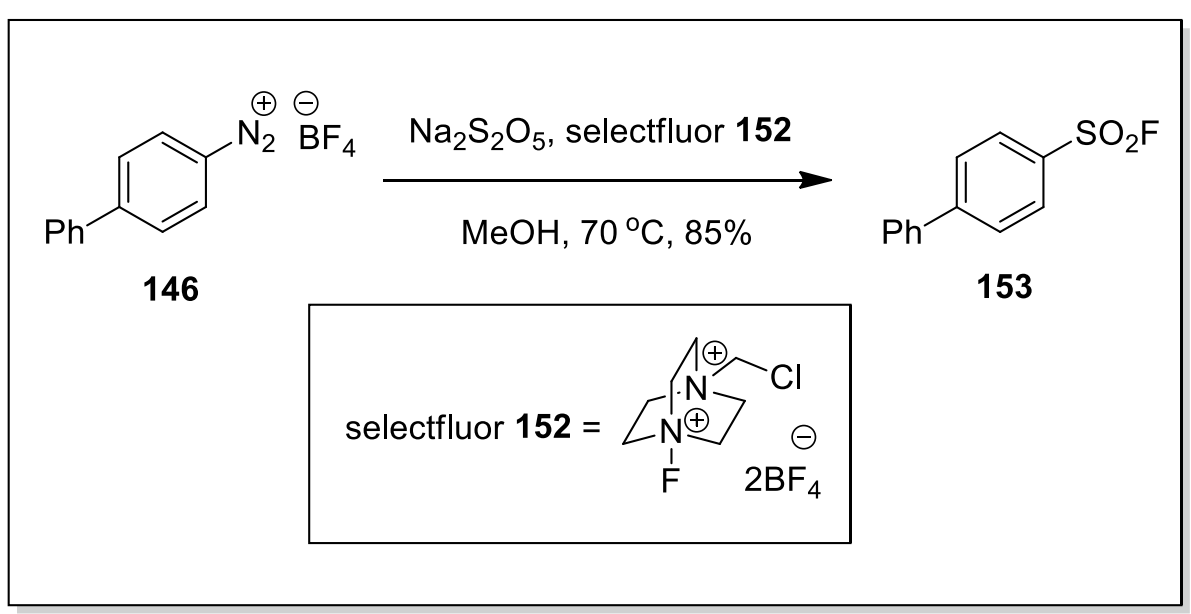


whose wide applications in organic synthesis create a dire need to develop new and efficient synthetic methods for aryl stannane compounds. On account of this, Qiu et al. [80] developed a Sandmeyer-type stannylation approach for the preparation of aryl trimethylstannanes. A highlighted example is presented in Scheme 38 in which amine $\mathbf{5 7}$ was treated with tert-butyl nitrite and $\left(\mathrm{SnMe}_{3}\right)_{2}$ in dichloroethane solvent at $0{ }^{\circ} \mathrm{C}$. Screening a variety of acidic additives such as $\mathrm{TsOH}, \mathrm{BF}_{3} \cdot \mathrm{OEt}_{2}, \mathrm{AlCl}_{3}$ and $\mathrm{AcOH}$ which found to be helpful for diazotization process, maximum yield was obtained with $p$-toluenesulfonic acid. Overall, moderate to good yield range (36-86\%) of the targeted products was obtained which were most likely subjected to different cross-coupling reactions without purification such as Stille reaction and can also be used for the synthesis of different pharmaceutical agents.

Later on, the same research group developed another methodology for stannylation of aromatic amines, simultaneously generating trimethylstannyl arylboronate analogs which were effectively subjected to Stille and Suzuki-Miyaura cross-coupling reactions [81]. For example, conversion of $p$-nitroaniline $\mathbf{5 7}$ into arylboronate $\mathbf{1 5 7}$ was accomplished in the presence of tert-butyl nitrite, bis(pinacolato)diboron, benzoyl peroxide and acetonitrile solvent under metal-free conditions. Then reduction of nitro group to $\mathrm{NH}_{2}$ group via palladium-catalyzed reaction generated boron-substituted aniline $\mathbf{1 5 8}$ in $98 \%$ yield which further converted into corresponding stannylation analog 159 under optimized Sandmeyer-type stannylation reaction conditions ( $t$-BuONO, $\left(\mathrm{SnMe}_{3}\right)_{2}$, TsOH, DCE) (Scheme 39).

\section{Formation of carbon-phosphorous linkage}

In an effort to search diversified methods for aryl phosphonates which play a vital role in material science, organic
Scheme 37 Sandmeyer reaction catalyzed by copper incorporating ionic liquid on Silochrom support
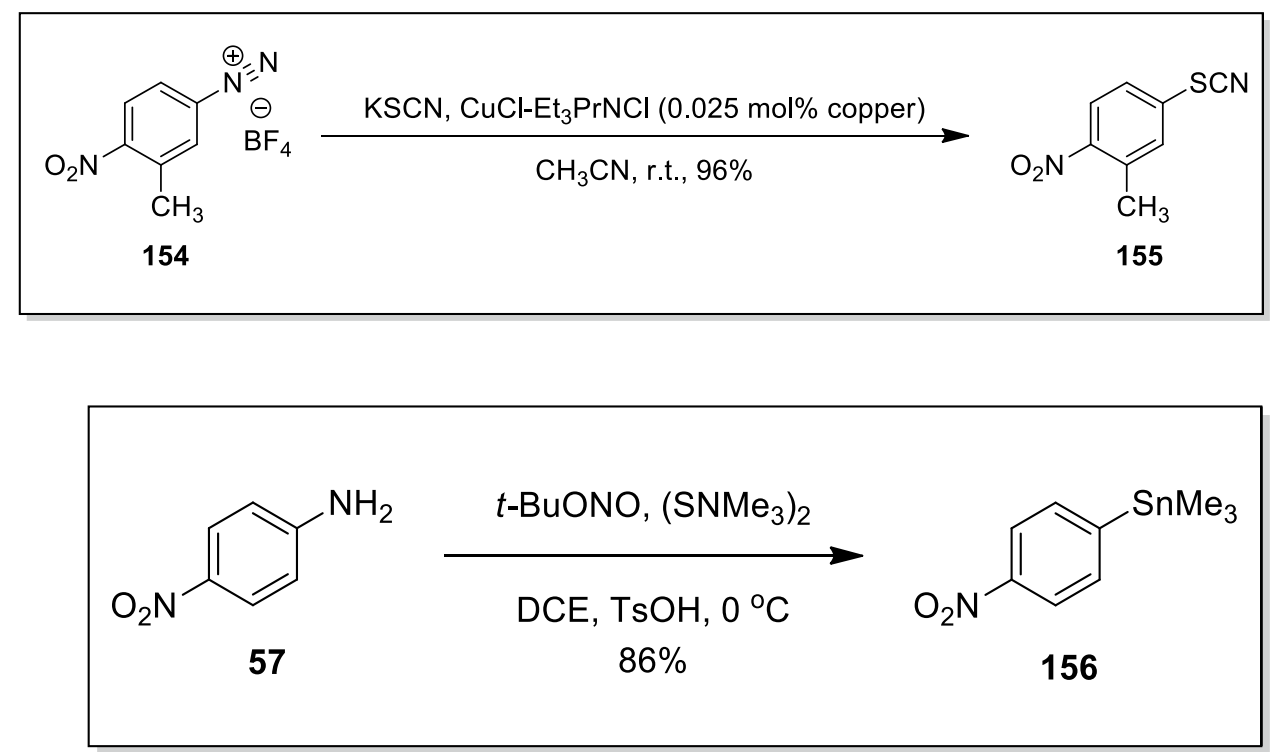

Scheme 38 Sandmeyer-type stannylation approach for the preparation of aryl trimethylstannanes

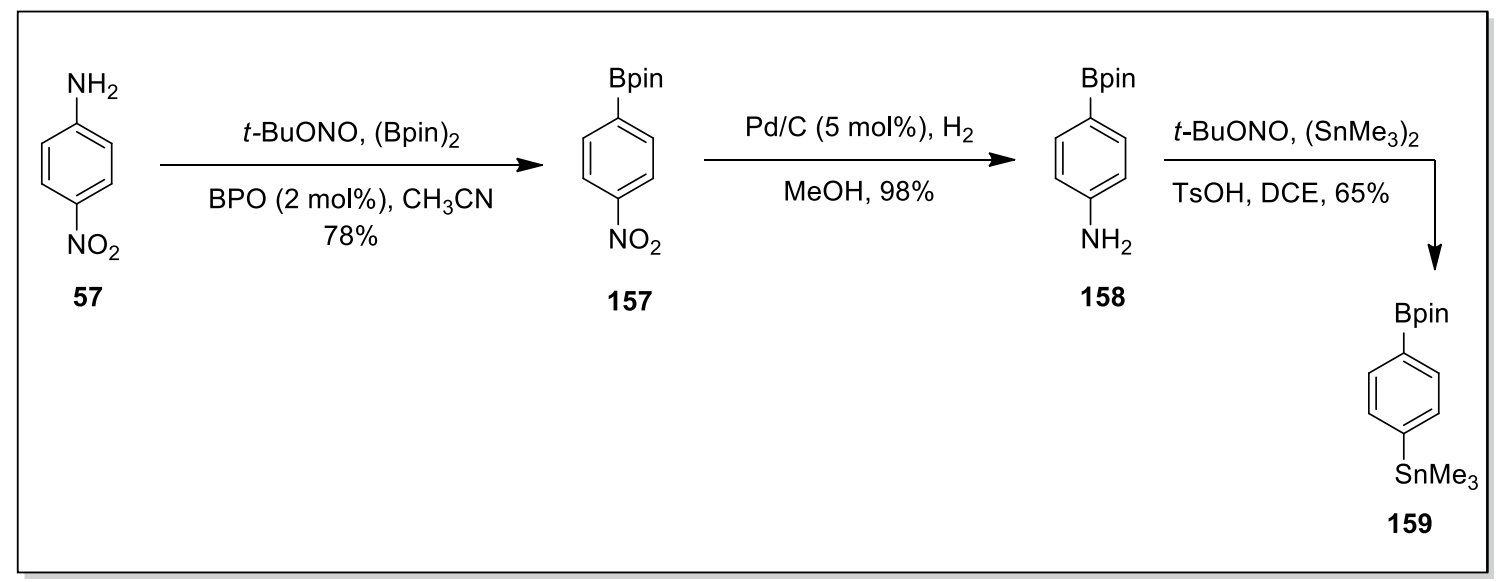

Scheme 39 Synthesis of trimethylstannyl arylboronate analog 159 
and medicinal chemistry, Wang and their colleagues studied the applicability of Sandmeyer phosphorylation reaction for the synthesis of these aryl phosphonates [82]. They began their investigation by the reaction of ethyl 4-aminobenzoate with tert-butyl nitrite under different conditions. First of all, trimethyl phosphite, triethyl phosphite and triphenyl phosphite were screened as phosphorous source and results supported the use of triphenyl phosphite which gave significant yield $(78 \%)$ as compared to the other phosphites. Reaction processed at $0{ }^{\circ} \mathrm{C}$ using $\mathrm{TsOH} \cdot \mathrm{H}_{2} \mathrm{O}$ as an additive which was selected among different acids such as $\mathrm{HCl}, \mathrm{TsOH} \cdot \mathrm{H}_{2} \mathrm{O}$, $\mathrm{H}_{2} \mathrm{SO}_{4}$ and $\mathrm{BF}_{3} \cdot \mathrm{OEt}_{2}$. Reaction completed within $8 \mathrm{~h}$ in acetonitrile solvent by giving $25-99 \%$ yield range.

\section{Formation of carbon-selenium linkage}

Matheis et al. [72] successfully utilized Sandmeyer approach for the preparation of trifluoromethylselenoethers under mild reaction conditions. For this purpose, $\mathrm{Me}_{4} \mathrm{NSeCF}_{3}$ was used as $\mathrm{SeCF}_{3}$ source which efficiently converted diazonium salt 99 to its corresponding selenoether $\mathbf{1 6 0}$ in $98 \%$ yield. Reaction processed at room temperature using $\mathrm{CuSCN}$ as copper salt in acetonitrile solvent. In order to evaluate substrate scope, maximum conversion was achieved within $1 \mathrm{~h}$ by giving 69-98\% yield range of the desired trifluoromethylselenoethers. Similarly, a straightforward approach for the insertion of trifluoromethylseleno group into aromatic amines was reported by Nikolaienko and Rueping in 2016 [83]. Reaction was accomplished via two steps, first converting diazonium salt 99 to its respective selenocyanate in the presence of $\mathrm{CuCl} / \mathrm{CuCl}_{2}$ catalytic system. 1,10-Phenanthroline was used as additive, cesium carbonate as base and $\mathrm{KSeCN}$ as SeCN source in acetonitrile solvent. In the second step, this selenocyanate was treated with TMS- $\mathrm{CF}_{3}$ for the insertion of $\mathrm{CF}_{3}$ group. Reaction was completed within $12 \mathrm{~h}$ at room temperature and afforded corresponding trifluoromethylselenoether 160 in $74 \%$ yield. In this methodology, arenediazonium salts having both electron-donating and withdrawing substituents were readily converted into desired selenoethers in $40-88 \%$ yield range (Scheme 40 ).

\section{Formation of carbon-boron linkage}

Focusing the green synthetic routes, Zhang et al. [84] published their report on Sandmeyer-type borylation for the synthesis of arylboronate esters. They began their investigation by treating 4-carboxylicphenyldiazonium tetrafluoroborate with bis(pinacolato)diboron as exemplary substrates. Reaction processed at room temperature in a mixture of solvents such as acetone-water, acetonitrile-water, dimethoxyethane-water, dioxane-water, water and acetone. Results revealed that 2:1 mixture of acetonitrile-water gave targeted arylboronate ester in $80 \%$ yield. Maximum conversion was achieved in the presence of $5 \mathrm{~mol} \% \mathrm{CuBr}$ which selected by observing the catalytic behavior of $\mathrm{Cu}(\mathrm{OAc})_{2}, \mathrm{FeCl}_{3}$, $\mathrm{Co}(\mathrm{Ac})_{2}, \mathrm{CeCl}_{2}$ and $\mathrm{CuBr}$. 24-85\% Yield range of different arylboronate esters was obtained within 3-6 h.

In continuation of this research work, Qiu et al. [85] in 2013 reported Sandmeyer-type borylation approach under metal-free condition. In this method, a variety of aryl amines were first diazotized in the presence of tert-butyl nitrite followed by the addition of bis(pinacolato)diboron in acetonitrile solvent afforded the desired pinacol arylboronates in $14-77 \%$ yield range by maintaining temperature at $80{ }^{\circ} \mathrm{C}$. These aryl boronates further used for Suzuki-Miyaura crosscoupling reaction to obtain a variety of biaryl compounds in moderate to high yield range which proved the efficacy of this protocol.

Some other reports on Sandmeyer-type borylation are presented in Table 3.

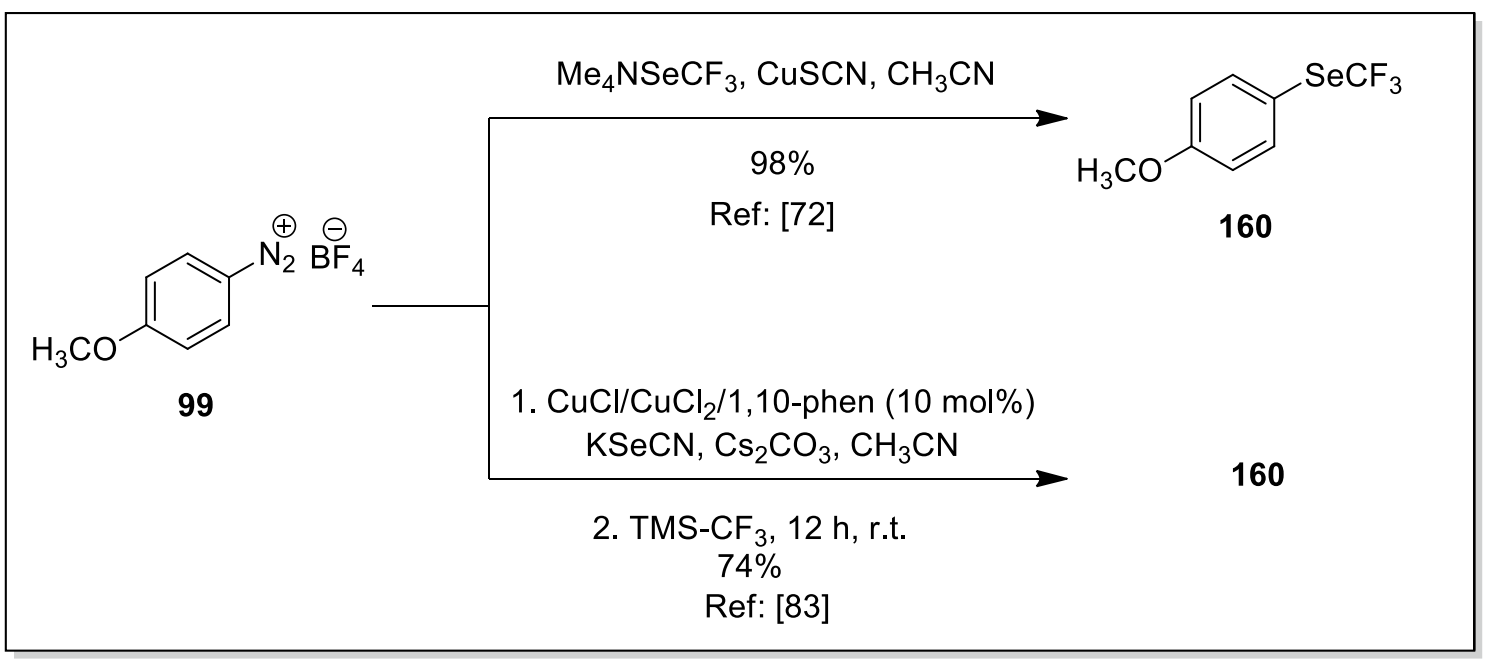

Scheme 40 Sandmeyer approach for the preparation of trifluoromethylselenoethers 
Table 3 Sandmeyer-type borylation

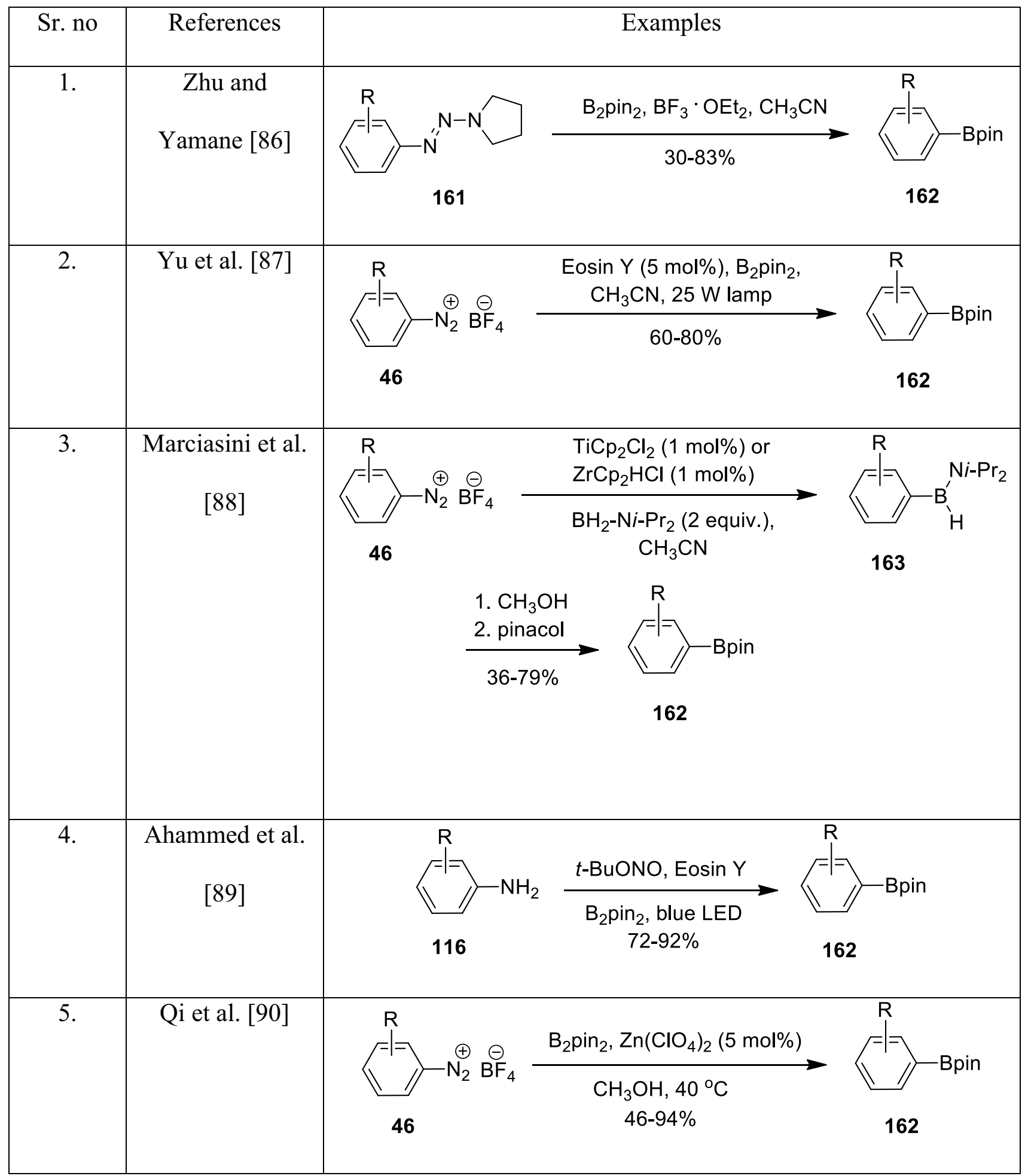




\section{Applications of Sandmeyer reaction for the synthesis of medicinally important compounds}

\section{Natural bioactive molecules}

Synthesis of alkaloid ficuseptine In 2002, Bracher and Daab developed an efficient protocol for the synthesis of alkaloid ficuseptine 167 (a good antifungal and antibacterial agent) which involved Suzuki, Sonogashira and Sandmeyer reactions as key steps [91]. Their methodology started from the Suzuki cross-coupling of bis(arylation) of 3,5-dibromopyridine (164) with 4-methoxyphenylboronic acid under optimized conditions resultantly afforded corresponding arylated compound $\mathbf{1 6 5}$ in $71 \%$ yield which was subsequently subjected to Sandmeyer reaction in the presence of $t$-BuONO, $\mathrm{CH}_{2} \mathrm{I}_{2}$ and $\mathrm{I}_{2}$. Consequently, iodopyridine 166 was obtained in $61 \%$ yield. In the next step, by applying Sonogashira reaction conditions followed by palladium-catalyzed hydrogenation and cyclization reactions afforded desired indolizidinium alkaloid 167 in $79 \%$ yield (Scheme 41 ).

Synthesis of indolizidinium alkaloid ipalbidinium Later on, the same research group utilized their previously reported methodology for the synthesis of indolizidinium alkaloid ipalbidinium 171 and quinolizidinium alkaloid clathryimine B [92]. Their recommended approach is described in
Scheme 42 which started from the Suzuki reaction of the bromopyridine 168 with boronic acid under standard conditions. As a result, corresponding arylpyridine 169 was obtained in $72 \%$ yield which subsequently subjected to Sandmeyer reaction in the presence of $t$-BuONO, $\mathrm{CH}_{2} \mathrm{I}_{2}, \mathrm{CuI}$ and $\mathrm{I}_{2}$, resultantly affording iodo compound $\mathbf{1 7 0}$ in $82 \%$ yield. Further, Sonogashira coupling followed by catalytic hydrogenation and cyclization reactions which after cleavage of the OMe group using $\mathrm{BBr}_{3}$ afforded desired ipalbidinium 171 in $19 \%$ yield. Likewise, clathryimine B was also prepared by using the same reaction conditions of these key steps.

Synthesis of curcuphenol Studies on biological activities of curcuphenol reveal that it can be used as antibacterial, antifungal, antimalarial as well as anticancer agent. Besides this, it plays a great role to inhibit proton-potassium ATPase enzyme, resultantly preventing/curing different stomach diseases such as gastroesophageal reflux disease and peptic ulcer disease. Remarkable pharmacological significance of curcuphenol has attracted researchers to develop various techniques for the efficient synthesis of this scaffold. On account of this, Kim and their colleagues proposed an enantioselective synthesis of (+)-curcuphenol via Sandmeyer and Negishi cross-coupling reactions [93]. Their pathway started from the easily available starting precursor, $m$-anisidine (172) which was protected using benzyl bromide and potassium carbonate base. Insertion of aldehyde into this moiety using crotonaldehyde

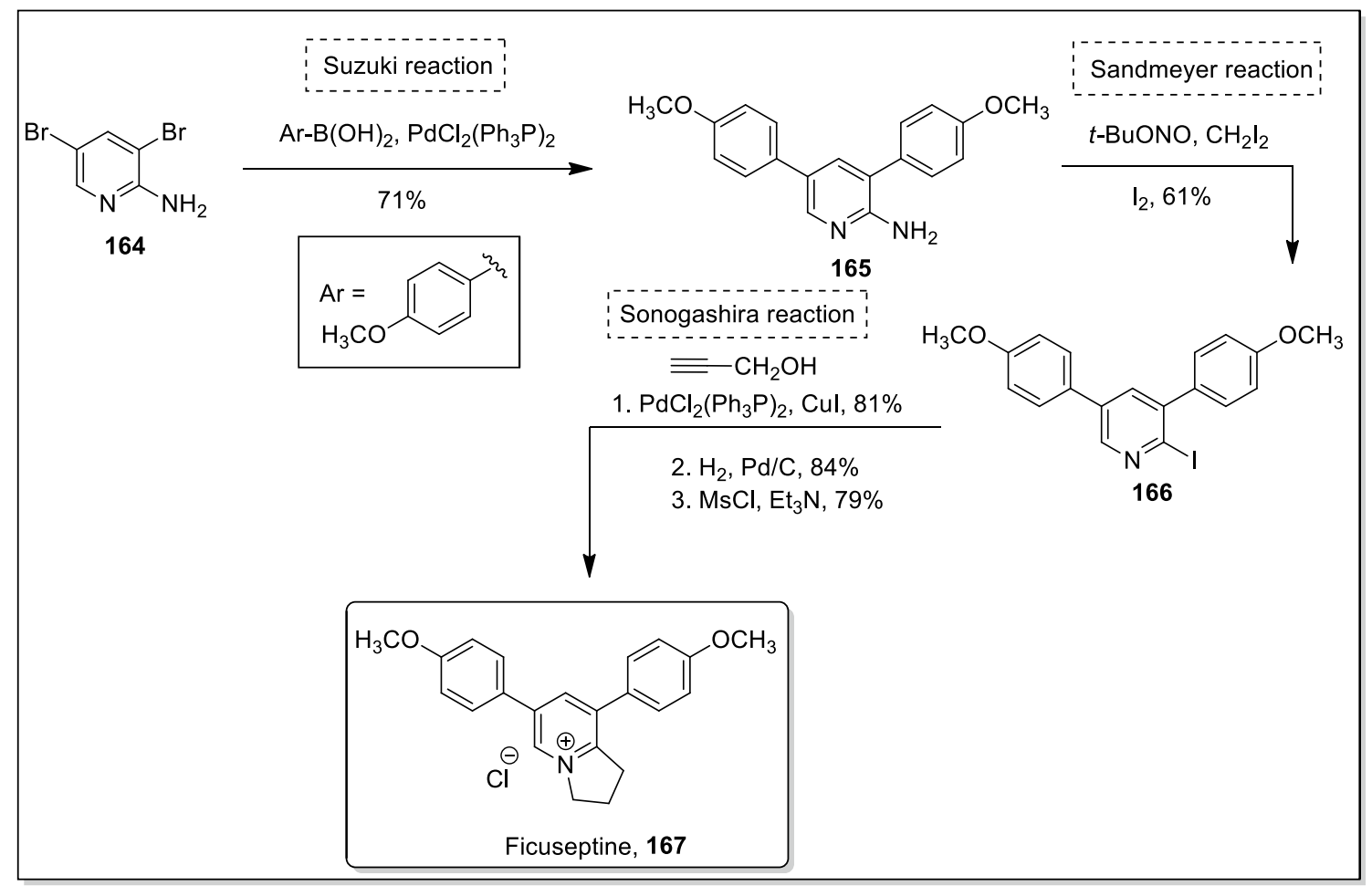

Scheme 41 Synthesis of alkaloid ficuseptine 167 using Suzuki, Sandmeyer and Sonogashira reactions as key steps 


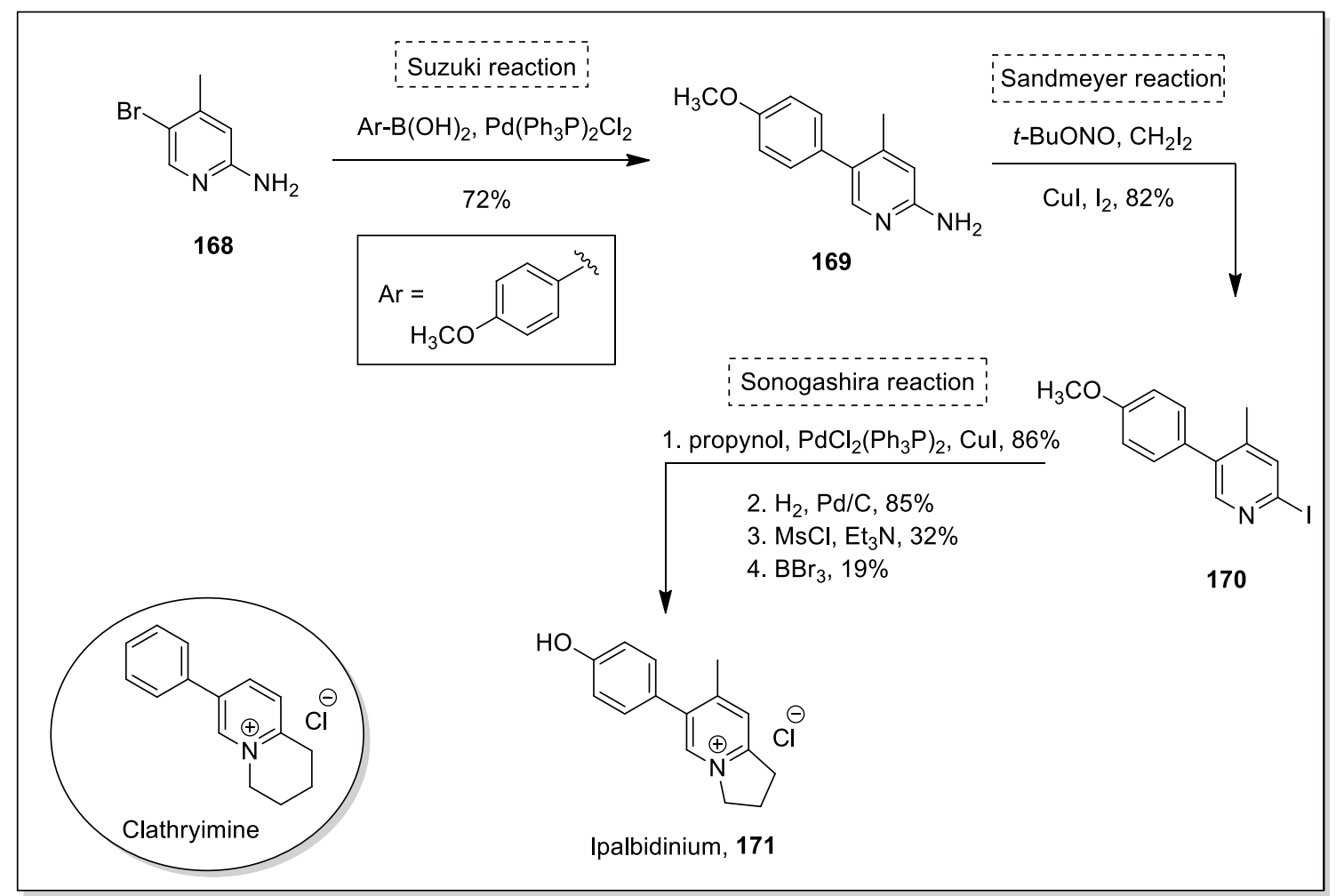

Scheme 42 Synthetic pathway for indolizidinium alkaloid ipalbidinium 171

$\mathbf{1 7 3}$ in the presence of imidazolidinone catalyst $\mathbf{1 7 4}$ provided corresponding aldehyde derivative in $90 \%$ yield. After reduction of this aldehyde with $\mathrm{NaBH}_{4}$ followed by deprotection, reaction provided compound $\mathbf{1 7 5}$ in $90 \%$ yield. Compound $\mathbf{1 7 5}$ was then converted to derivative $\mathbf{1 7 6}$ by passing through Sandmeyer reaction. Optimized reagents for this conversion were sodium nitrite and copper bromide which gave resultant analog 176 in 55\% yield. Next step was Negishi coupling for the replacement of bromo group to methyl group, and the resultant compound was treated with triphenylphosphine, imidazole and iodine to obtain iodo compound $\mathbf{1 7 7}$ in $84 \%$ yield. Last step was the reaction of compound 177 with 2-methyl1-propenylmagnesium bromide (178) followed by the cleavage of the methyl ether functionality afforded $(S)-(+)$-curcuphenol (179) in 92\% yield (Scheme 43).

\section{Synthetic bioactive molecules}

Synthesis of agomelatine Kandagatla et al. [94] established a convenient and simple approach for the synthesis of agomelatine (an antidepressant drug) including easily available starting precursors. For this purpose, 8-aminonaphthalen-2-ol (180) was first subjected to Sandmeyer reaction. Diazotization of $\mathbf{1 8 0}$ in the presence of $\mathrm{NaNO}_{2}$ followed by halogenation with KI provided 8-iodo- $\beta$-naphthol (181) in $73 \%$ yield. After that protection of $\mathrm{OH}$ group using dime- thyl sulfate with subsequent formylation reaction afforded 7-methoxy-1-naphthaldehyde (182) in 70\% yield. Reaction of this aldehyde (182) with nitromethane followed by catalytic hydrogenation and acetylation provided targeted agomelatine $\mathbf{1 8 3}$ in $95 \%$ yield (Scheme 44).

Synthesis of ceritinib For the treatment of lung cancer, crizotinib, a tyrosinase kinase inhibitor, was effectively used in the past few years. However, resistance to this drug creates an option to develop new potent anticancer drug alternate to crizotinib. Ceritinib (LDK378) is another new and efficient anaplastic lymphoma kinase inhibitor which is efficiently used to treat cancer with greater potency. Considering its importance, Liu et al. [95] described a cost-effective route for the synthesis of ceritinib (LDK378) which started from easily available starting substrates under mild reaction conditions. In their methodology, first 1,3-dichloro-4-nitropyridine (184) was coupled with 2-(propane-2-sulfonyl)-phenylamine (185) in the presence of chloroform; resultantly, corresponding compound $\mathbf{1 8 6}$ (95\%) was obtained by the displacement of $3-\mathrm{Cl}$ of $\mathbf{1 8 4}$ with $\mathrm{NH}_{2}$ group of $\mathbf{1 8 5}$. In the next step, 1-Cl group of compound 186 was displaced with $\mathrm{NH}_{2}$ group of Boc protected compound 187 in acetonitrile solvent to obtain coupled product 188 in $94 \%$ yield. Later, catalytic hydrogenation followed by Sandmeyer reaction in the presence of 


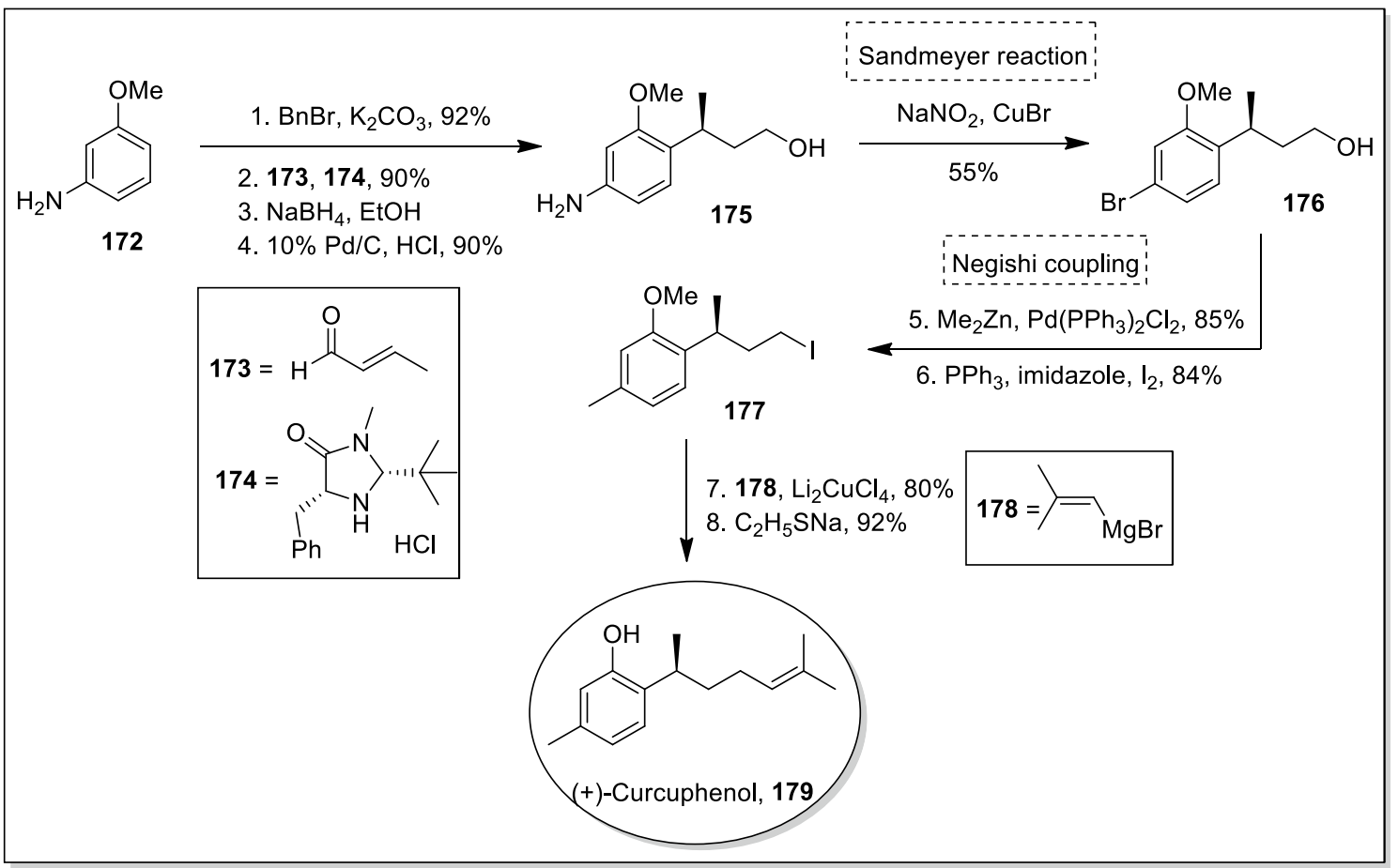

Scheme 43 Synthesis of (+)-curcuphenol 179 via Sandmeyer and Negishi cross-coupling reactions

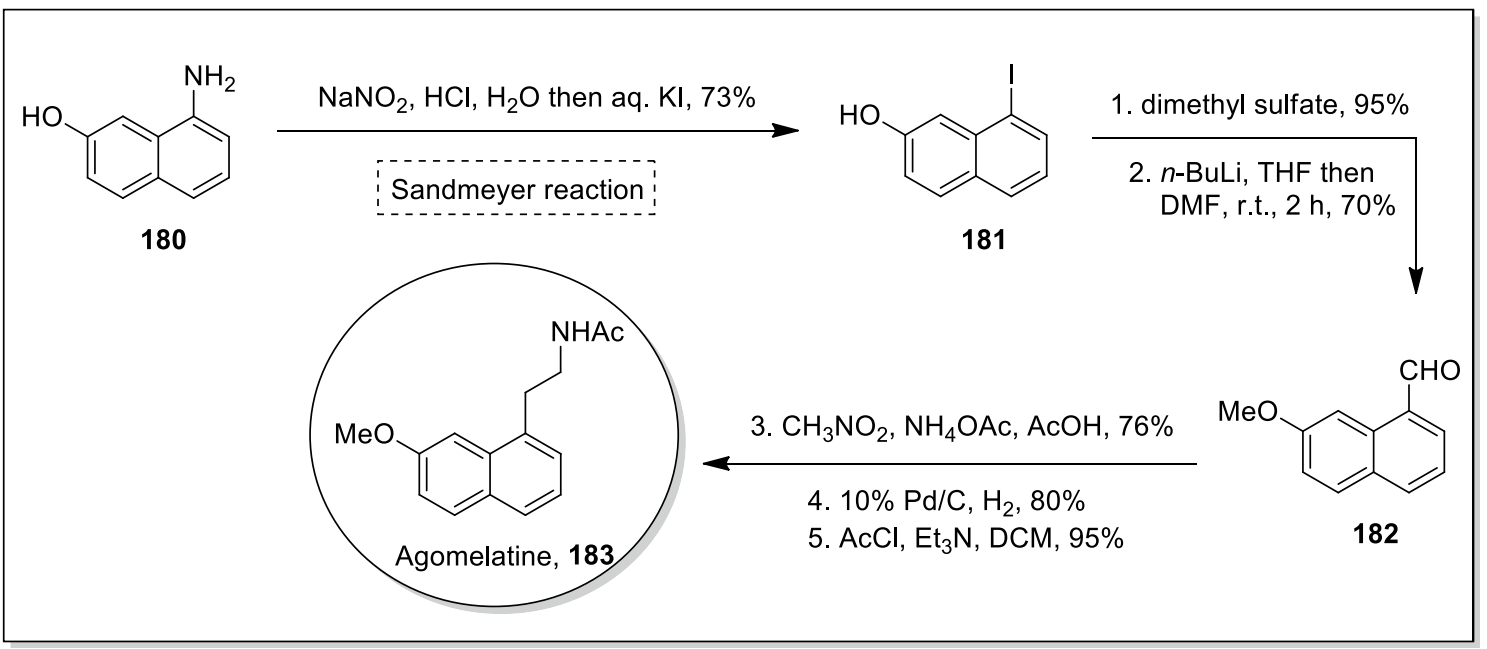

Scheme 44 Synthetic pathway for agomelatine 183, an antidepressant drug

isobutyl nitrite, $\mathrm{HCl}$ and cuprous compound gave desired ceritinib (LDK378) 190 in 67\% yield (Scheme 45).

Synthesis of favipiravir Favipiravir, a pyrazine ring containing compound, mainly acts as anti-influenza drug. It can also be used to treat a variety of viral strains (alphavirus, ebola virus, bunyavirus, and flavivirus) by disrupting the activity of RNA polymerase of virus. It is wide spread biological functions in antiviral and antiparasitic field encour- age researchers to develop efficient and low-cost pathways for the synthesis of favipiravir in good yield. On account of this, Guo et al. [96] reported a mild and simple protocol starting from the chlorination of commercially available 2-aminopyrazine 191 in the presence of 1.1 equivalent of TSA ( $N$-chloro- $N$-methoxy-4-methylbenzenesulfonamide) 192. As a result, corresponding chlorinated product 193 was obtained in $80 \%$ yield which subsequently subjected to bromination and palladium-catalyzed cyanation reactions 


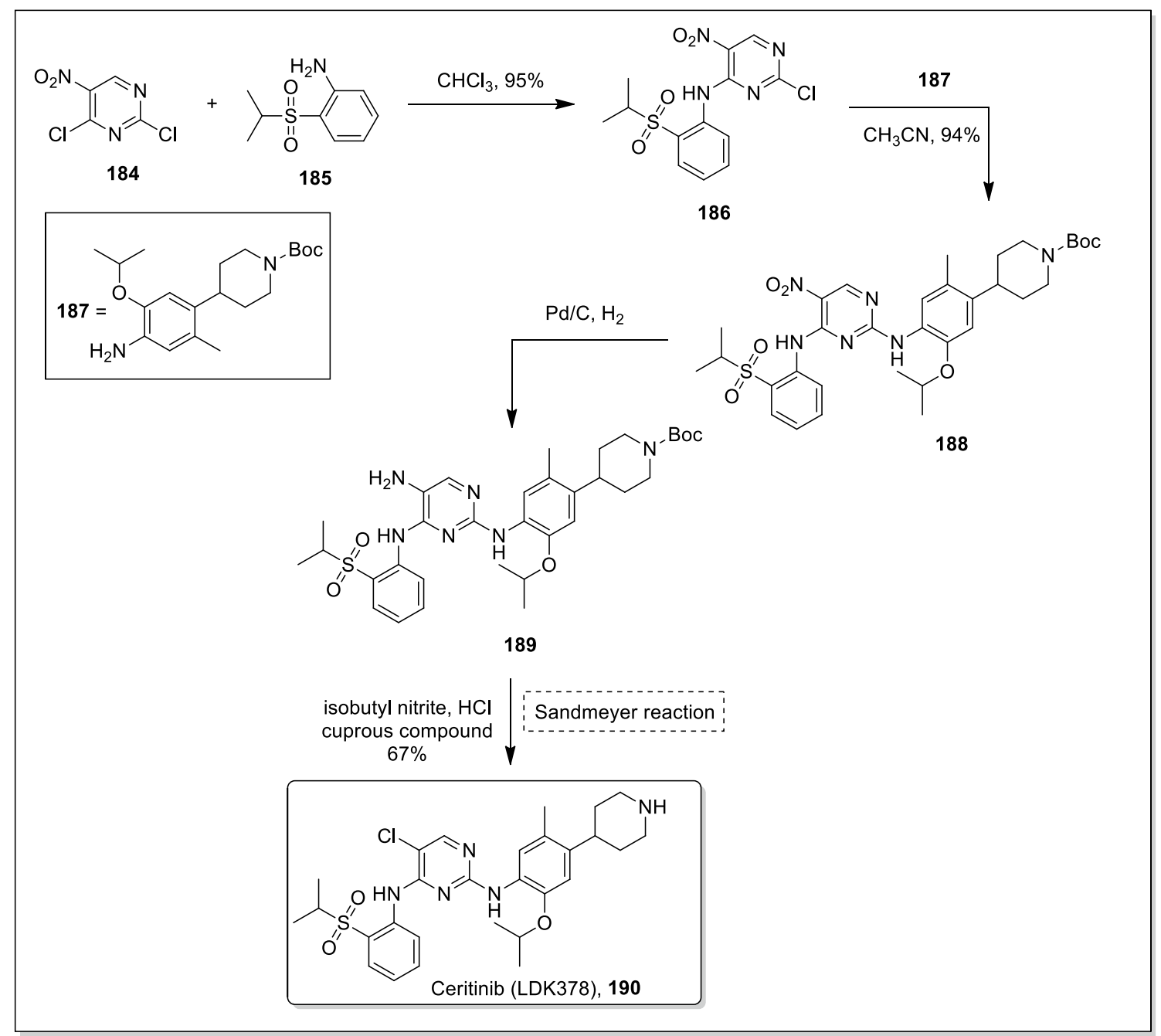

Scheme 45 Synthesis of ceritinib (LDK378) 190, an anaplastic lymphoma kinase inhibitor

using NBS and $\mathrm{NaCN}$, respectively, to obtain compound 195. 2-Amino group of compound $\mathbf{1 9 5}$ was further replaced with chloro group by adopting Sandmeyer approach which afforded good yield of the corresponding derivative 196 with simple workup procedure. This reaction was carried out at room temperature by using $t$-butyl nitrite, $\mathrm{TiCl}_{4}$ and DCM as optimized reagents. After that, fluorination of compound 196 followed by acid mediated nitrile hydration and reaction with sodium bicarbonate provided desired favipiravir 197 in $82 \%$ yield (Scheme 46).

\section{Miscellaneous}

Tsintsadze et al. [97] reported a direct, simple and selective approach for the synthesis of benzo[b]thiophenoindoles. For this purpose, 3-aminodibenzothiophene 198 was used as starting precursor which in the presence of chloral hydrate and hydroxylamine hydrochloride and subsequent reaction with sulfuric acid afforded a mixture of isatins 199 and 200 via Sandmeyer pathway. Alkaline solution of these compounds (199 and 200) was then treated with acetic acid followed by acidification with $\mathrm{HCl}$ provided separated compounds 199 and 200 in $60 \%$ and $25 \%$ yields, respectively. Later, reduction of compound $\mathbf{1 9 9}$ with diborane in the presence of THF produced compound $\mathbf{2 0 1}$ in $\mathbf{7 0 \%}$ yield. However, by using $\mathrm{LiAlH}_{4} / \mathrm{NaBH}_{4}$ as reducing agents, a mixture of corresponding benzo[b]thiophenoindoles 201 and $\mathbf{2 0 2}$ were obtained. On the other side, by applying same reaction conditions, compound $\mathbf{2 0 0}$ was reduced to benzo $[b]$ thiophenoindoles 203 and a mixture of 203 and compound 204 as depicted in Scheme 47. Later on, by using same reaction parameters Khoshtariya et al. in 2004 [98] and 2007 [99] synthesized 2,3-dioxo-2,3-dihydrobenzo[ $b]$ furoindoles and dioxodihydro- $1 H$-benzo[b]furoindole, respectively.

To synthesize a variety of aryl azides through green approach, Zarchi and Ebrahimi utilized polymer-supported 


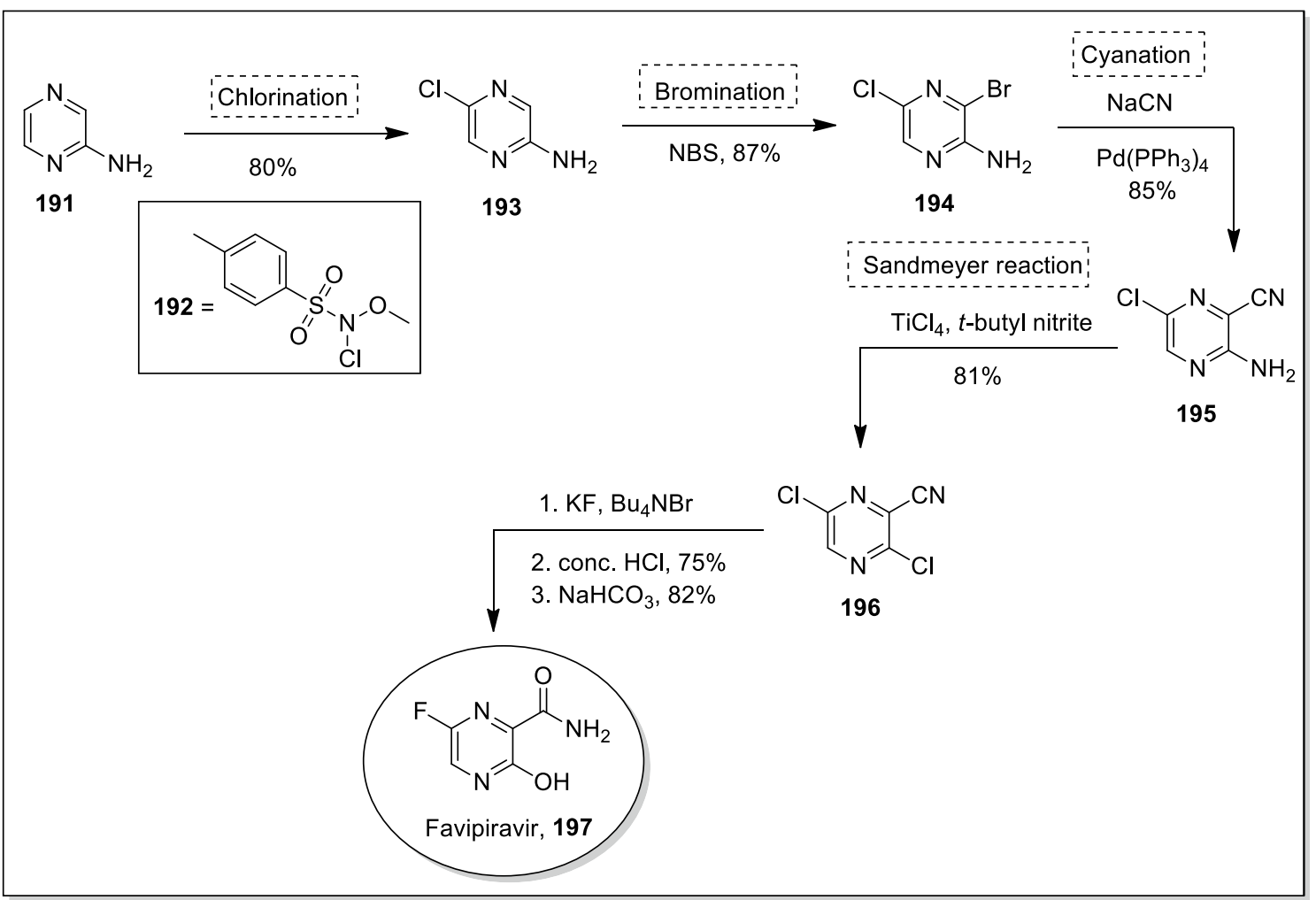

Scheme 46 Preparation method for favipiravir 197, an anti-influenza drug

nitrite ion ((poly(4-vinylpyridine)-supported nitrite ion, $\left.\left[\mathrm{P}_{4}-\mathrm{VP}\right] \mathrm{NO}_{2}\right)$ for diazotization process [100]. First, reaction of aromatic amines in the presence of $\mathrm{NaNO}_{2},\left[\mathrm{P}_{4}-\mathrm{VP}\right]$ $\mathrm{NO}_{2}$ and $\mathrm{H}_{2} \mathrm{SO}_{4}$ provided corresponding diazonium salts which on reaction with $\mathrm{NaN}_{3}$ afforded targeted aryl azides in 70-90\% yield range. Later, in 2014 the authors used (poly(4vinylpyridine)-supported ethyl bromide ([ $\left.\left.\mathrm{P}_{4}-\mathrm{VP}\right] \mathrm{Et}-\mathrm{Br}\right)$ for the diazotization-bromination of a variety of aromatic amines [101]. Reaction worked very well in the presence of $\mathrm{CuBr}$ and afforded $40-94 \%$ yield range. Simple recovery and reusability of polymeric reagent with good functional groups tolerance proved the efficacy of this Sandmeyer protocol.

To highlight the importance of gold catalysis which is effectively used to activate carbon-carbon multiple bonds, Peng et al. [102] reported gold-catalyzed Sandmeyer reaction for the formation of $\mathrm{C}-\mathrm{Br}, \mathrm{C}-\mathrm{S}$ and $\mathrm{C}-\mathrm{P}$ linkages. For $\mathrm{C}-\mathrm{Br}$ bond formation, different aryl diazonium salts were reacted with sodium bromide and $3 \% \mathrm{PPh}_{3} \mathrm{AuCl}$ in acetonitrile solvent. As a result, desired derivatives were attained in $57-88 \%$ yield range at $50{ }^{\circ} \mathrm{C}$. On the other hand, $\mathrm{C}-\mathrm{S}$ cross-coupling reaction was accomplished by the treatment of aryldiazonium salt with $(S)$-methyl 2-((tertbutoxycarbonyl)amino)-3-mercaptopropanoate (a cysteine derivative used as sulfur nucleophile) in acetonitrile solvent. $3 \mathrm{Mol} \%$ catalyst loading using sodium carbonate as base completed this reaction within $3 \mathrm{~h}$ at room temperature. Furthermore, reaction of diazonium salts with $\mathrm{HP}(\mathrm{O})(\mathrm{OEt})_{2}$ (a phosphorous source) in the presence of $5 \mathrm{~mol} \% \mathrm{PPh}_{3} \mathrm{AuCl}$ gave desired derivatives in 51-87\% yield range. Reaction accomplished within $5 \mathrm{~h}$ with the help of 3-chloropyridine additive at $50{ }^{\circ} \mathrm{C}$.

Owing to the synthetic as well as pharmacological importance of 1,2-diamines, Gan et al. [103] performed a coupling reaction of ketimine 205 with $N$-Boc aldimine 206 by using $5 \mathrm{~mol} \%$ mesitylcopper as catalyst and $\left(R, R_{P}\right)$-TANIAPHOS as ligand in dimethoxyethane. As a result, 1,2-diamine 


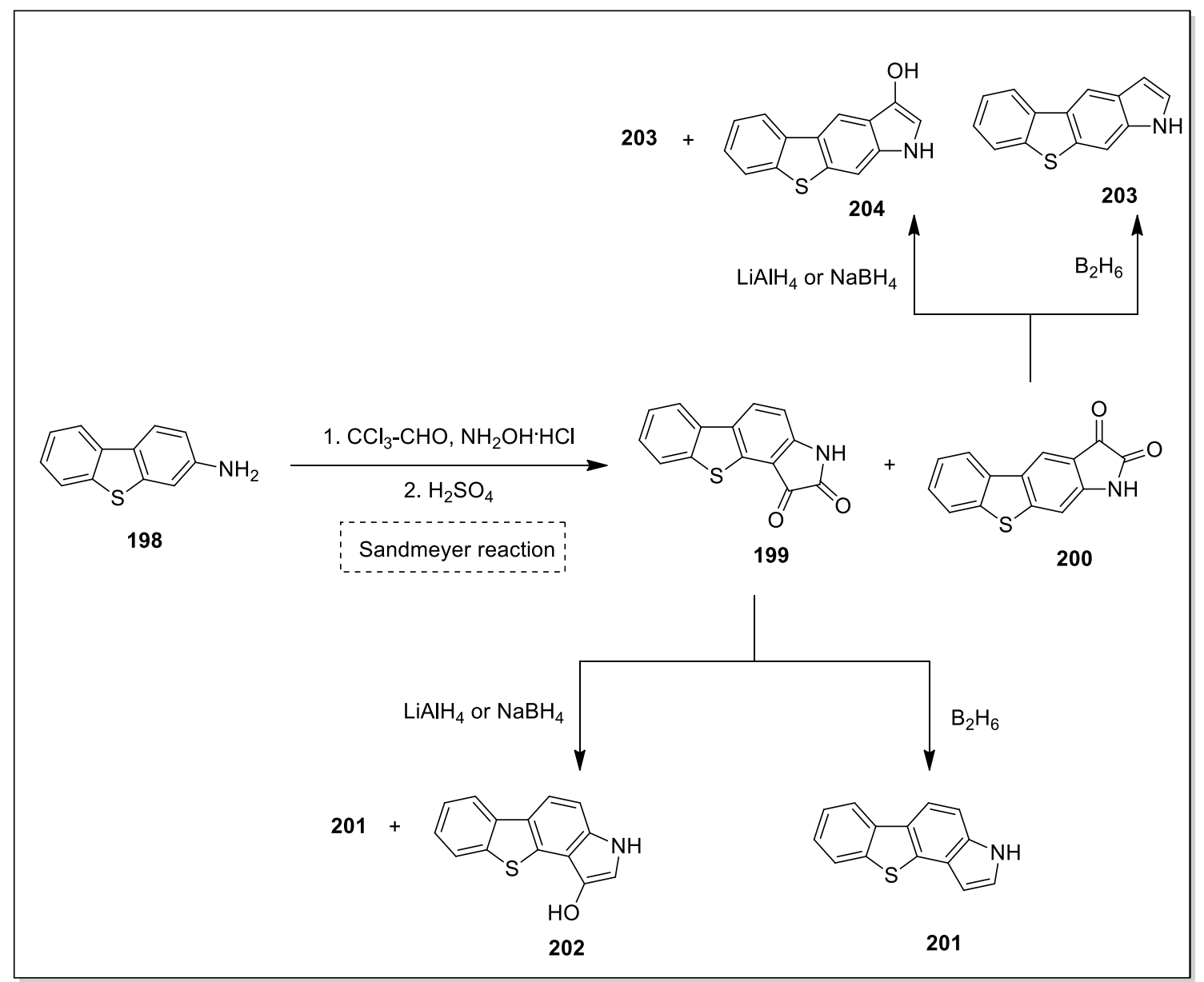

Scheme 47 3-Aminodibenzothiophene 198, a starting precursor for the synthesis of benzo[b]thiophenoindoles

compound 207 was obtained in 79\% yield with 97\% ee. After that, removal of ketimine moiety in acidic condition followed by protection of amino group with tosyl chloride and reduction of nitro group provided arylamine $\mathbf{2 0 8}$ which readily underwent Sandmeyer reaction to obtain 1,2-diaryldiamine 209, phenol 210, arylbromide 211, trifluoromethylated compound $\mathbf{2 1 2}$ and arylboronate $\mathbf{2 1 3}$ in 80\%, 73\%, 75\%, $54 \%$ and $66 \%$ yields, respectively, under different reaction conditions as depicted in Scheme 48.

\section{Conclusion}

In conclusion, we have collected a number of Sandmeyertype approaches with plausible mechanisms published during 2000-2021. This review has witnessed that significant efforts have been made for the conversion of aromatic amino group to boryl, stannyl, phosphoryl, and trifluoromethyl groups by adopting Sandmeyer protocol with or without copper catalysts. However, aryl halides and trifluoromethylated compounds were the most prevalent choices prepared via Sandmeyer reaction. These Sandmeyer-type conversions processed under mild reaction conditions using easily available starting materials proved to be helpful for synthesizing various biologically active compounds. Although many developments regarding Sandmeyer reaction have been made in the recent past yet a lot of improvements are required to address limitations and hindrances involved in its industrial scale use such as excessive use of metals and restricted choice of reagents in diazotization step. On further detailed mechanistic investigation of Sandmeyer reaction, adopting green synthetic methodologies, implementing electrochemical and photocatalytic approaches, incorporating simple reaction methods with minimum use of expensive metals, the researchers may be able to prepare novel biologically active molecules through Sandmeyer transformation in near future. 


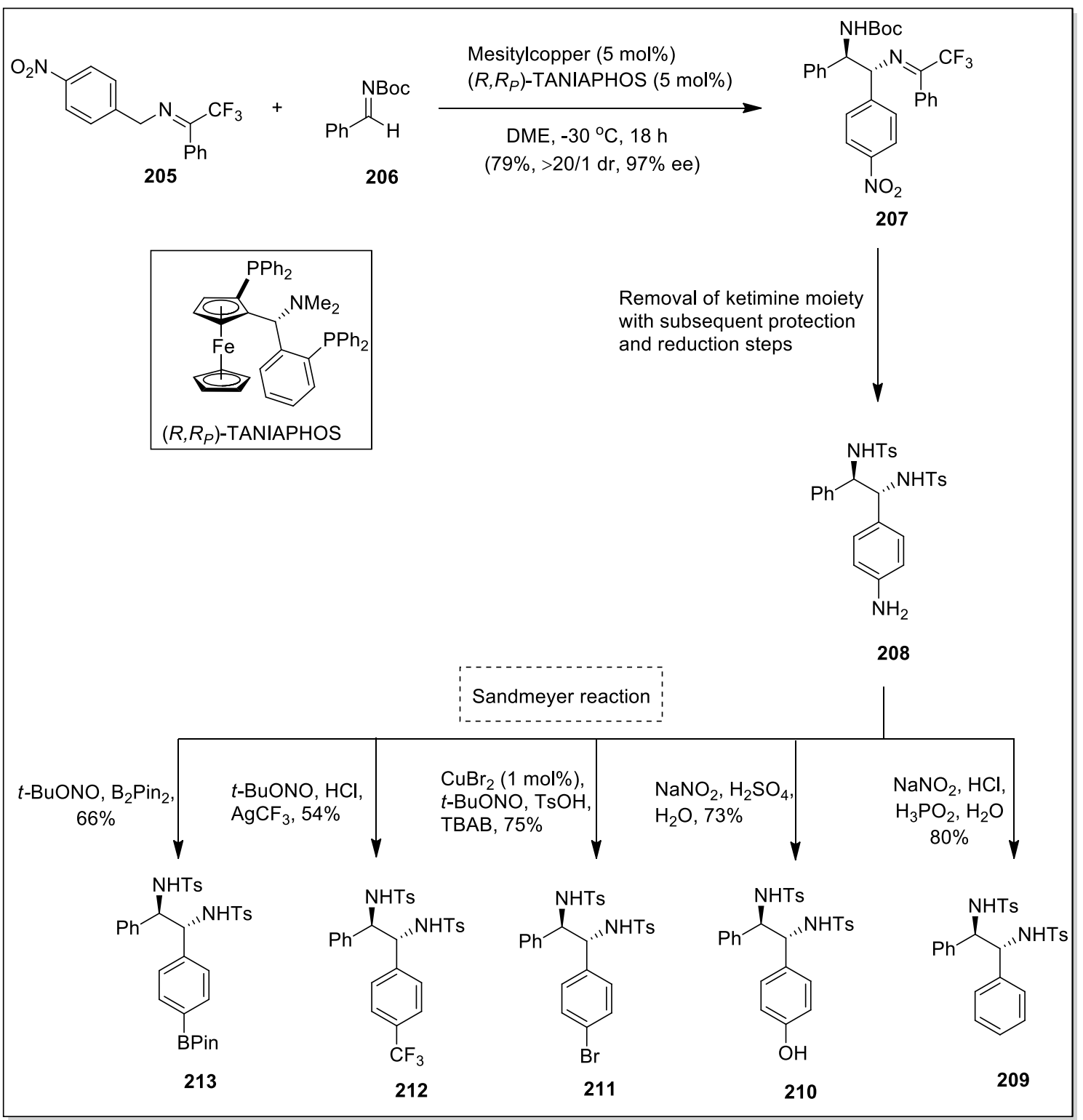

Scheme 48 Sandmeyer reaction for the synthesis of 1,2-diamines (209-213)

Acknowledgements Provision of facilities from Government College University, Faisalabad is highly acknowledged.

\section{Declarations}

Conflict of interest The authors declare that they have no conflict of interest.

\section{References}

1. P Griefs 1858 Vorläufige Notiz über die Einwirkung von salpetriger Säure auf Amidinitro-und Aminitrophenylsäure Justus Liebigs Ann Chem 106123125 https://doi.org/10.1002/jlac. 18581060114
2. MAK Zarchi N Ebrahimi 2012 Diazotization-cyanation of aromatic amines with crosslinked poly(4-vinylpyridine)-supported cyanide ions J Appl Polym Sci 12521632169 https://doi.org/10. 1002/app.36394

3. H Meerwein E Büchner K Emster van 1939 Über die Einwirkung aromatischer Diazoverbindungen auf $\alpha, \beta$-ungesättigte Carbonylverbindungen J Prakt Chem 152237266 https://doi.org/10.1002/ prac. 19391520705

4. D Prasad-Hari T Hering B König 2014 The photoredox-catalyzed Meerwein addition reaction: Intermolecular amino-arylation of alkenes Angew Chem Int Ed 53725728 https://doi.org/10.1002/ anie.201307051

5. G Balz G Schiemann 1927 Über aromatische Fluorverbindungen, I.: Ein neues Verfahren zu ihrer Darstellung Ber Dtsch Chem Ges 6011861190 https://doi.org/10.1002/cber.19270600539

6. S Abele G Schmidt MJ Fleming H Steiner 2014 A One-pot diazotation-fluorodediazoniation reaction and fluorine gas for 
the production of fluoronaphthyridines Org Process Res Dev 18 9931001 https://doi.org/10.1021/op500100b

7. A Roglans A Pla-Quintana M Moreno-Mañas 2006 Diazonium salts as substrates in palladium-catalyzed cross-coupling reactions Chem Rev 10646224643 https://doi.org/10.1021/cr050 9861

8. T Okazaki KK Laali SD Bunge SK Adas 2014 4-(Pentafluorosulfanyl)benzenediazonium tetrafluoroborate: a versatile launch pad for the synthesis of aromatic SF5 compounds via cross Coupling, azo coupling, homocoupling, dediazoniation, and click chemistry Eur J Org Chem 201416301644 https://doi.org/10.1002/ejoc. 201301538

9. L He G Qiu Y Gao J Wu 2014 Removal of amino groups from anilines through diazonium salt-based reactions Org Biomol Chem 1269656971 https://doi.org/10.1039/C4OB01286K

10. PY Yeung CM So CP Lau FY Kwong 2011 A mild and efficient palladium-catalyzed cyanation of aryl chlorides with $\mathrm{K} 4[\mathrm{Fe}(\mathrm{CN}) 6]$ Org Lett 13648651 https://doi.org/10.1021/ol102 8892

11. J Han C Pan X Jia C Zhu 2014 Rhodium-catalyzed ortho-cyanation of symmetrical azobenzenes with N-cyano-N-phenyl-ptoluenesulfonamide Org Biomol Chem 1286038606 https://doi. org/10.1039/C4OB01736F

12. P Hanson SC Rowell PH Walton AW Timms 2004 Promotion of Sandmeyer hydroxylation (homolytic hydroxydediazoniation) and hydrodediazoniation by chelation of the copper catalyst: Bidentate ligands Org Biomol Chem 218381855 https://doi. org/10.1039/B404699D

13. F Xie Z Qi X Li 2013 Rhodium(III)-catalyzed azidation and nitration of arenes by $\mathrm{CH}$ activation Angew Chem 12512078 12082 https://doi.org/10.1002/ange.201305902

14. BV Silva FA Violante AC Pinto LS Santos 2011 The mechanism of Sandmeyer's cyclization reaction by electrospray ionization mass spectrometry Rapid Commun Mass Spectrom 25423428 https://doi.org/10.1002/rcm.4869

15. R Akhtar AF Zahoor B Parveen M Suleman 2019 Development of environmental friendly synthetic strategies for Sonogashira cross coupling reaction: an update Synthetic Commun 49167 192 https://doi.org/10.1080/00397911.2018.1514636

16. R Akhtar AF Zahoor 2020 Transition metal catalyzed Glaser and Glaser-Hay coupling reactions: scope, classical/green methodologies and synthetic applications Syn Commun 5033373368 https://doi.org/10.1080/00397911.2020.1802757

17. M Yousaf AF Zahoor R Akhtar M Ahmad S Naheed 2020 Development of green methodologies for Heck, Chan-Lam, Stille and Suzuki cross-coupling reactions Mol Divers 24821839 https:// doi.org/10.1007/s11030-019-09988-7

18. S Tabassum AF Zahoor S Ahmad R Noreen SG Khan H Ahmad 2021 Cross-coupling reactions towards the synthesis of natural products Mol Divers In press https://doi.org/10.1007/ s11030-021-10195-6

19. I Munir AF Zahoor N Rasool SAR Naqvi KM Zia R Ahmad 2019 Synthetic applications and methodology development of ChanLam coupling: a review Mol Divers 23215259 https://doi.org/ 10.1007/s11030-018-9870-z

20. T Sandmeyer 1884 Ueber die Ersetzung der Amidgruppe durch Chlor in den aromatischen Substanzen Ber Dtsch Chem Ges 17 16331635 https://doi.org/10.1002/cber.18840170219

21. T Sandmeyer 1884 Ueber die Ersetzung der Amidgruppe durch Chlor, Brom und Cyan in den aromatischen Substanzen Ber Dtsch Chem Ges 1726502653 https://doi.org/10.1002/cber. 188401702202

22. MP Doyle B Siegfried JF Dellaria 1977 Alkyl nitrite-metal halide deamination reactions. 2. Substitutive deamination of arylamines by alkyl nitrites and copper(II) halides. A direct and remarkably efficient conversion of arylamines to aryl halides J Org Chem 42 $24262431 \mathrm{https}: / /$ doi.org/10.1021/jo00434a017

23. MP Doyle JF Dellaria B Siegfried SW Bishop 1977 Reductive deamination of arylamines by alkyl nitrites in N, $N$-dimethylformamide. A direct conversion of arylamines to aromatic hydrocarbons J Org Chem 4234943498 https://doi.org/10.1021/jo004 $42 \mathrm{a} 009$

24. K Kikukawa T Matsuda 1977 Reaction of diazonium salts with transition metals. I. Arylation of olefins with arenediazonium salts catalyzed by zero valent palladium Chem Lett 6159162 https://doi.org/10.1246/cl.1977.159

25. K Kikukawa K Nagira N Terao F Wada T Matsuda 1979 Reaction of diazonium salts with transition metals. II. Palladium catalyzed arylation of ethylene with arenediazonium salts Bull Chem Soc Jpn 5226092610 https://doi.org/10.1246/bcsj.52.2609

26. Waters WA (1942) Decomposition reactions of the aromatic diazo compounds. X. Mechanism of the Sandmeyer reaction. J Chem Soc 266-270. https://doi.org/10.1039/JR9420000266

27. JK Kochi 1957 The mechanism of the Sandmeyer and Meerwein reactions J Am Chem Soc 7929422948 https://doi.org/10.1021/ ja01568a066

28. D Sucunza A Samadi M Chioua DB Silva C Yunta L Infantes MC Carreiras E Sorianoa J Marco-Contelles 2011 A practical two-step synthesis of imidazo[1,2-a]pyridines from N-(prop-2yn-1-yl)pyridin-2-amines Chem Commun 4750435045 https:// doi.org/10.1039/C1CC10641D

29. R Sott C Hawner JE Johansen 2008 Synthesis of dioxin-like monofluorinated PCBs: For the use as internal standards for PCB analysis Tetrahedron 6441354142 https://doi.org/10.1016/j.tet. 2008.01.003

30. R Dumeunier C Lamberth S Trah 2013 Synthesis of tetrasubstituted pyrazoles through different cyclization Strategies; Isosteres of imidazole fungicides Synlett $2411501154 \mathrm{https} / / / \mathrm{doi} . o r g / 10$. 1055/s-0033-1338433

31. TV Hughes SL Emanuel AK Beck SK Wetter PJ Connolly P Karnachi M Reuman J Seraj AR Fuentes-Pesquera RH Gruninger SA Middleton R Lin JM Davis DFC Moffat 2007 4-Aryl5-cyano-2-aminopyrimidines as VEGF-R2 inhibitors: Synthesis and biological evaluation Bioorganic Med Chem Lett 173266 3270 https://doi.org/10.1016/j.bmcl.2007.04.021

32. F Rancati SM Bromidge SD Sordo SL Rosa C Parini S Gagliardi 2008 Synthesis of 7-substituted-(2,3-dihydro-1,4-benzodioxin5-yl)-piperazine Synth Commun 3825072520 https://doi.org/ 10.1080/00397910802219148

33. C-H Park C Lee JS Yang B-Y Joe K Chun H Kim HY Kim JS Kang JI Lee M-H Kim G Han 2014 Discovery of thienopyrimidine-based FLT3 inhibitors from the structural modification of known IKK inhibitors Bioorganic Med Chem Lett 2426552660 https://doi.org/10.1016/j.bmcl.2014.04.058

34. Y Ding L Zhao Y Fu L Hao Y Fu Y Yuan P Yu Y Teng 2021 Synthesis and antiproliferatory activities evaluation of multisubstituted isatin derivatives Molecules $26176189 \mathrm{https} / / /$ doi. org/10.3390/molecules26010176

35. L Lee KD Kreutter W Pan C Crysler J Spurlino MR Player B Tomczuk T Lu 2007 2-(2-Chloro-6-fluorophenyl)acetamides as potent thrombin inhibitors Bioorganic Med Chem Lett 176266 6269 https://doi.org/10.1016/j.bmcl.2007.09.013

36. TS Lobana R Sultana RJ Butcher 2011 A Sandmeyer type reaction for bromination of 2-mercapto-1-methyl-imidazoline (N2C4H6S) into 2-bromo-1-methyl-imidazole (N2C4H5Br) in presence of copper(I) bromide Dalton Trans 401138211384 https://doi.org/10.1039/C1DT11327E

37. A Hubbard T Okazaki KK Laali 2008 Halo- and azidodediazoniation of arenediazonium tetrafluoroborates with trimethylsilyl halides and trimethylsilyl azide and Sandmeyer-type 
bromodediazoniation with $\mathrm{Cu}(\mathrm{I}) \mathrm{Br}$ in $[\mathrm{BMIM}]\left[\mathrm{PF}_{6}\right]$ ionic liquid J Org Chem 73316319 https://doi.org/10.1021/jo701937e

38. MA Bobko AC Kaura KA Evans D-S Su 2012 Novel synthesis of 5-amino-3-bromo- 1-(tert-butyl)-1H-pyrazole-4-carbonitrile: A versatile intermediate for the preparation of 5-amino-3-aryl1-(tert-butyl)-1H-pyrazole-4-carboxamides Org Lett 143906 $3908 \mathrm{https}: / /$ doi.org/10.1021/ol301655f

39. H Özkan A Dişli Y Yıldırır L Türker 2007 A novel synthesis of bromobenzenes using molecular bromine Molecules 122478 $2483 \mathrm{https}: / /$ doi.org/10.3390/12112478

40. G Schäfer T Fleischer M Ahmetovic S Abele 2020 Development of a scalable route for a key thiadiazole building block via sequential Sandmeyer bromination and room-temperature Suzuki-Miyaura coupling Org Process Res Dev 24228234 https://doi.org/10.1021/acs.oprd.9b00495

41. R Striela G Urbelis J Sūdžius S Stončius R Sadzevičienè L Labanauskas 2017 Synthesis of bromocyclopropylpyridines via the Sandmeyer reaction Tetrahedron Lett 5816811683 https://doi. org/10.1016/j.tetlet.2017.03.029

42. IP Beletskaya AS Sigeev AS Peregudov PV Petrovskii 2007 Catalytic Sandmeyer bromination Synthesis $1625342538 \mathrm{https} / / /$ doi.org/10.1055/s-2007-983784

43. FG Siméon MT Wendahl VW Pike 2009 Efficient and regioselective halogenations of 2-amino-1,3-thiazoles with copper salts J Org Chem 7425782580 https://doi.org/10.1021/jo802799c

44. WW Mao TT Wang HP Zeng ZY Wang JP Chen JG Shen 2009 Synthesis and evaluation of novel substituted 5-hydroxycoumarin and pyranocoumarin derivatives exhibiting significant anti-proliferative activity against breast cancer cell lines Bioorg Med Chem Lett 1945704573 https://doi.org/10.1016/j.bmcl.2009.06.098

45. H-Y Kim W-J Lee H-M Kang C-G Cho 2007 Benzidine rearrangement reactions of polyether tethered cyclic $\mathrm{N}, N^{\prime}$-diaryl hydrazides Org Lett 931853186 https://doi.org/10.1021/ol071 320r

46. M Gon Y Morisaki Y Chujo 2015 Optically active cyclic compounds based on planar chiral [2.2]paracyclophane: extension of the conjugated systems and chiroptical properties J Mater Chem C 3521529 https://doi.org/10.1039/C4TC02339K

47. Q Liu B Sun Z Liu Y Kao B-W Dong S-D Jiang F Li G Liu Y Yang F Mo 2018 A general electrochemical strategy for Sandmeyer reaction Chem Sci 987318737 https://doi.org/10.1039/ C8SC03346C

48. PG Tsoungas M Searcey 2001 A convenient access to benzosubstituted phthalazines as potential precursors to DNA intercalators Tetrahedron Lett 4265896592 https://doi.org/10.1016/ S0040-4039(01)01302-8

49. R Buchtík J Slouka J Hlaváč 2006 Polycyclic heterocycles with acidic N-H group VII ${ }^{1}$ Synthesis of some polynuclear heterocyclic compounds derived from 5-phenyl-6-azauracil ARKIVOC 20067885 https://doi.org/10.3998/ark.5550190.0007.507

50. J Hong G Wang L Huo C Zheng 2017 Copper-promoted conversion of aromatic amines into trifluoromethylated arenes: onepot Sandmeyer trifluoromethylation Chin J Chem 3517611767 https://doi.org/10.1002/cjoc.201700311

51. G Danoun B Bayarmagnai MF Gruenberg LJ Goossen 2014 Sandmeyer trifluoromethylthiolation of arenediazonium salts with sodium thiocyanate and Ruppert-Prakash reagent Chem Sci 513121316 https://doi.org/10.1039/C3SC53076K

52. G Danoun B Bayarmagnai MF Gruenberg C Matheis E Risto LJ Gooßen 2014 Sandmeyer trifluoromethylation Synthesis 462283 2286 https://doi.org/10.1055/s-0034-1378549

53. G Danoun B Bayarmagnai MF Gruenberg LJ Gooßen 2013 Sandmeyer trifluoromethylation of arenediazonium tetrafluoroborates Angew Chem Int Ed 5279727975 https://doi.org/10.1002/anie. 201304276
54. B Bayarmagnai C Matheis E Risto LJ Goossen 2014 One-pot Sandmeyer trifluoromethylation and trifluoromethylthiolation Adv Synth Catal 35623432348 https://doi.org/10.1002/adsc. 201400340

55. J-J Dai C Fang B Xiao J Yi J Xu ZJ Liu X Lu L Liu Y Fu 2013 Copper-promoted Sandmeyer trifluoromethylation reaction J Am Chem Soc 13584368439 https://doi.org/10.1021/ja404217t

56. C Matheis K Jouvin LJ Goossen 2014 Sandmeyer difluoromethylation of (hetero)arenediazonium salts Org Lett 1659845987 https://doi.org/10.1021/ol5030037

57. X Wang Y Xu Y Zhou Y Zhang J Wang 2014 Conversion of aromatic amino into trifluoromethyl groups through a Sandmeyertype transformation Synthesis $4621432148 \mathrm{https}$ ://doi.org/10. 1055/s-0033-1338659

58. J Wu Y Gu X Leng Q Shen 2015 Copper-promoted Sandmeyer difluoromethylthiolation of aryl and heteroaryl diazonium salts Angew Chem 12777587762 https://doi.org/10.1002/ange.20150 2113

59. B Xing L Li C Ni J Hu 2019 Pentafluoroethylation of arenediazonium tetrafluoroborates using on-site generated tetrafluoroethylene Chin J Chem 3711311136 https://doi.org/10.1002/cjoc. 201900268

60. J Hong L Huo Y Yang G Wang C Zheng 2017 Copper-promoted one-pot trifluoromethylation of aromatic amines with Togni's reagent ChemistrySelect 237163720 https://doi.org/10.1002/ slct.201700789

61. D-F Jiang C Liu Y Guo JC Xiao QY Chen 2014 A general, regiospecific synthetic route to perfluoroalkylated arenes via arenediazonium salts with $\mathrm{RFCu}(\mathrm{CH} 3 \mathrm{CN})$ complexes Eur J Org Chem 201463036309 https://doi.org/10.1002/ejoc.20140 2820

62. A Lishchynskyi G Berthon VV Grushin 2014 Trifluoromethylation of arenediazonium salts with fluoroform-derived $\mathrm{CuCF} 3$ in aqueous media Chem Commun 501023710240 https://doi.org/ 10.1039/C4CC04930F

63. W-B Xu Q-H Xu Z-F Zhang J-Z Li 2014 Copper(I)-oxidemediated cyanation of arenediazonium tetrafluoroborates with trimethylsilyl cyanide: A method for synthesizing aromatic nitriles Asian J Org Chem 310621065 https://doi.org/10.1002/ ajoc. 201402084

64. W Xu Q Xu J Li 2015 Sandmeyer cyanation of arenediazonium tetrafluoroborate using acetonitrile as cyanide source Org Chem Front 2231235 https://doi.org/10.1039/C4QO00301B

65. M Barbero S Cadamuro S Dughera 2016 Copper-free Sandmeyer cyanation of arenediazonium o-benzenedisulfonimide Org Biomol Chem 1414371441 https://doi.org/10.1039/C5OB02321A

66. D Silva Da A Samadi M Chioua MDC Carreiras J Marco-Contelles 2010 The Sandmeyer reaction on some selected heterocyclic ring systems: Synthesis of useful 2-chloroheterocyclic3-carbonitrile intermediates Synthesis $1627252730 \mathrm{https} / / / \mathrm{doi}$. org/10.1055/s-0030-1258149

67. H Xu L-L Fan 2011 Antifungal agents. Part 4: Synthesis and antifungal activities of novel indole[1,2-c]-1,2,4-benzotriazine derivatives against phytopathogenic fungi in vitro Eur J Med Chem 46364369 https://doi.org/10.1016/j.ejmech.2010.10.022

68. IP Beletskaya AS Sigeev AS Peregudov PV Petrovskii 2004 Catalytic Sandmeyer cyanation as a synthetic pathway to aryl nitriles J Organomet Chem 68938103812 https://doi.org/10. 1016/j.jorganchem.2004.07.019

69. Q Lin Z Ma C Zheng X-J Hu Y Guo Q-Y Chen C Liu 2020 Arenesulfonyl fluoride synthesis via copper-free Sandmeyertype fluorosulfonylation of arenediazonium salts Chin J Chem 3811071110 https://doi.org/10.1002/cjoc.202000175

70. X Yang L Shi H Fu 2014 Copper-mediated cascade synthesis of diaryl sulfones via the Sandmeyer reaction Synlett 2508470852 https://doi.org/10.1055/S-0033-1340736 
71. B Bayarmagnai C Matheis K Jouvin LJ Goossen 2015 Synthesis of difluoromethyl thioethers from difluoromethyl trimethylsilane and organothiocyanates generated in situ Angew Chem 1275845 5848 https://doi.org/10.1002/ange.201500899

72. C Matheis V Wagner LJ Goossen 2016 Sandmeyer-type trifluoromethylthiolation and trifluoromethylselenolation of (hetero)aromatic amines catalyzed by copper Chem Eur J $227982 \mathrm{https}$ :// doi.org/10.1002/chem.201503524

73. C Matheis B Bayarmagnai K Jouvin LJ Goossen 2016 Convenient synthesis of pentafluoroethyl thioethers via catalytic Sandmeyer reaction with a stable fluoroalkylthiolation reagent Org Chem Front 3949952 https://doi.org/10.1039/C6QO00194G

74. K Zhang X-H Xu F-L Qing 2015 Copper-promoted trifluoromethanesulfonylation and trifluoromethylation of arenediazonium tetrafluoroborates with NaSO2CF3 J Org Chem 807658 7665 https://doi.org/10.1021/acs.joc.5b01295

75. S Kovacs B Bayarmagnai A Aillerie LJ Gooßen 2018 Practical reagents and methods for nucleophilic and electrophilic phosphorothiolations Adv Synth Catal 36019131918 https://doi.org/10. 1002/adsc.201701549

76. Y Ou LJ Goossen 2019 Copper-mediated synthesis of (diethylphosphono)difluoromethyl thioethers from diazonium salts, NaSCN, and TMS-CF2PO(OEt)2 Asian J Org Chem 8650653 https://doi.org/10.1002/ajoc.201800461

77. S Liu Y Huang X-H Xu F-L Qing 2020 Fluorosulfonylation of arenediazonium tetrafluoroborates with $\mathrm{Na} 2 \mathrm{~S} 2 \mathrm{O} 5$ and N-fluorobenzenesulfonimide J Fluor Chem 240109653 https:// doi.org/10.1016/j.jfluchem.2020.109653

78. T Zhong M-K Pang Z-D Chen B Zhang J Weng G Lu 2020 Copperfree Sandmeyer-type reaction for the synthesis of sulfonyl fluorides Org Lett 2230723078 https://doi.org/10.1021/acs.orglett.0c00823

79. IG Tarkhanova MG Gantman AS Sigeev KI Maslakov VM Zelikman IP Beletskaya 2018 Highly efficient Sandmeyer reaction on immobilized CuI/CuII-based catalysts Mendeleev Commun 28 $261263 \mathrm{https}: / /$ doi.org/10.1016/j.mencom.2018.05.010

80. D Qiu H Meng L Jin S Wang S Tang X Wang F Mo Y Zhang J Wang 2013 Synthesis of aryl trimethylstannanes from aryl amines: a Sandmeyer-type stannylation reaction Angew Chem 1251179511798 https://doi.org/10.1002/ange.201304579

81. D Qiu S Wang S Tang H Meng L Jin F Mo Y Zhang J Wang 2014 Synthesis of trimethylstannyl arylboronate compounds by Sandmeyer-type transformations and their applications in chemoselective cross-coupling reactions J Org Chem 7919791988 https://doi.org/10.1021/jo402618r

82. S Wang D Qiu F Mo Y Zhang J Wang 2016 Metal-free aromatic carbon-phosphorus bond formation via a Sandmeyer-type reaction J Org Chem 811160311611 https://doi.org/10.1021/acs.joc.6b01820

83. P Nikolaienko M Rueping 2016 Trifluoromethylselenolation of aryldiazonium salts: a mild and convenient copper-catalyzed procedure for the introduction of the SeCF3 group Chem Eur J 22 26202623 https://doi.org/10.1002/chem.201504601

84. J Zhang X Wang H Yu J Ye 2012 Sandmeyer-type reaction to Pinacol arylboronates in water phase: a green borylation process Synlett 2313941396 https://doi.org/10.1055/s-0031-1290960

85. D Qiu L Jin Z Zheng H Meng F Mo X Wang Y Zhang J Wang 2013 Synthesis of Pinacol arylboronates from aromatic amines: A metal-free transformation J Org Chem 7819231933 https:// doi.org/10.1021/jo3018878

86. C Zhu M Yamane 2012 Transition-metal-free borylation of aryltriazene mediated by BF3. OEt2 Org Lett 1445604563 https:// doi.org/10.1021/ol302024m

87. J Yu L Zhang G Yan 2012 Metal-free, visible light-induced borylation of aryldiazonium salts: a simple and green synthetic route to arylboronates Adv Synth Catal 35426252628 https:// doi.org/10.1002/adsc.201200416
88. LD Marciasini M Vaultier M Pucheault 2014 Borylation using group IV metallocene under mild conditions Tetrahedron Lett 55 17021705 https://doi.org/10.1016/j.tetlet.2014.01.080

89. S Ahammed S Nandi D Kundu BC Ranu 2016 One-pot Suzuki coupling of aromatic amines via visible light photocatalyzed metal free borylation using t-BuONO at room temperature Tetrahedron Lett 57 15511554 https://doi.org/10.1016/j.tetlet.2016.02.097

90. X Qi L-B Jiang C Zhou J-B Peng X-F Wu 2017 Convenient and general zinc-catalyzed borylation of aryl diazonium salts and aryltriazenes under mild conditions ChemistryOpen 6345349 https://doi.org/10.1002/open.201700036

91. F Bracher J Daab 2002 Total synthesis of the indolizidinium alkaloid ficuseptine Eur J Org Chem 200222882291 https://doi.org/10.1002/ 1099-0690(200207)2002:14<2288::AID-EJOC2288>3.0.CO;2-G

92. J Daab F Bracher 2003 Total syntheses of the alkaloids ipalbidinium and clathryimine B Monatsh Chem 134573583 https:// doi.org/10.1007/s00706-002-0540-5

93. S-G Kim J Kim H Jung 2005 Efficient total synthesis of (+)-curcuphenol via asymmetric organocatalysis Tetrahedron Lett 46 24372439 https://doi.org/10.1016/j.tetlet.2005.02.047

94. B Kandagatla VVNKVP Raju GM Reddy SC Rao J Iqbal R Bandichhor S Oruganti 2012 A facile synthesis of melatonergic antidepressant agomelatine Tetrahedron Lett 5371257127 https://doi.org/10.1016/j.tetlet.2012.10.077

95. H Liu Y Li D Wang Y Qin M Jia 2015 An efficient synthesis of ceritinib (LDK378) using a Sandmeyer reaction J Chem Res 39 475477 https://doi.org/10.3184/174751915X14381780373834

96. Q Guo M Xu S Guo F Zhu Y Xie J Shen 2019 The complete synthesis of favipiravir from 2-aminopyrazine Chem Pap 731043 $1051 \mathrm{https}: / /$ doi.org/10.1007/s11696-018-0654-9

97. TG Tsintsadze TE Khoshtariya LN Kurkovskaya NT Mirziashvili MI Sikharulidze 2002 Novel route for btaining isomeric benzo[b] thiophenoindoles Chem Heterocycl Compd 38472476 https:// doi.org/10.1023/A:1016043608441

98. TE Khoshtariya MM Matnadze NT Mirziashvili LN Kurkovskaya MI Sikharulidze TO Dzhashi 2004 Synthesis and reductive reactions of 2,3-dioxo-2,3-dihydrobenzo-[b]furo[2,3-f]-, -[2,3g]-, and -[3,2-e]indoles Chem Heterocycl Compd 4014541459 https://doi.org/10.1007/s10593-005-0065-z

99. TE Khoshtariya LN Kurkovskaya MM Matnadze MI Sikharulidze TO Dzhashi VO Ananiashvili KT Batsikadze 2007 Condensed tetracyclic systems with an isatin fragment in the molecule Chem Heterocycl Compd 4311111117 https://doi. org/10.1007/s10593-007-0171-1

100. MAK Zarchi N Ebrahimi 2012 Facile and one-pot synthesis of aryl azides via diazotization of aromatic amine using cross-linked poly(4-vinylpyridine)-supported nitrite ion and azidation by a Sandmeyer-type reaction Iran Polym J 21591599 https://doi. org/10.1007/s13726-012-0063-9

101. MAK Zarchi SZ Mousavi 2014 Diazotization-bromination of aromatic amines using polymer-supported bromide via Sandmeyer-type reaction J Polym Res 21330338 https://doi.org/10. 1007/s10965-013-0330-2

102. H Peng R Cai C Xu H Chen X Shi 2016 Nucleophile promoted gold redox catalysis with diazonium salts: C-Br, C-S and C-P bond formation through catalytic Sandmeyer coupling Chem Sci 761906196 https://doi.org/10.1039/C6SC01742H

103. X-C Gan C-Y Zhang F Zhong P Tian L Yin 2020 Synthesis of chiral anti-1,2-diamine derivatives through copper(I)-catalyzed asymmetric $\alpha$-addition of ketimines to aldimines Nat Commun 1144734480 https://doi.org/10.1038/s41467-020-18235-9

Publisher's Note Springer Nature remains neutral with regard to jurisdictional claims in published maps and institutional affiliations. 